\title{
INVESTIGATION OF CONTAMINATION OF EARTHEN COVERS ON INACTIVE URANIUM MILL TAILINGS
}

\author{
Prepared by: G. Markos and K. J. Bush \\ Geochemistry and Environmental Chemistry Research, Inc., \\ One Concourse Drive, P. 0. Box 725, Rapid City, SD 57709
}

D.O.E. Contract \#DE-ACO4-82AL18797

Approved by

James A. MorTey, Manager

UMTRA Project.

\section{SUMMARY}

The upward migration of contaminants into earthen covers on uranium mill tailings was evaluated from chemical and isotopic analysis of samples from $5-10 \mathrm{~cm}$ intervals through the cover and into the tailings at three locations on the Riverton pile. Thres to 20 percent of the cover were tailings, estimated from the potassium and $\mathrm{Pb}-210$ concentrations in solid samples from tailings, cover, and uncontaminated soil. Migration of thorium, radium, uranium, and molybdenum into the cover was detected. The migration behavior of thorium is consistent among the three locations and varies from 2 to $23 \mathrm{pCi} / \mathrm{g}$. The mobility appears to be controlled by the solubility of thorium oxides and hydroxides. Uranium, radium, and molybdenum show significant chemical migration at one sampling location. The mobility of these eleinents appears to be controlled hy thermodynamics and adsorption on iron hydroxides and amorphous aluminosilicate components. Other contaminants, $\mathrm{As}, \mathrm{Cr}$, $\mathrm{Ni}$, and Se are immobilized at the interface between the cover and tailings. Najor parameters influencing the solubility of components are variations in the partial pressure of carbon dioxide produced by respiration in plant roots, temperature, and the activities of anions which form soluble complexes with the cations. Moisture content between 20 and 100 nercent does not greatly affect the concentrations of trace metals in solution because the aqueous components are assumed to be in equilibrium with the solid phase. Transport of contaminants into the cover was primarily along fluid gradients infuced by evaporation. With thicker covers on tailings, capillary potentials as a function of pore size and viscosity of solution will be the dominant transporting mechanism.

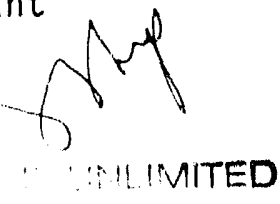


TABLE OF CONTENTS

Page

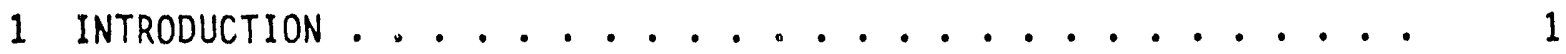

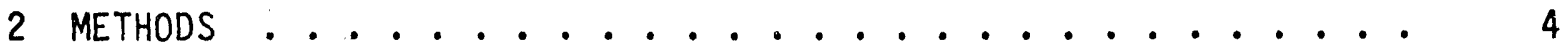

SAMPLING . . . . . . . . . . . . . . . . . 4

SAMPLE PROCESSING AND ANALYSIS . . . . . . . . . . . 9

EMPIRICAL RELATIONSHIPS AMONG ELEMENTS . . . . . . . . 10

MODELING MIGRATION MECHANISMS ............. 11

DATA PROCESSING AND INTERPRETATION . . . . . . . . 12

3 DATA PRESENTATION . . . . . . . . . . . . . . . . . . 14

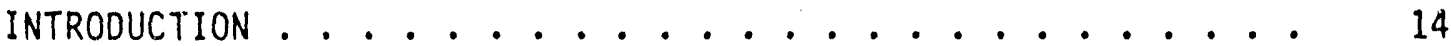

Eh-pH DIAGRAMS . . . . . . . . . . . . . 14

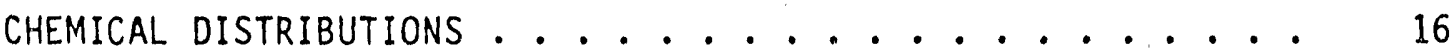

4 INTERPRETATION OF DATA . . . . . . . . . . . . 28

PHYSICAL MIXING ................. 28

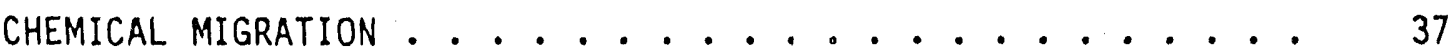

Migration of Uranium and Thorium . . . . . . . . 37

Migration of Radium .............. . . 4 40

5 MECHANISMS OF MOBILIZATION AND RETARDATION OF ELEMENTS IN

TAILINGS . . . . . . . . . . . . . . . . . 45

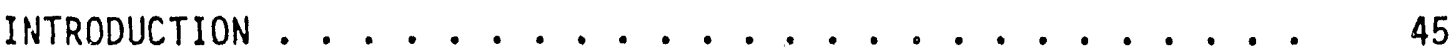

MOBILITY OF URANIUM, RADIUM, AND THORIUM ......... 46

RETARDATION OF ELEMENTS IN THE COVER .......... 50

6 THERMODYNAMIC MODELING OF MIXING OF TAILINGS SOLUTION WITH COVER 59

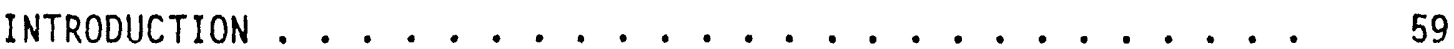

CHARACTERISTICS OF THE COVER ............. 64

INTERACTION OF TAILINGS SOLUTION WITH COVER . . . . . . . 69 
TABLE OF C.ONTENTS

(Continued)

$\underline{\text { Page }}$

7 CONCLUSIONS . . . . . . . . . . . . . . . .

REFERENCES .......................

APPENDIX A - MEHTOOS USED BY BENDIX FIELD ENGINEERING CORPORATION FOR CHEMICAL AND ISOTOPIC ANALYSIS ......... SAMPLES, $>5$ MICRON FRACTIONS, AND REPRECIPITATED WATER-SOLUBLE SALTS .............

\section{DISCLAIMER}

This report was prepared as an account of work sponsored by an agency of the United States Government. Neither the United States Government nor any agency thereof, nor any of their employees, makes any warranty, express or implied, or assumes any legal liability or responsi. bility for the accuracy, completeness, or usefulness of any information, apparatus, product, or process disclosed, or represents that its use would not infringe privately owned rights. Reference herein to any specific commercial preduct, presess, or service by trade name, trademark, manufacturer, or otherwise does not necessarily constitute or imply its endorsement, recom. mendation, of favoring by the linted States (jovernment or any agency thereof. The views and opinions of authors expressed herein do not necessarily state or reflect those of the United States (iovernment or any agency thereof. 


\section{LIST OF FIGURES}

Figure No.

Page

1 Sites of trenches ( $\left.5^{\prime} \times 3^{\prime} \times 3^{\prime}\right)$ where consecutive samples of about $5 \mathrm{~cm}$ depth intervals were taken from surface through cover and into tailings about $90 \mathrm{~cm} . .$. .

Eh-pH diagram illustrating the positions of the cover, tailings, and interface samples .........

Vertical distributions of concentrations of components in the solid samples from RIV 164 and 165 ......

4 Vertical distributions of concentrations of components in the solid samples from RIV 166 .........

Vertical distributions of isotope concentrations in solid samples through cover and into tailings from three locations on the Riverton Tailings pile....

Calculated ionic strength and total dissolved solids (TDS) of water extracts across cover and tailings at three locations on Riverton tailings .........

Vertical distribution of total extractable $\left(\mathrm{H}_{2} \mathrm{O}+\mathrm{HCl}\right)$ concentrations of component's represented by heavy solid lines and $\mathrm{HCl}$ extractable represented by fine solid lines for RIV 164 .............

Vertical distribution of total extractable $\left(\mathrm{H}_{2} \mathrm{O}+\mathrm{HCl}\right)$ concentrations of components represented by heavy solid lines and $\mathrm{HCl}$ extractable represented by fine solid lines for RIV 164 .............

Vertical distribution of total extractable $\left(\mathrm{H}_{2} \mathrm{O}+\mathrm{HCl}\right)$ concentrations of components represented by heavy solid lines and $\mathrm{HCl}$ extractable represented by fine solid lines for RIV 165 .............

Vertical distribution of total extractable $\left(\mathrm{H}_{2} \mathrm{O}+\mathrm{HCl}\right)$ concentratioris of components represented by heavy solid lines and $\mathrm{HCl}$ extractable represented by fine solid lines for RIV 165

11 Vertical distribution of total extractable $\left(\mathrm{H}_{2} \mathrm{O}+\mathrm{HCl}\right)$ concentrations of components represented by heavy solid lines and HCL extractable represented by fine solid lines for RIV 166 
LIST OF FIGURES

(Continued)

Figure No.

Page

Vertical distribution of total extractable $\left(\mathrm{H}_{2} \mathrm{O}+\mathrm{HCl}\right)$ concentrations of components represented by heavy solid lines and $\mathrm{HCl}$ extractable represented by fine solid lines for RIV 166 .

Linearized normal cumulative distribution of the potassium concentrations in the solid samples of tailings and cover................

14 Linearized normal cumulative distribution of the Ra-226/Pb-210 ratios in solid samples from the tailings cover, and interface ..........

Fractions of isotopes in RIV 164 cover and interface sampies contributed by the physical mixing of tallings, calculated from the isotope concentrations in the cover samples and an average isotope concentration in tailings and uncontaminated soil ....

Fractions of isotopes in RIV 166 cover and interface samples contributed by the physical mixing of tailings, calculated from the isotope concentrations in the cover samples and an average isotope concentration in tailings and uncontaminated soil ....

Fractions of isotopes in RIV 165 cover and interface samples contributed by the physical mixing of tailing;, calculated from the isotope concentrations in the cover samples and an average isotope concentration in tailings and uncontaminated soil .....

18 Linearized normal cumulative distribution of the

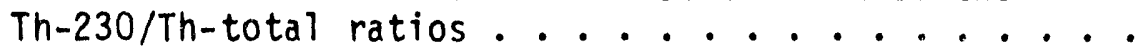

19 Linearized normal cumulative distributions of $\mathrm{Pb}-210 /$ $T h-230$ and $\mathrm{Pb}-210 / \mathrm{U}-238$ ratios in the tailings, cover,

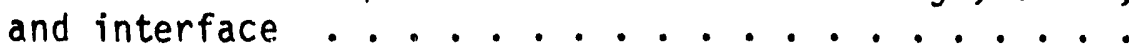

20 Linearized normal cumulative distributions of the extractable fractions of aluminum and uranium in the cover and interface samples ..........

21 Vertical distributions of total extractable Ra-226 and percentage of total extractable Ra-226 to Ra-226 in buik solid for RIV 164, RIV 165, and RIV 166 ... 


\section{LIST OF FIGURES}

(Continued)

Figure No.

Regression analysis of total extractable and $\mathrm{HCl}$

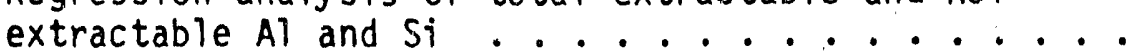

Regression analysis of Ra-226 and aluminum in the acid extracts of cover and interface........

Linearized normal cumulative distribution of acidsoluble aluminum in cover and interface samples...

Regression analysis of acid-soluble iron against cobalt and nickel in cover and interface samples...

Regression analysis of acid-soluble iron against

arsenic and chromium in cover and interface samples. .

Regression analysis of acid-soluble iron against uranium and vanadium in cover and interface samples. .

Eh-pH field calculated as the function of temperature and carbon dioxide fugacity $\left(\mathrm{pfCO}_{2}\right.$ means the negative logarithm of $\mathrm{CO}_{2}$ fugacity) and the solid phases maintaining equilibrium with solution (calcite, magnesite, silica gel, dawsonite, $\mathrm{MnHPO}_{4}$, manganite, and microcrystalline ferric hydroxide) . . . . . . . .

Behavior of calcite in cover as the function of cemperature, $\mathrm{pfCO}_{2}$ and the corresponding $\mathrm{pH}$.....

Behavior of $\mathrm{MnHPO}_{4}$ in cover as a function of temperature, $\mathrm{pfC}_{2}$ and the corresponding Eh ......

Pore volume change in cover as a function of temperature, $\mathrm{pfCO}_{2}$, and the corresponding $\mathrm{pH} . \mathrm{Cm}^{3}$ of pore volume increase $(+)$ or decrease $(-)$ per kilogram of solution ................

Change of $\mathrm{pH}$ as the function of acid addition to cover solution under conditions of no mineralogic buffer $0=5^{\circ} \mathrm{C}, \mathrm{x}=35^{\circ} \mathrm{C}$ temperatures .........

Eh-pH field and its shift from original position resulting from mixing tailings with cover solution in $1: 9$ ratio, as the function of temperature, $\mathrm{PfCO}_{2}$, and the corresponding $\mathrm{pH}$.............

Changes in SI (saturation index) of $\mathrm{UO}_{2}(\mathrm{OH})_{2}$ as the function of temperature, $\mathrm{pfCO}_{2}$, and the corresponding $\mathrm{pH}$. . . . . . . . . . . . . . . . 


$$
\text { yi }
$$

LIST OF TABLES

Table

Page

1 Sampling Record for Site Number 164 . . . . . . . 6

2 Sampling Record for Site Number 165 ......... . 7

3 Sampling Record for Site Number 166 ......... 8

$4 \quad$ Fraction of Isotopes in Cover and Interface Samples

Contributed by the Presence of Tailings Material . . . . 32

5 Concentrations of Th-230 and U-238 in Cover Samples from

Chemical Migration...................... 39

6 . Dominant Aqueous Species in the Tailings Waters of

Riverton Tailings Determined by Calculations of PHREEQE. . 48

7 Dominant Aqueous Species in the Cover Waters of Riverton

Tailings Determined by Calculations of PHREEQE ..... . 49

8 Saturation Indexes Calculated by PHREEQE for Mineral Phases

in Riverton Tailings Interstitial Water ........ 60

9 Concentrations (ppm) of Elements in the Cover Pore Water

at Varying Moisture Contents ............

10 Thermodynamic Saturation Indexes of Minerals of Thorium, Uranium, and Radium at Varying Moisture Contents as

Calculated by PHREEQE ............... 


\section{INTRODUCTION}

Stabilizing inactive uranium mill tailings with earthen covers is an accepted practice to retard the emission of radon gas and prevent dispersal of contaminants by wind and run-off. An acceptable cover system must demonstrate effectiveness, as well as longevity, of control against contaminant dispersal. The thickness of the cover is generally assumed to control the effectiveness of earthen covers and is calculated on the basis of the diffussion of radon gas from a given radium source term in the tailings. Longevity is generally considered to be a function of the erosional processes occurring on the surface of the covered tailings. In addition to the physical processes, however, assessment of the longevity of the cover must consider the physical and chemical processes in the cover and between the cover and tailings which may affect the source terms and retardation properties of the cover.

Accumulations of salts and trace metals on the surface of thin covers were observed in previous geochemical characterizations of several inactive uranium mill tailings [1,2, and 3]. If the processes transporting components to the surface of thin covers continue to operate in the thick earthen covers currently proposed for stabilization of tailings, the expected results would be: (1) an increase in the source term for radon gas in the cover from the accumulation of Ra-226 and Th-230, which are precursors in the decay to radon gas; (2) accumulation of salts and trace metals on the surface available for dispersal; and (3) the addition of salts ( $\mathrm{Ca}, \mathrm{Na}, \mathrm{SO}_{4}$, and $\left.\mathrm{Cl}\right)$ into the cover which may induce changes in the chemical state of minerals in the earthen materials, a redistribution of the moisture content by hygroscopic salts, and alterations in compaction by electrostatic interactions.

The Uranium Mill Tailings Remedial Action Project elected to determine the significance of migration of salts and contaminants into earthen covers emplaced on tailings by funding this investigation of the migration which has occurred through an earthen cover since the time of emplacement on an inactive uranium mill tailings pile. The Riverton tailings pile, covered with 20 to $40 \mathrm{~cm}$ of local sandy soil, was chosen for the study. The objectives of the study were to: 
1. determine vertical distributions of concentrations of salts, trace metals, and radionuclides through the cover and into the tailings;

2. determine the concentrations of salts and contaminants in the cover from chemical migration;

3. relate the migration of salts to the contaminants;

4. model the mechanisms responsible for promoting and retarding migration; and

5. evaluaie the chemical and physical properties of the cover influencing migration.

Objectives 1, 2, and 3 involve evaluation of chemical data generated by analysis of samples from the Riverton tailings site. Objectives 4 and 5 take the specific data $1: 0$ a general form by evaluating the data using chemical thermodynamics and relationships among elements to predict the geochemical mechanisins. Understanding the mechanisms responsible for migration and retardation of contaminants is the key to understanding migration processes and application of the results from this study to a generic cover design.

Migration requires a mobile form of an element and moving water for a transporting medium. The mobile forms are predicted by chemical thermodynamics which determine the distribution of aqueous species and minerals. The concentrations of elements available for migration in equilibrium with a precipitated phase are controlled by solubility constants and the formation of aqueous complexes. Factors such as adsorption and kinetics of precipitation and dissolution, not included in thermodynamics, are determined by comparison of the empirical distributions of the components with the thermodynamic predictions.

The upward migration of water through earthen covers occurs primarily by capillary potentials and fluid gradients induced by evaporation from the surface. Application of the results of this study of migration in a thin cover to migration in a thick cover must include an estimate of the height. of the capillary rise in the cover and the upward movement of water by fluid gradients. Processes of upward migration due to evaporation are understood well enough to allow numerical modeling of the vertical gradient 
of fluid potentials [4]. Results of fluid potential measurements at the Riverton site indicate an upward movement of water within about the top one meter of the thinly covered tailings [4]. A major portion of the contaminants described in this report which migrated into the cover of the Riverton tailings were most likely transported upward by evaporation induced fluid gradients. Emplacement of a thick cover on the tailings will decrease upward fluid gradients in the tailings, thereby minimizing the upward movement of tailings solution.

The reduction of evaporation of tailings solution by a thick cover may increase the role of capillary potentials in the upward movement of water. Capillary potentials differ from fluid gradients in that they arise from surface tension between the solid particles and pore solution as a fuction of pore size within the soil and concentration and composition of solution and are independent of cover thickness. The finer the grain size, the greater is the capillary potential. In some silty-clayey soils, capillary rise as great as four meters has been measured. As chemical reactions which cement the soil grains occur, the capillary rise increases as the pore space decreases. Estimation of the height of capillary rise in the tailings is difficult because of the variability in the size of pore spaces, the variation in solution viscosity between the tailings and cover, and the partially saturated state of the tailings material.

Engineered capillary barriers interrupt capillary potentials and retard the rate of water movement; however, they do not preclude water movement due to differential vapor pressure across the barrier. Vapor movement in unsaturated soils is a complicated process because of the free energy exchange in the vapor-liquid phase changes [5]. Highly charged small cations tend to be concentrated in water films on the solid particles and, therefore, are more apt to be transported across the vapor phase. Because of the uncertainty in predicting water movement over long periods of time, cover designs should include geochemical concepts to retard the mobility of salts and contaminants in addition to hydrologic considerations to minimize the transport of mobile components. 


\section{METHODS}

\section{SAMPLING}

The Riverton tajlings pile was used for this study; because of the thickness of its cover, and data were available on the general characterization of the pile to aid in selecting sampling locations [1]. The original plan of investigation called for sampling of three tailings piles with relatively thick covers. Other sites with thick covers, however, proved inaccessible; access to the Lakeview, Oregon, site was denied by the oregon Department of Energy; and a 3 -foot snow cover prevented access to the Montice110, Utah, site.

The Riverton tailings pile has a nominal $45-\mathrm{cm}$ cover of local soil emplaced about 20 years ago, assuming the cover was emplaced at the time the mill ceased operations. Sparse vegetation of native grasses and weeds grows on the pile without irrigation. Three locations on the Riverton tailings pile were sampled to represent examples of different conditions within the pile (Figure 1). Fine sand dominates the material of the western one-third (RIV $164)$ and a plastic liner used to collect the acidic raffinate solution for recirculation in the milling process underlies this portion of the tailings [4]. The surface of the middle area exhibited salt encrustations indicative of the upward movement of salts (RIV 165). The eastern area contains the shallowest section of tailings, and the ground water is nearest to the base of the tailings (RIV 166). Previous data showed Ra-226 enrichment in the cover in this area [1].

Walls of trenches dug with a backhoe were sampled in about $5 \mathrm{-cm}$ intervals from the surface to about $50 \mathrm{~cm}$ into the tailings over a lateral area large enough to collect a total of about $1.5 \mathrm{~kg}$ of material. The interface sample of about 2-3 cm contains tailings and soil material. The sample depth from the surface, the type of material, and a description of the material was recorded during sampling (Tables 1,2 , and 3 ). The moisture in the upper $15-20 \mathrm{~cm}$ of soil was frozen at the time of sampling $(11 / 18 / 82)$. Sampling was done with a hand trowel and extreme care was exercised to prevent cross contamination. The samples were placed in gas impermeable polyethylene bags and bathed in nitrogen gas to displace the oxygen-rich atmosphere. Upon 


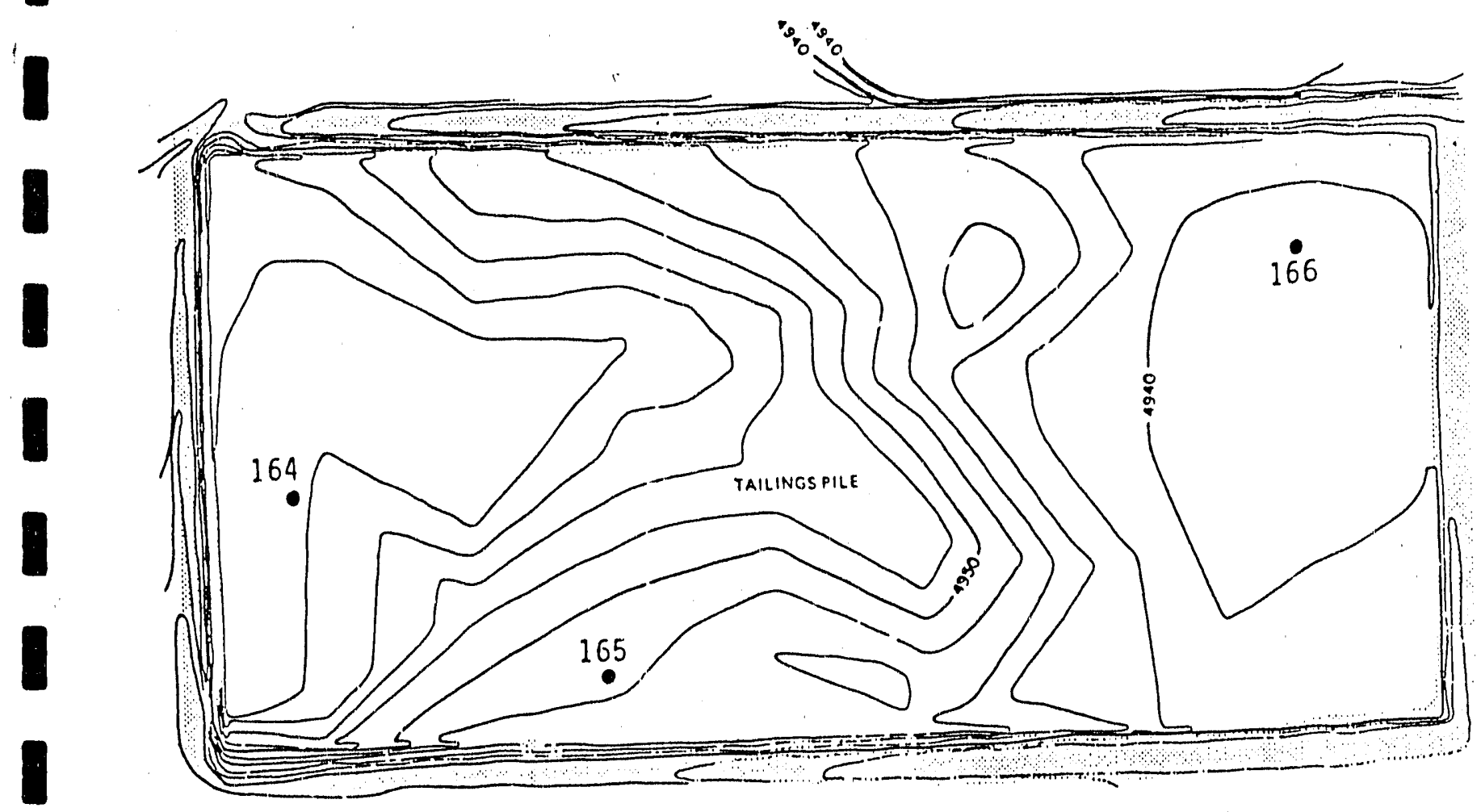

Figure 1. Sites of trenches $\left(5^{\prime} \times 3^{\prime} \times 3^{\prime}\right)$ where consecutive samples of about $5 \mathrm{~cm}$ depth intervals were taken from surface through cover and into tailings about $90 \mathrm{~cm}$. Sampling by GECR, $11 / 82$. Base map from Ford, Bacon and Davis Utah, Inc. [5] 
Table 1. Sampling Record for Site Number 164

\begin{tabular}{|c|c|c|c|c|c|}
\hline \multirow{2}{*}{$\begin{array}{l}\text { Sample } \\
\text { Number }\end{array}$} & \multirow{2}{*}{$\begin{array}{l}\text { Sample } \\
\text { Intervail } \\
\text { (cm) }\end{array}$} & \multirow{2}{*}{$\begin{array}{l}\text { Sample } \\
\text { Type }\end{array}$} & \multicolumn{2}{|c|}{$\begin{array}{c}\text { Field } \\
\text { Measurements } \\
\end{array}$} & \multirow[t]{2}{*}{ Remarks } \\
\hline & & & $\mathrm{pH}$ & $E h(m V)$ & \\
\hline 1 & $0-5$ & C & 8.2 & 385 & $\begin{array}{l}\text { Frozen; moist; sandy with } \\
\text { cobbles }\end{array}$ \\
\hline 2 & $5-10$ & C & 8.7 & 340 & Frozen; moist; clayey sand \\
\hline 3 & $10-15$ & C & 8.3 & 400 & Frozen; moist; clayey sand \\
\hline 4 & $15-23$ & C & 8.1 & 420 & Not frozen; moist \\
\hline 5 & $23-26$ & I & 5.4 & 570 & $\begin{array}{l}\text { Moist; iron oxides marking } \\
\text { interface }\end{array}$ \\
\hline 6 & $26-30$ & $T$ & 4.0 & 635 & $\begin{array}{l}\text { Moist; yellow sand; } \mathrm{Fe}(\mathrm{OH})_{3} \\
\text { inclusions }\end{array}$ \\
\hline 7 & $30-37$ & $T$ & 3.2 & 680 & Moist; uniform brown sand \\
\hline 8 & $37-43$ & T & 2.8 & 750 & Moist; gray/brown sandy cläy \\
\hline 9 & $43-53$ & T & 2.9 & 755 & Moist; uniform brown sand \\
\hline 10 & $74-79$ & $\mathrm{~T}$ & 2.5 & 770 & $\begin{array}{l}\text { Moist; brown clay w/coarse black } \\
\text { grains }\end{array}$ \\
\hline 11 & $86-93$ & $T$ & 2.4 & 785 & $\begin{array}{l}\text { Moist; uniform browr clay; } \\
\text { plastic }\end{array}$ \\
\hline 12 & $96-104$ & $T$ & 2.7 & 765 & Moist; light yellow loose sand \\
\hline
\end{tabular}

1 Depth from surface.

2. $T=$ Tailings; $I$ = Interface; $C=$ Cover.

3 Measurements made on a 1:4 solid:water slurry. 
Table 2. Sampling Record for Site Number 165

\begin{tabular}{|c|c|c|c|c|c|}
\hline \multirow{2}{*}{$\begin{array}{l}\text { Sample } \\
\text { Number }\end{array}$} & \multirow{2}{*}{$\begin{array}{c}\text { Sample } \\
\text { Interval1 } \\
(\mathrm{cm})\end{array}$} & \multirow{2}{*}{$\begin{array}{l}\text { Sample } \\
\text { Type }^{2}\end{array}$} & \multicolumn{2}{|c|}{$\begin{array}{l}\text { Field } \\
\text { Measurements }\end{array}$} & \multirow[t]{2}{*}{ Remarks } \\
\hline & & & $\mathrm{pH}$ & $E h(m V)$ & \\
\hline 1 & $0-5$ & C & 7.6 & 490 & Dry; sandy \\
\hline 2 & $5-10$ & C & 7.7 & 485 & Moist; frozen; sandy \\
\hline 3 & $14-19$ & C & 76 & 490 & $\begin{array}{l}\text { Moist; frozen; sandy with } \\
\text { cobbles }\end{array}$ \\
\hline 4 & $19-28$ & C & 7.9 & 405 & $\begin{array}{l}\text { Moist; frozen; sandy with } \\
\text { cobbles }\end{array}$ \\
\hline 5 & $28-35$ & c & 7.9 & 415 & Moist; unfrozen; sandy \\
\hline 6 & $35-37$ & $I$ & 3.8 & 590 & $\begin{array}{l}\text { Moist; iron oxides marking } \\
\text { interface }\end{array}$ \\
\hline 7 & $38-42$ & $T$ & 3.5 & 625 & Moist; yellow sand \\
\hline 8 & $44-51$ & $T$ & 2.7 & 715 & Wet; brown clay \\
\hline 9 & $52-63$ & $T$ & 2.6 & 720 & Wet; brown sandy clay \\
\hline 10 & $82-94$ & $T$ & 2.3 & 770 & Wet; gray clay; plastic \\
\hline
\end{tabular}

1 Depth from surface.

$2 T=$ Tailings; $I$ = Interface; $C=$ Cover.

3 Measurements made on a 1:4 solid:water slurry. 
Table 3. Sampling Record for site Number 166

\begin{tabular}{|c|c|c|c|c|c|}
\hline \multirow{2}{*}{$\begin{array}{l}\text { Sample } \\
\text { Number }\end{array}$} & \multirow{2}{*}{$\begin{array}{c}\text { Sample } \\
\text { Interval1 } \\
(\mathrm{cm})\end{array}$} & \multirow{2}{*}{$\begin{array}{l}\text { Sample } \\
\text { Type }\end{array}$} & \multicolumn{2}{|c|}{$\begin{array}{l}\text { Field } \\
\text { Measurements }\end{array}$} & \multirow[t]{2}{*}{ Remarks } \\
\hline & & & $\mathrm{pH}$ & $E h(m V)$ & \\
\hline 1 & $0-5$ & c & 8.1 & 430 & Moist; frozen; sandy \\
\hline 2 & $5-10$ & C & 8.0 & 435 & $\begin{array}{l}\text { Moist; frozen; sandy with } \\
\text { cobbles }\end{array}$ \\
\hline 3 & $13-20$ & $c$ & 8.0 & 450 & $\begin{array}{l}\text { Moist; frozen; sandy with } \\
\text { cobbles }\end{array}$ \\
\hline 4 & $20-23$ & I & 5.1 & 500 & $\begin{array}{l}\text { Moist; not frozen; no sharp } \\
\text { interface }\end{array}$ \\
\hline 5 & $23-26$ & $T$ & 3.5 & 620 & $\begin{array}{l}\text { Moist; yellow sand with brown } \\
\text { clay stringers }\end{array}$ \\
\hline 6 & $27-33$ & $T$ & 3.3 & 655 & Moist; gray/yellow clay \\
\hline 7 & $33-42$ & $T$ & 3.2 & 665 & Moist; very fine white sand \\
\hline 8 & $61-66$ & $\mathrm{~T}$ & 3.1 & 665 & $\begin{array}{l}\text { Moist; clay with yellow clay } \\
\text { stringers; plastic }\end{array}$ \\
\hline
\end{tabular}

1 Depth from surface.

$2 T=$ Tailings; $I$ = Interface; $C=$ Cover.

3 Measurements made on a 1:4 solid:water slurry. 
returning to the laboratory, $\mathrm{Eh}$ and $\mathrm{pH}$ measurements were made on 1:4 solid:water slurries. The samples were dried at ambient conditions, disaggregated with a porcelain mortar and pestle, and split with a precision chutetype stainless steel sample splitter for extractions, chemical and isotopic analysis, and $X$-ray diffraction analysis.

\section{SAMPLE PROCESSING AND ANALYSIS}

The study of migration requires data on the chemical composition of the chemically unique phases of the dried solid matrix to establish relationships between mobile and inmobile phases. The composition of the insoluble phase reflects the mineralogy of the tailings and cover materials and, therefore, distinguishes between the different types of materiais. The chemical composition of the bulk solid is used to determine ine quantity of tailings mixed with the soil of the cover. The water-soluble phase contains the elements available for migration upon the addition of water. The chemical composition of water extracts, calculated to represent varying degrees of moisture saturation, approximate the composition of the pore water within the tailings and cover. The acid-soluble phase contains the hydrous oxides of iron, manganese, aluminum, and silicon, the carbonate salts and the trace elements immobilized by precipitation and adsorption on the hydrous precipitates. The relationships between the concentrations of major and trace elements in the acid soluble phase provides information on mechanisms of immobilization such as adsorption and co-precipitation.

The water extract procedure has been developed in our laboratory to obtain maximum removal of soluble materials in the shortest time at the chemical conditions of the samples. A measured weight of approximately 50 grams of solid was added to approximately $200 \mathrm{ml}$ of distilled water and agitated with a wrist action shaker at a rate which maintained the solid in suspension. After fifteen minutes, the solution was centrifuged; the $\mathrm{pH}$, Eh, and specific conductance of the solution was measured; and the supernatant was decanted. The solid residue was washed twice by repeating the shaking with $200 \mathrm{ml}$ of water. After each washing, the solution was centrifuged and the supernatant was decanted. The extract was filtered with a $0.45 \mathrm{um}$ filter, acidified with concentrated nitric acid, and diluted 
volumetrically to one liter. A $50 \mathrm{ml}$ aliquot was evaporated to dryness for a measure of total dissolved solids (TDS).

Acid extracts with hydrochloric acid on the water extracted solids removed the hydroxides, cartonates, oxides, and the included contaminants. Hydrochloric acid was used as a nonoxidizing, strong acid with minimal complexing effects. The final pH values of the acid extracts were below the isoelectric point ( $\mathrm{pH}-2$ ) of most silicate minerals, so dissolution of precipitate coatings on mineral surfaces and the desorption of cations was maximized. The solid residues from the water extracts were weighed to the nearest 0.1 gram. Hydrochloric acid $(200 \mathrm{ml}$ of $0.05 \mathrm{~N})$ was added to the solid and agitated on a wrist action shaker for one hour. The solution was centrifuged and the $\mathrm{pH}$ of the solution was measured. If the $\mathrm{pH}$ was greater than two, additional $\mathrm{HCl}$ was added and the shaking repeated until the $\mathrm{pH}$ was maintained at less than two. The solution was then filtered through a $0.45 \mu \mathrm{m}$ filter and diluted volumetrically to one liter.

All of the chemical and isotopic analysis was done by Bendix Field Engineering Corporation, Grand Junction, Colorado. The methods and references are listed in Appendix A. The chemical data of the solid samples, water extracts, and acid extracts are listed in Tables 1, 2, and 3 of Appendix $B$. The $X$-ray diffraction results are summarized in Appendix $C$.

\section{EMPIRICAL RELATIONSHIPS AMONG ELEMENTS}

Relationships between sets of data of different elements and within a set of data of a single element are very useful in determining the source and mechanisms controlling the availability of the elements. Regression analysis quantifies relationships between elements by the slope of the regression line. The slope of the line is defined by the ratio of two eiements. In a precipitation or dissolution reaction, the slope approximates the stoichiometry between two or more elements in a solid phase. For example, a correlation between $\mathrm{Pb}-210$ and $\mathrm{Ra}-226$ in the tailings material with a slope of one indicates isotopic equilibrium; $i$. e., the specific activity of $\mathrm{Pb}-210$ equals that of $\mathrm{Ra}-226$. The slope of the correlation between extractable alumirum and silicon represents the stuichiometry of the aluminosilicate mineral being dissolved in the extraction process. 
The correlation between acid soluble iron and a trace metal provides information for calculating the adsorption coefficients.

Plotting normalized linear cumulative frequency distributions is a technique to evaluate the relationships within a set of anlaysis of a single element. Normal populations are identified for calculation of parametric statistics, and the different populations within the data set are identified in relationship to some physical reality. For example, tailings, contaminated soils, and noncontaminated soils are distinguished as three unique populations of concentrations of isotopes or elements composing the bulk mineralogy. Data points outside the populations are usually from samples influenced by external processes of chemical migration or physical mixing.

\section{MODELING MIGRATION MECHANISMS}

Thermodynamics provide the basis for determination of the species available for migration and the solid phases responsible for immobilization. The success of thermodynamics to interpret and predict processes lies in the ability to include the interrelationships and the dynamics of a complex heterogeneous system, with a set of simultaneous equations. A modified version of the computer program PHREEQE $[7,8]$ was used in this study to calculate simultaneous milticomponent multiphase equilibria. The simultaneous equations include mass balance of the aqueous species to equal the anaiytical input data and the equilibrium expressions of aqueous species and solid and gas phases. The output of the calculations contains the concentrations and activity coefficients of aqueous species, and the saturation indexes of mineral and gas phases. PHREEOE includes the options to equilibrate a solution with mineral phases which acts to add or delete soluble components to attain the specified saturation indexes of specified minerals and calculates the resultant Eh and $\mathrm{pH}$. Other options are to calculate the resultant solution (1) upon mixing two solutions either at constant or variable volume, and (2) upon evaporation of a solution.

The results of the calculations depend upon the thermodynamic data base entered into the program. The data base contains two important variables: (1) the equilibrium constants calculated from Gibbs free energy values of 
formation of the aqueous species and minerals; and (2) the aqueous species and minerals entered into the thermodynamic data base available for use in the calculations. There is always some discussion about the most correct Gibbs free energy values, but for most important compounds there are agreed upon published values. The most subjective area of geochemical modeling is the aqueous species and minerals included in the calculations. Choosing the components which realistically describe the system requires experience and basic geochemical knowledge of the system of concern.

\section{DATA PROCESSING AND INTERPRETATION}

Data from the water and acid extracts were converted to gram of element per gram of solid used in the extraction process and were input data for thermodynamic calculations by PHREEQE. Operations on the water extract data with PHREEQs estimate the chemical composition of the original pore water. Water extract solutions inciude the quantity of components in the original pore water plus the solid material solubilized in the extraction process. The objective in using thermodynamic modeling of the water extract data to represent pore water is to partition the total quanticy of element between the solid and aqueous phases at a moisture saturation describing the field conditions and arrive at the correct concentration of trace and major elements in the aqueous phase.

The composition of pore water in the tailings was calculated from the water extract data by assuming a dry soil density of $1.6 \mathrm{~g} / \mathrm{cm}^{3}$ and 50 percent porosity. To remove the quantity of elements from solution that was in a precipitated phase under field conditions and which was solubilized during the extraction process, the solution was equilibrated with mineral phases of the major elements with calculations by PHREEQE. The calculations precipitate mineral phases and deduct the elements from the aqueous phase to attain specified equilibrium conditions. Minerals with saturation indexes greaten than zero are present as precipitated salts under field conditions of interstitial saturation, and the quantity of the elements in solution is controlled by their solubility constants. The mineral phases which control the solution composition, $\mathrm{pH}$ and $\mathrm{Eh}$, were determined by comparison with the chemistry of pore waters from within the 
Riverton tailings by Lawrence Berkeley Laboratory [4]. Additionally, the trace metals can be equilibrated with mineral phases; however, other processes besides thermodynamics often are important in controlling the mobility of trace elements and, therefore, the maximum concentrations are oftentimes the most usefur in representing the concentrations available to migrate.

The geochemical conditions of migration of tailings solution into the cover was modeled by calculations of PHREEQE. A typical pore solution in the tailings was calculated from the composition of the water extracts from the tailings. This was mixed with a pore water typical of the cover in incremental steps to represent upward migration. Each step was equilibrated with the dominant soluble minerals, under varying conditions of moisture, temperature, and carbon dioxide. The concentration of soluble trace metals remaining in the solutions are those available to migrate. The number of pore volumes of water which moved through the cover can be calculated from the quantity of a given element on the surface and the concentration of the element in solution. 


\section{DATA PRESENTATION}

\section{INTRODUCTION}

Evaluation of the chemical migration from the tailings into the cover that has occurred sirce the emplacement of the cover requires many types of data. The composition of the solid material supplemented with mineralogic data from $x$-ray diffraction characterizes the bulk solid material. Water extractable components indicate those elements available to move, and the acid soluble components are those that have precipitated in water insoluble forms at the $\mathrm{pH}$ conditions of the sample. The chemical environment, characterized by the $\mathrm{pH}$ and Eh (redox potential with respect to the hydrogen electrode), are essential to the interpretation of the compositional data. Measurements of $\mathrm{Eh}$ and $\mathrm{pH}$ provide a basis for the qualitative understanding and prediction of the chemical interrelationships between the tailings and cover system. The prevailing F.h-pH conditions dominante the precipitation-dissolution reactions of electroactive and $\mathrm{pH}$ sensitive components, which in turn control the mobility of trace elements and radionuclides.

Eh-pH DIAGRAMS

Eh-pH diagrams simply express the gross character of the chemical environment of the tailings and cover (Figure 2). The measured $\mathrm{Eh}$ and $\mathrm{pH}$ values for the solid samples and the water extracts are superimposed upon equilibrium lines for the iron and manganese components calculated at concentrations typical to tile tailings and soils.

The ferric/ferrous equilibrium apparentiy controls the chemical character of the tailings, indicated by the trend of data points parallel to the ferric hydroxide equilibrium line. The scatter along the line is probably due to varying activities of ferrous iron in solution. The $\mathrm{pH}$ of the cover is well buffered at about $\mathrm{pH} 8$ with a $100 \mathrm{mV}$ range in Eh values within the stability field for manganese minerals. The equilibrium Eh lies in the $M n$ (III) stability field, which is probably a mixed oxide of $M n$ (II) and $\mathrm{Mn}$ (IV). The Eh and $\mathrm{pH}$ conditions of the interface samples clearly lie between the conditions of tailings and cover soils. This is a 

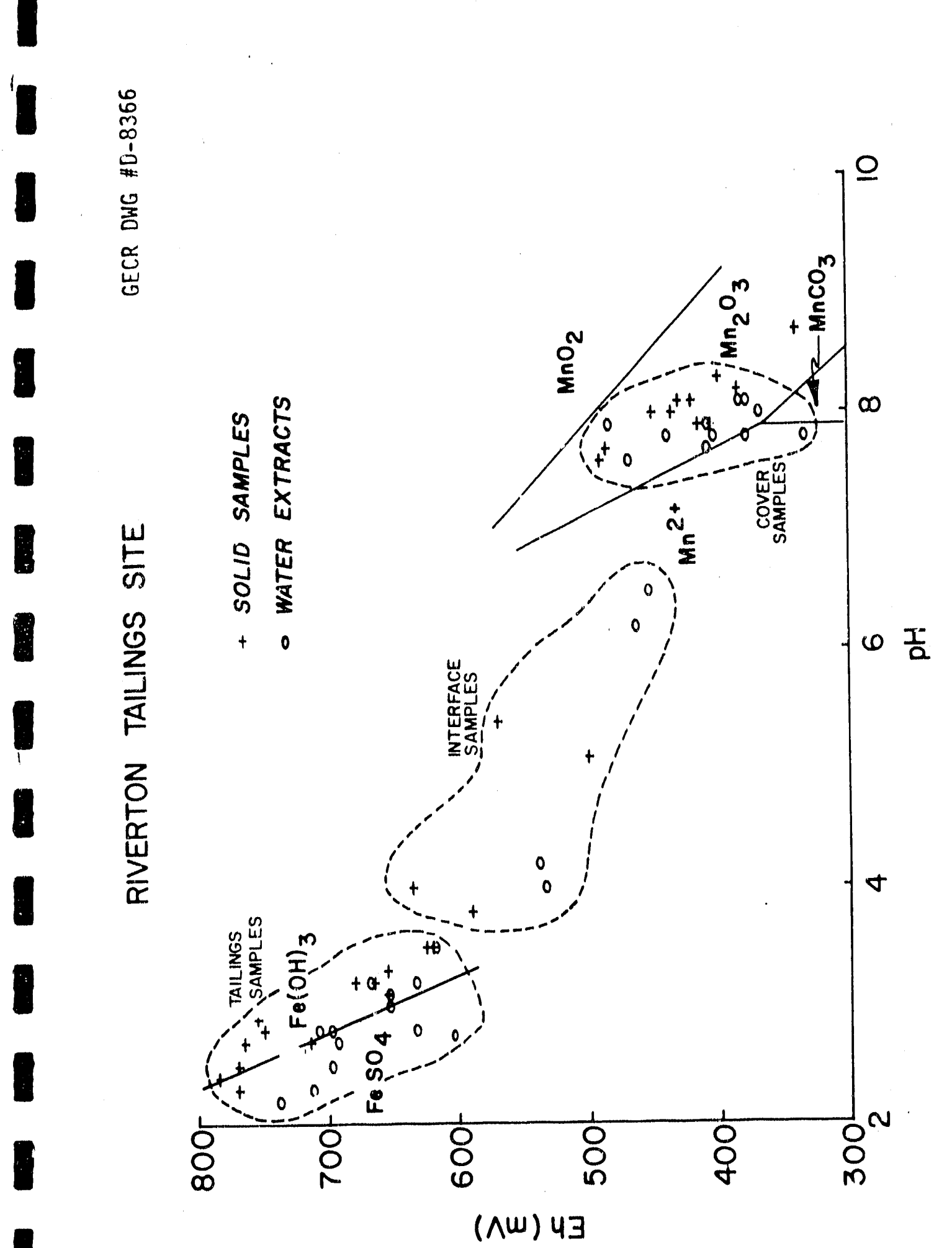

吾

.

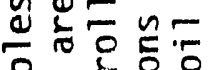

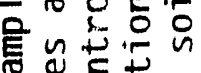

的要它它

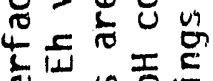

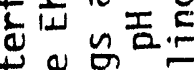

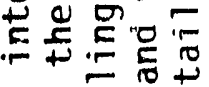

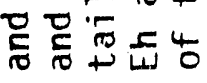

ทำ용

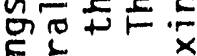

焉告. 肴

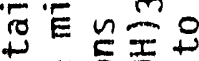

为

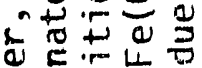

列

论

Q

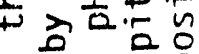

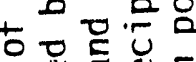

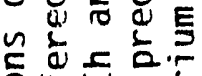

ธ。出吉

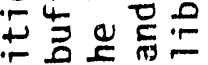

的

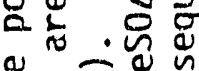

的三出

+

g'o

들

就可

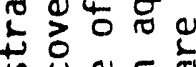

눙

额

$=\mp 2$

E4

TO

象的可。

它.

亖药至

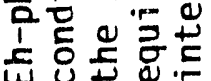

定 
disequilibrium zone where reactions are proceeding toward the most highly buffered system by neutralization of acid with carbonate and oxidation oi $\mathrm{Fe}$ (II) coupled with reduction of $M n(I V)$. The manganese and carbonate minerals in the soil serve as buffers for the redox potential and $\mathrm{pH}$. The trend of the Eh and $\mathrm{PH}$ values in the soil is shifted slightly to the right from the Eh and $\mathrm{pH}$ trend of the water extracts. This pattern is produced by the greater activities of dissolved $\mathrm{Mn}$ (II) and $\mathrm{Fe}(\mathrm{II})$ in the extracts. The more complex relat: nship between the solid samples and extacts of the interface samples is no doubt related to the disequilibrium conditions of a mixture of soil and tailings. Also, the logical system portrayed by the Eh and $\mathrm{pH}$ diagram supports the validity of using measured Eh values.

\section{CHEMICAL DISTRIBUTIONS}

Diagrams of the vertical distribution of chemical data clearly expresses significant patterns within the tailings and cover. The major composition of the bulk solid samples distinguishes the soils of the cover, the sand tailings, and the slime tailings (Figures 3,4, and 5). Of the elements determined in the bulk solids, concentrations of $\mathrm{Al}, \mathrm{Si}$, and $\mathrm{Fe}$ are not significantly different in the tailings and soils. The concentrations of manganese, however, are consistently greater in the cover than in the tailings; whereas the concentrations of potassium are greater in the tailings than in the covier. The isotope concentrations in the cover exhibit large variations and are generally greater than the background concentrations of isotopes. The interface samples are significantly enriched in isotopes. The isotope concentrations greater than background are comprised of the concentrations due to the physical mixing of tailings in the cover and chemical migration of isotopes. The distribution of isotopes within the tailings also distinguishes the sand and slime tailings. Slime tailings characteristicaliy contain concentrations of isotopes greater than sand tailings. The slime tailings dominate the tailings at site 165 and a layer near the lower samples of sites 164 and 166. The upper portions of RIV 164 and RIV 166 are mainly sandy tailings.

The tailings zenerally contain greater concentrations of water extractable components than the cover soils, expressed as the ionic strength and 
0
0
0
0
1
0
0
0
0
0
0
0
0
0
0
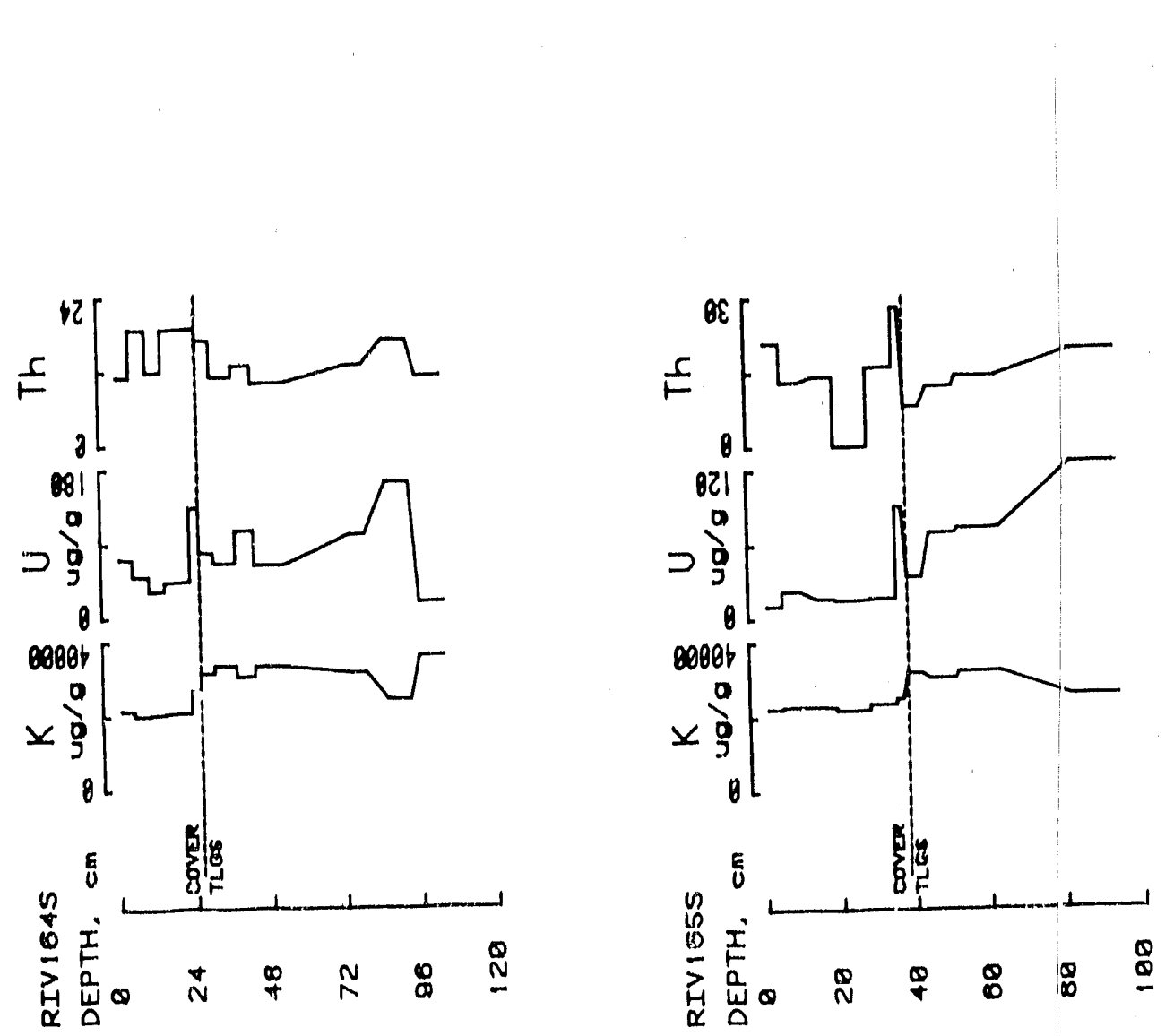

萬
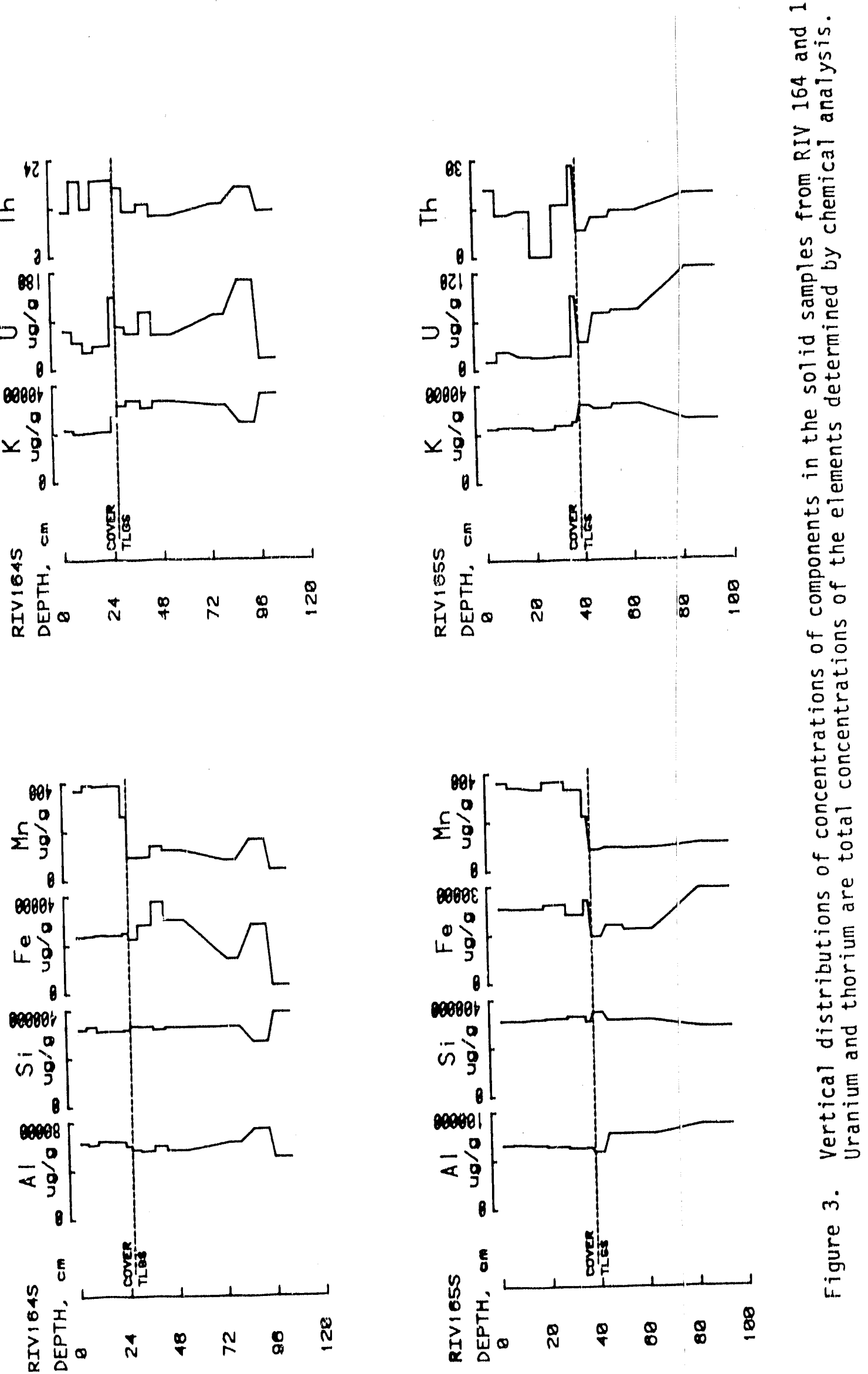


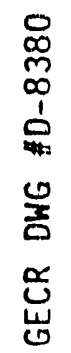

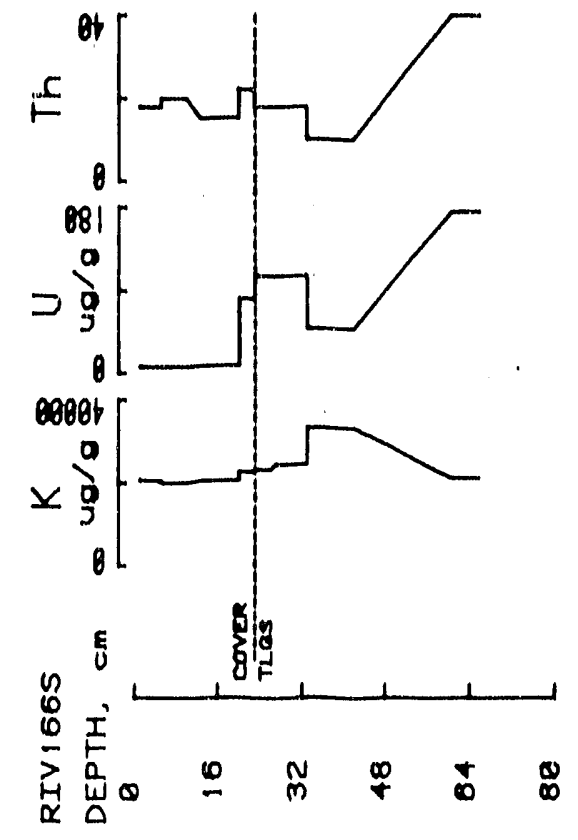

$\dot{0}_{0} \frac{n}{\frac{n}{n}}$

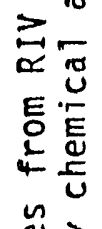

兘

을명

出

몽

용

足

드

눈

몽

능 0

4 บ

등

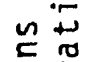

둥

$\omega$

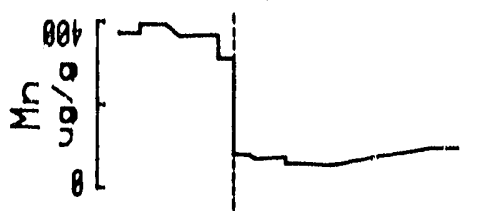

는

옹

등 -

언둥

4

o

䑻

음

3.

농

논

$\therefore$ 뭉

ป

돋

题

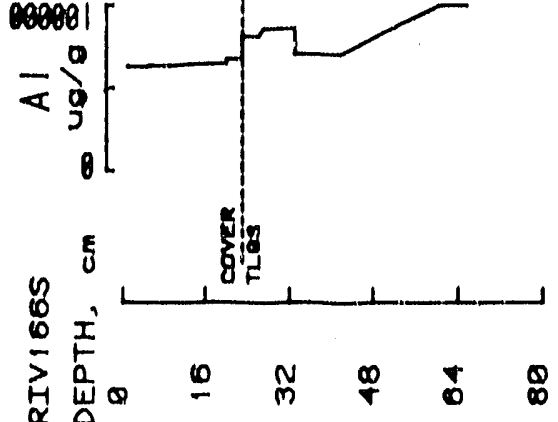

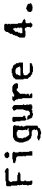



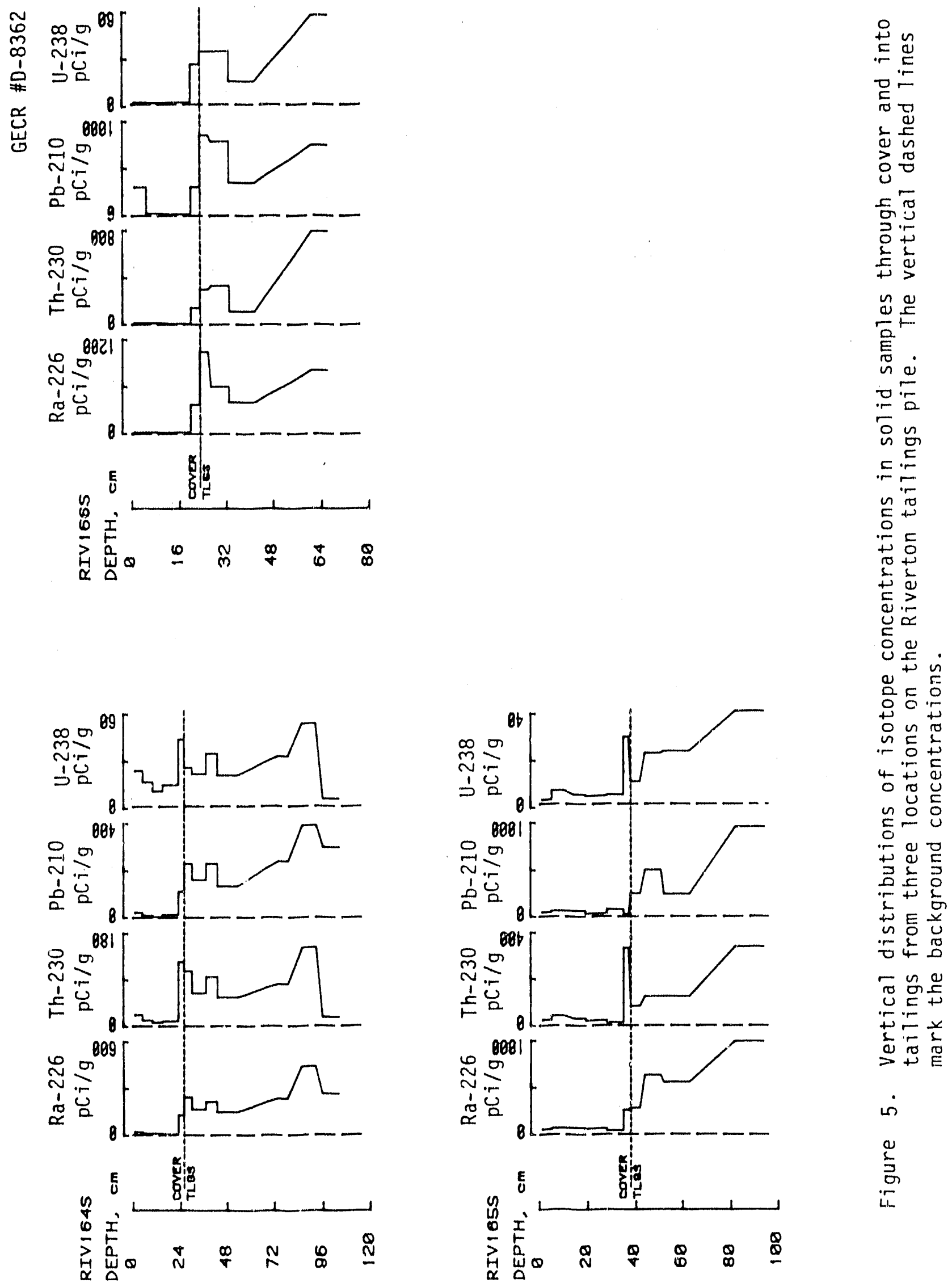
total dissolved solids of the water extracts (Figure 6). The TDS is oredominantly sulfate salts. The distribution of salts decreases from the tailings upward to the surface. This indicates that the salts are soluble and are leached downward by surface precipitation or that the front of migrating salts from the tailings is progressing upward and has not yet reached the surface. The distribution of salts does not appear to be related to the contaminant migration. Site RIV 165 has a greater TDS in the cover compared to sites RIV 164 and RIV 166 because of larger quantities of water soluble sulfate minerals (Figures $7,8,9,10,11$, and 12). Greater concentrations of total extractable aluminum, arsenic, cobalt, chromium, iron, magnesium, manganese, molybdenum, nickel, selenium, sulfate, uranium, and vanadium distinguish the tailings from the cover with the greatest concentrations in the slime tailings (Figures 7, 8, 9, 10, 11, and 12). The high degree of mobility is due to the low pH, high Eh, and availabilicy of sulfate for formation of soluble complexes.

The extractable trace elements show contamination by arsenic, molybdenum, selenium, radium, and uranium in the cover. The tendency of arsenic, molybdenum, and selenium to form oxyanions promote their mobility in neutral pH conditions. The soluble anions present in the cover are very important because of the tendency to form mobile complex species with trace metals. Phosphate and bicarbonate, for example, form mobile complexes with thorium and uranium, respectively. The interface samples are generaliy enriched in aluminum, chromium, and nickel, which indicates that these elements were immobilized under the chemical conditions of the cover and did not undergo further migration. 


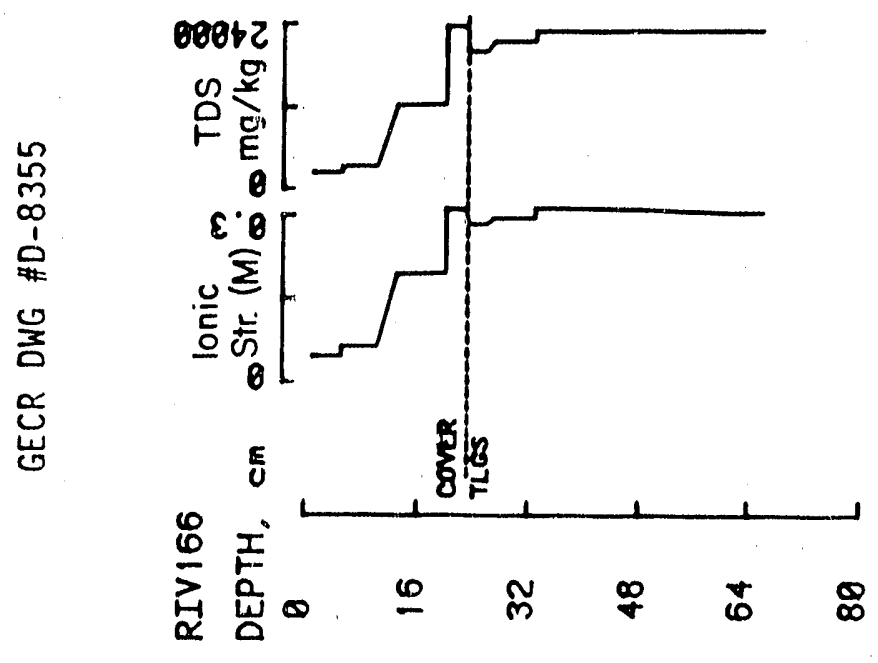

\begin{tabular}{l}
0 \\
0 \\
0 \\
0 \\
0 \\
0 \\
0 \\
0 \\
0 \\
0 \\
0 \\
0 \\
0 \\
0 \\
0 \\
0 \\
0 \\
0 \\
0 \\
0 \\
0 \\
0 \\
3 \\
4 \\
0 \\
0 \\
0 \\
0 \\
\hline
\end{tabular}
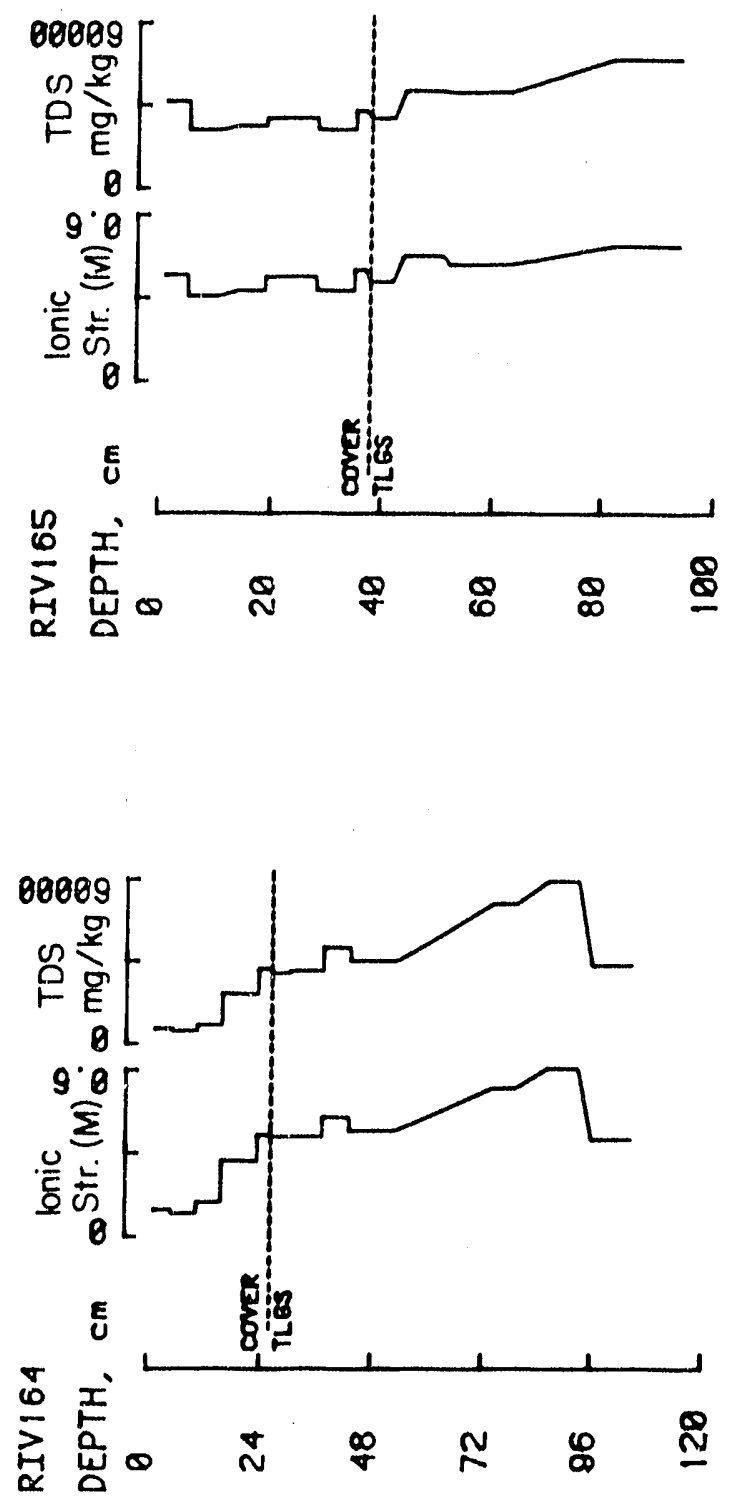

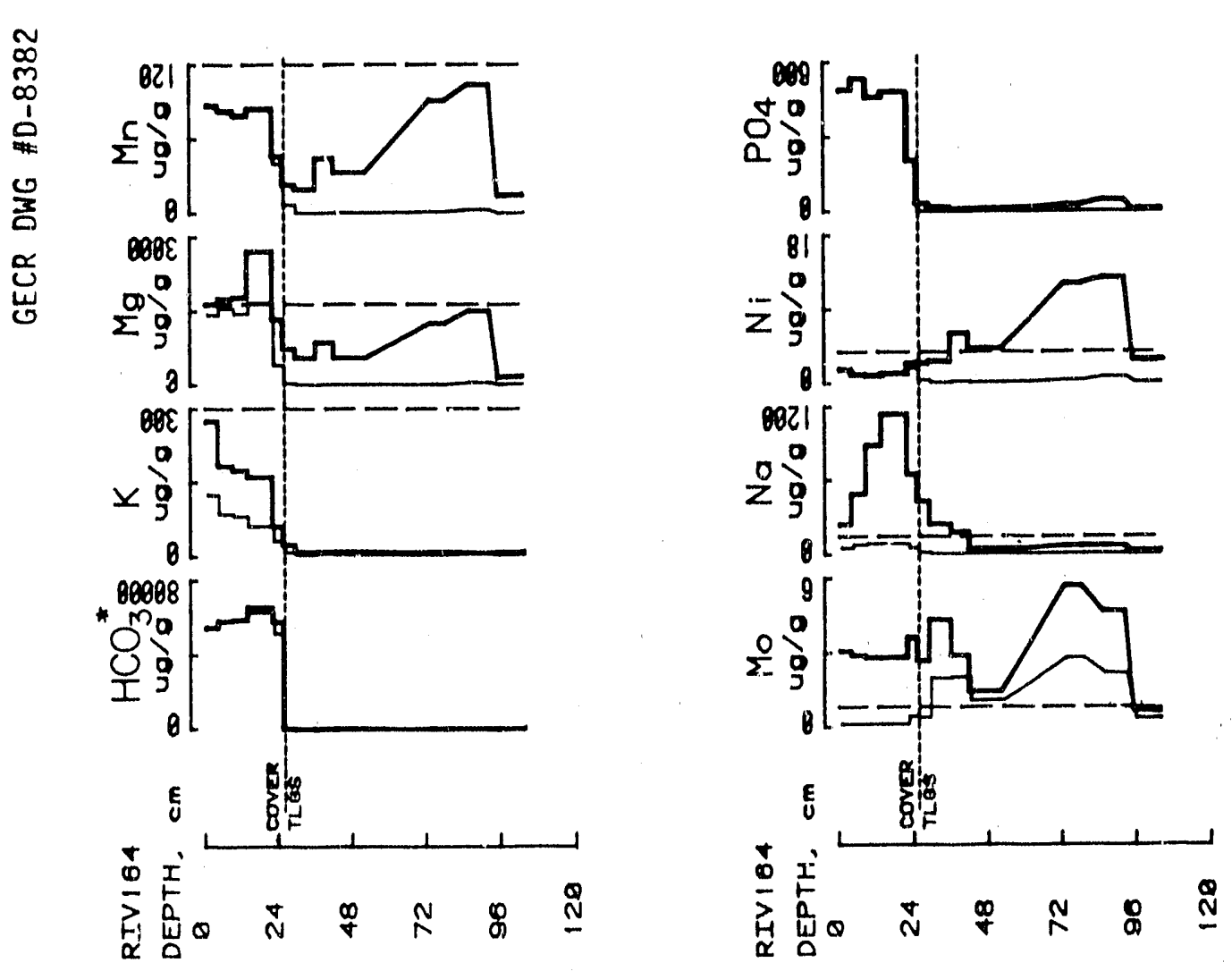

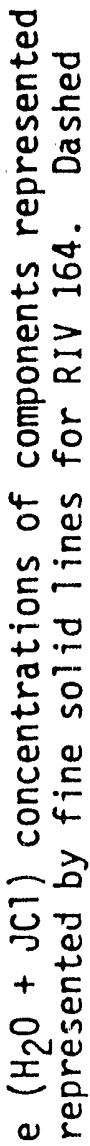

둥
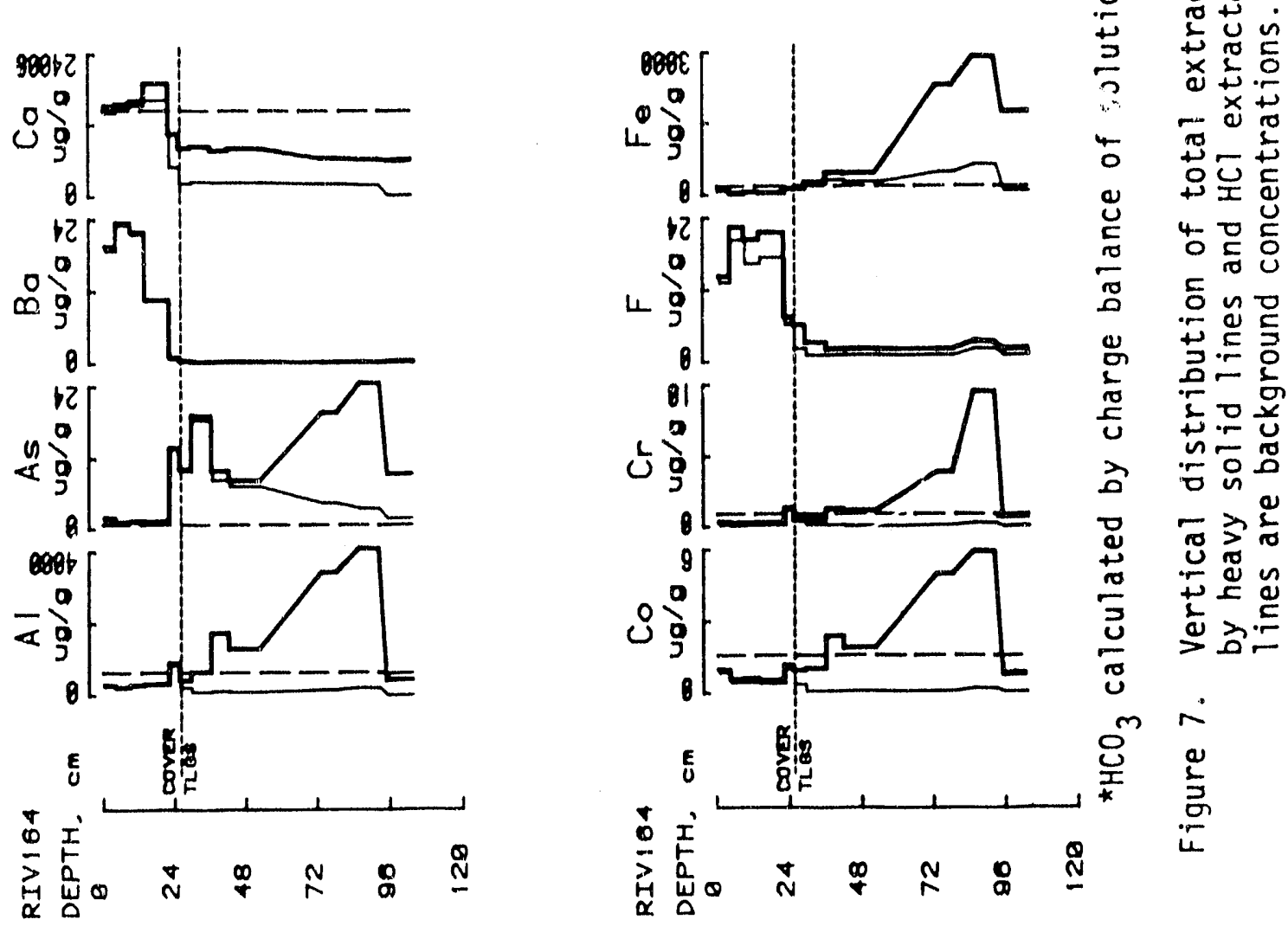

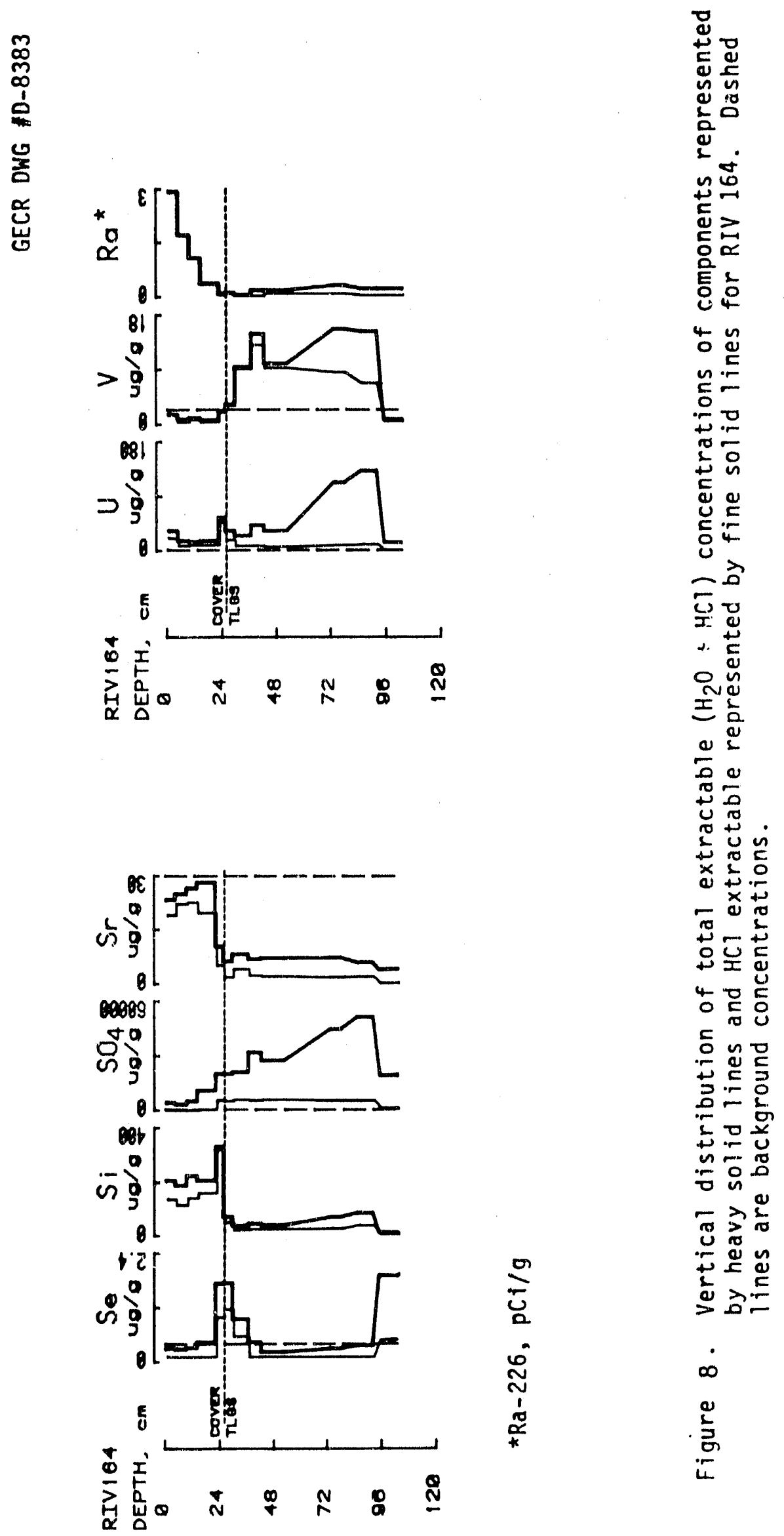

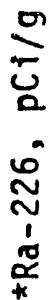

家 


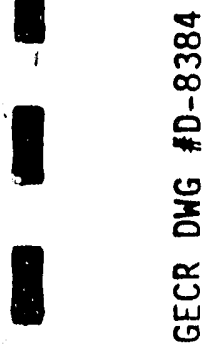
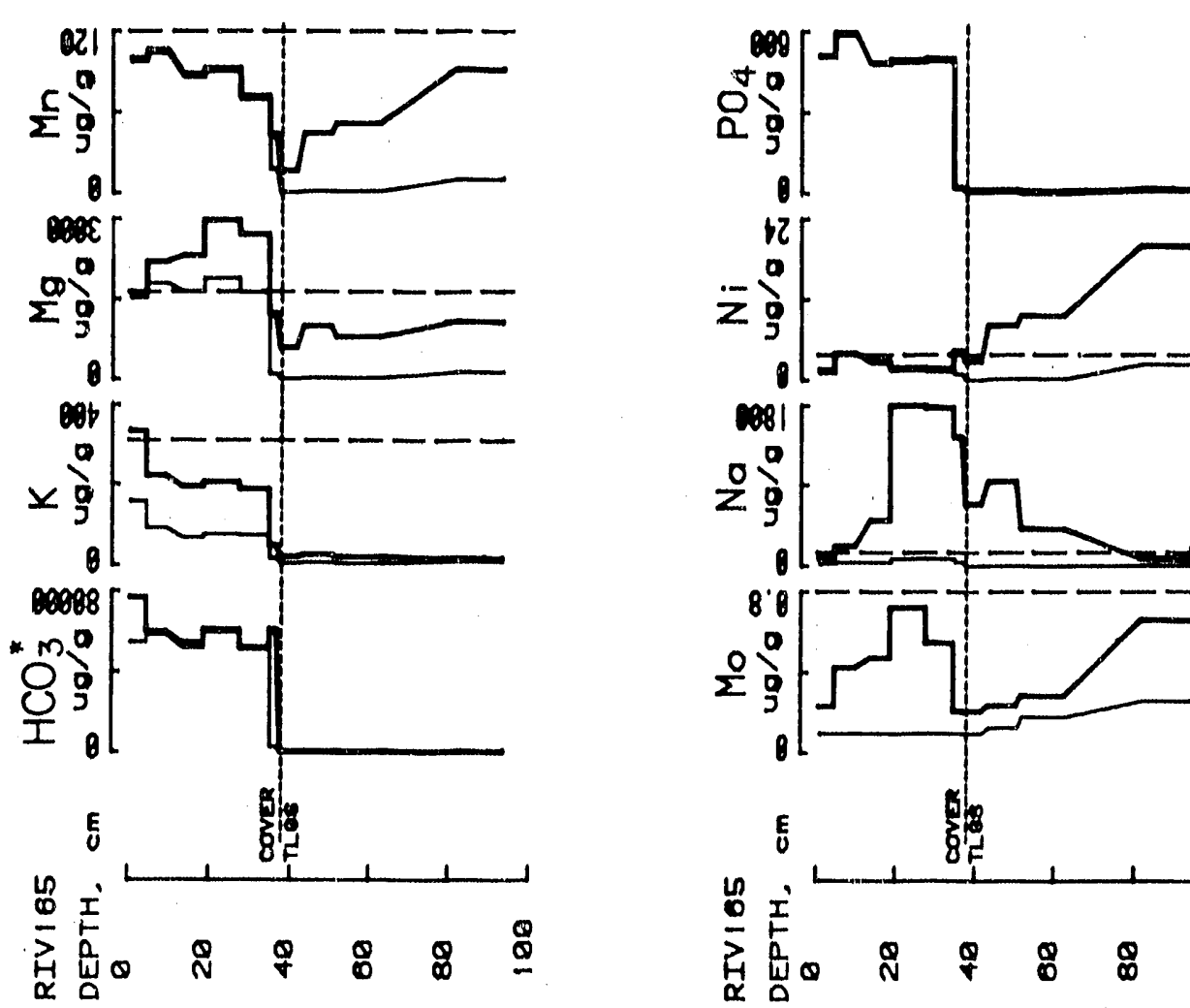

ఫ్
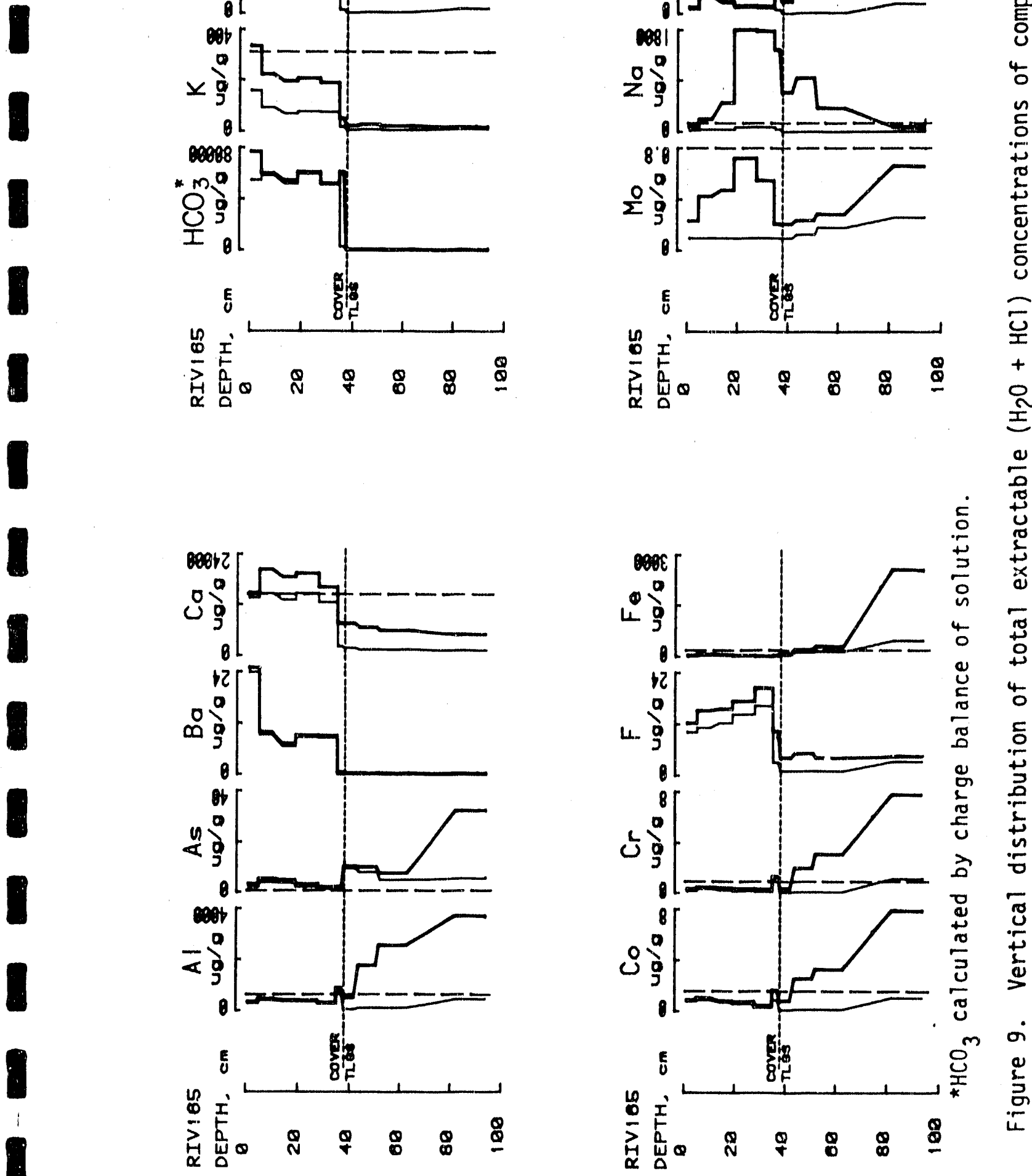

岕

造

\%

ฯ

동

员完

4 先

드

잉

웅

+ 늘

氖.

U

चे

모

$+\frac{1}{5}$

웜

Iิ

a)

\%

용

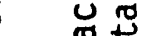

su

和。

बै।

-

范

오늗ㅇ

40

등

등 는

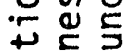

3.

든

5 믄

ज告

용

万各充

엉

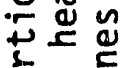

变客品

$\dot{0}$

骂

紊点。 

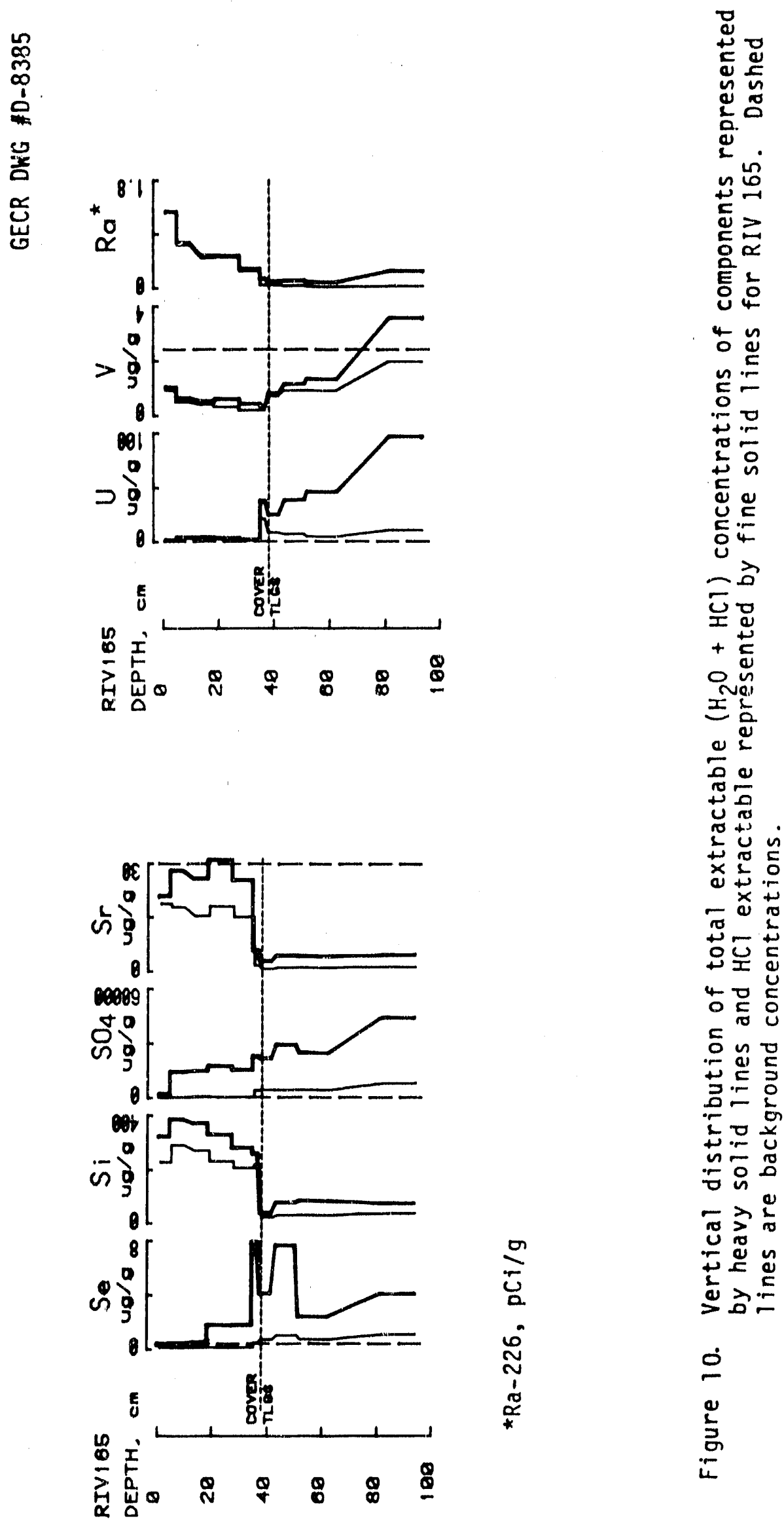

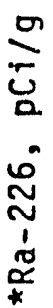




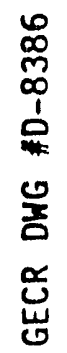
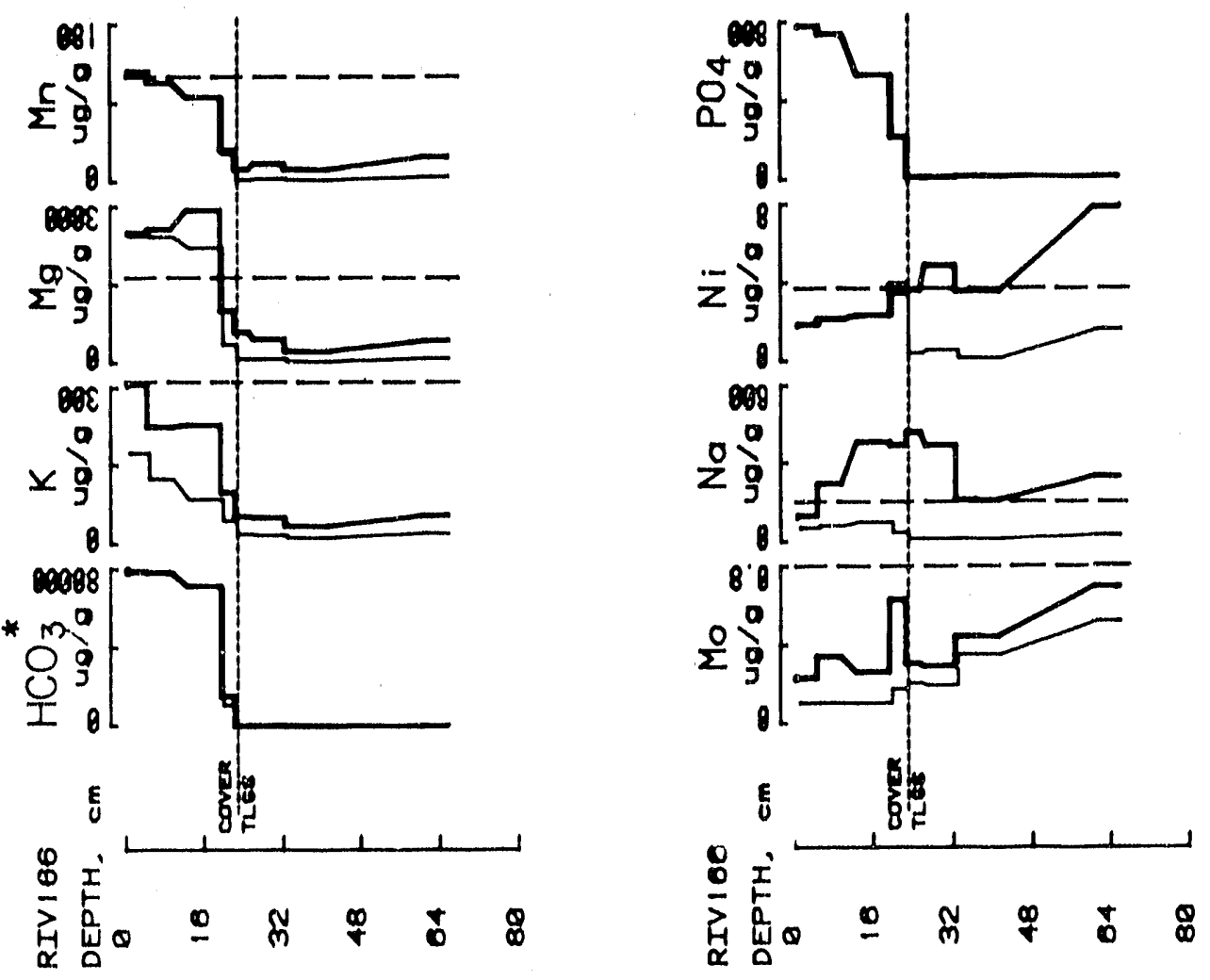

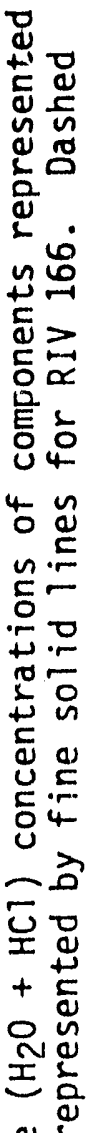

as

范

- 4

-
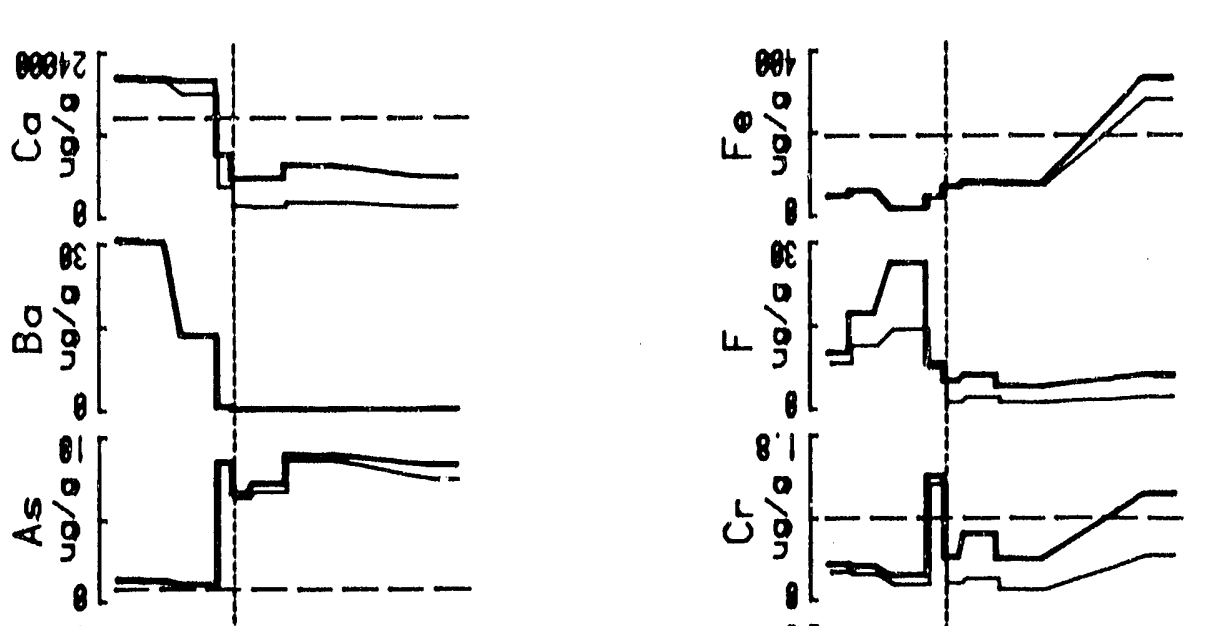

此

$\frac{1}{3}$

운

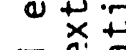

ग

+口苞

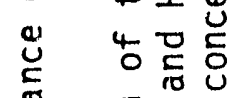

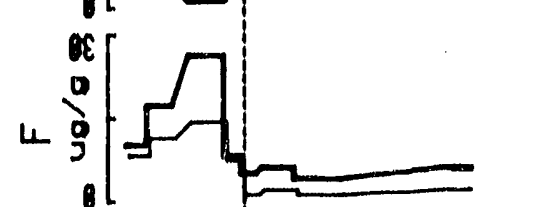

5 능

๘

금도

50

\$든

ज下

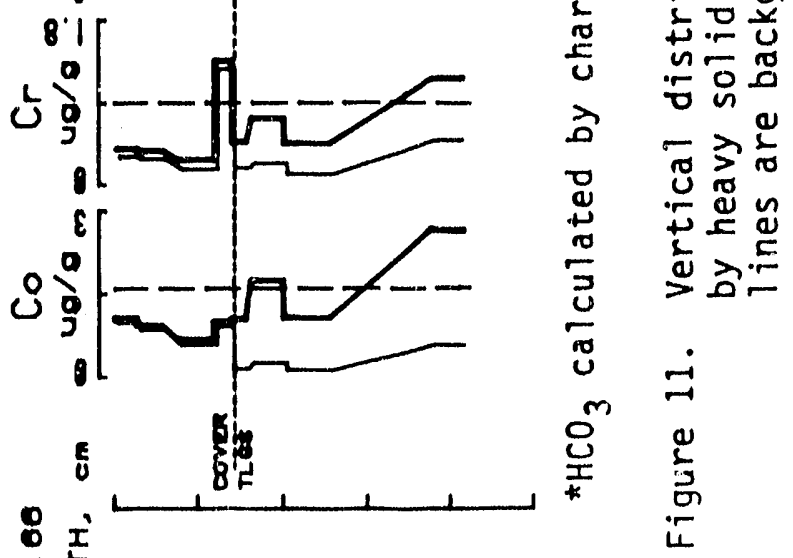

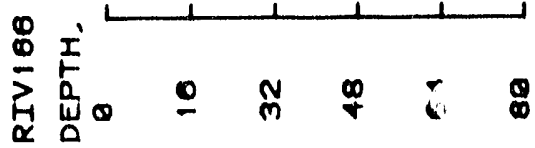

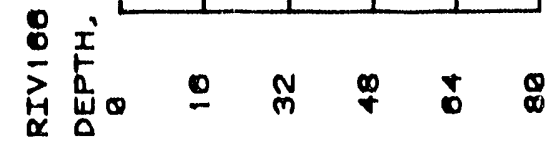




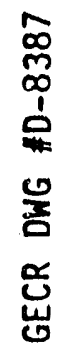
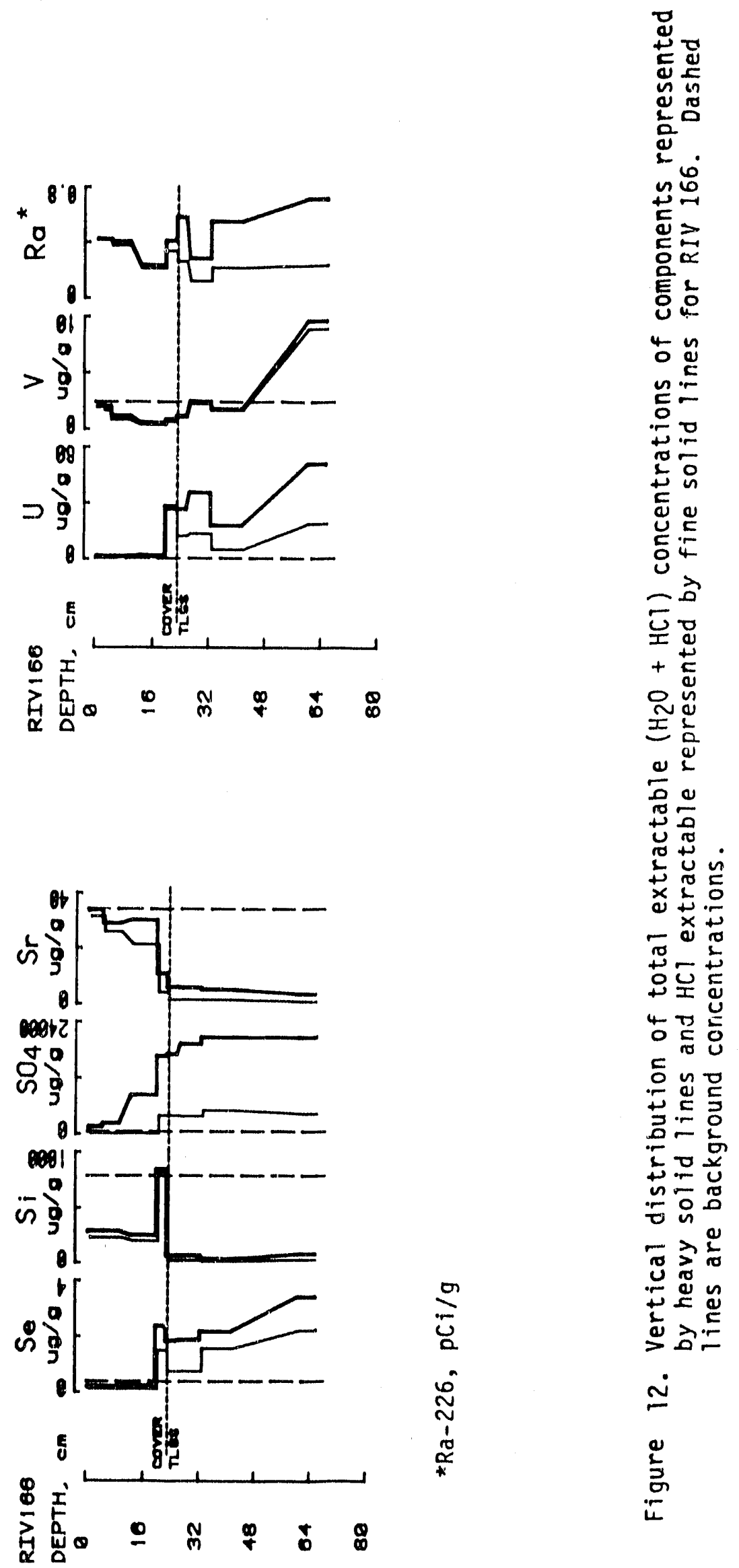

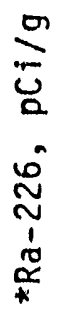




\section{INTERPRETATION OF DATA}

PHYSICAL MIXING

Evaluation of chemical migration of trace components from the distribution of chemical compositions of solid and extractable phases requires an identification of that portion of the components attrihuted to the physical presence of tailings in the cover material. The presence of tailings in the cover may be due to (1) mixing of tailings with the cover during emplacement; (2) mixing of wind blown tallings from exposed tailings; and (3) dispersal of tailings particles and movement into the cover. Particle dispersal and movement tends to block pore space and, therefore, could be determined by microscopic analysis of an undisturbed sample. The question of particle dispersal and movement is important in long-term tailings management; however, the mechanism of tailings/cover mixing is not determined in this study.

The gross chemical composition distinguishes soil and tailings and can be used to recognize the presence of tailings mixed with soil. The concentration of potassium, reflecting the content of $K$-feldspar, is significantly greater in the tailings than the cover (Figure 13). Less than one percent of the total potassium in the tailings is water and acid soluble; therefore, the potassium concentrations are a conservative quantity kith no danger of contamination of the cover from the chemical migration of potassium. The normalized linear cumulative distribution shows four populations reflecting variations in the bulk compositions of the material (Figure 13). The soils of the cover contain the lowest potassium concentrations. As the quantity of tailings mixed into the cover increases, the potassium concentration increases, producing a second population. The interface samples which contain a significant portion of tailings have potassium concentrations in the same populations as the fine tailings. The potassium concentrations of the sandy tailings comprise the fourth population with the greatest concentrations.

The chemical contribution of tallings in the cover was quantified by interpretation of the isotope concentrations (Ra-226, Pb-210, U-238, Th-230) in the bulk samples from the cover and tailings. Radium and lead 


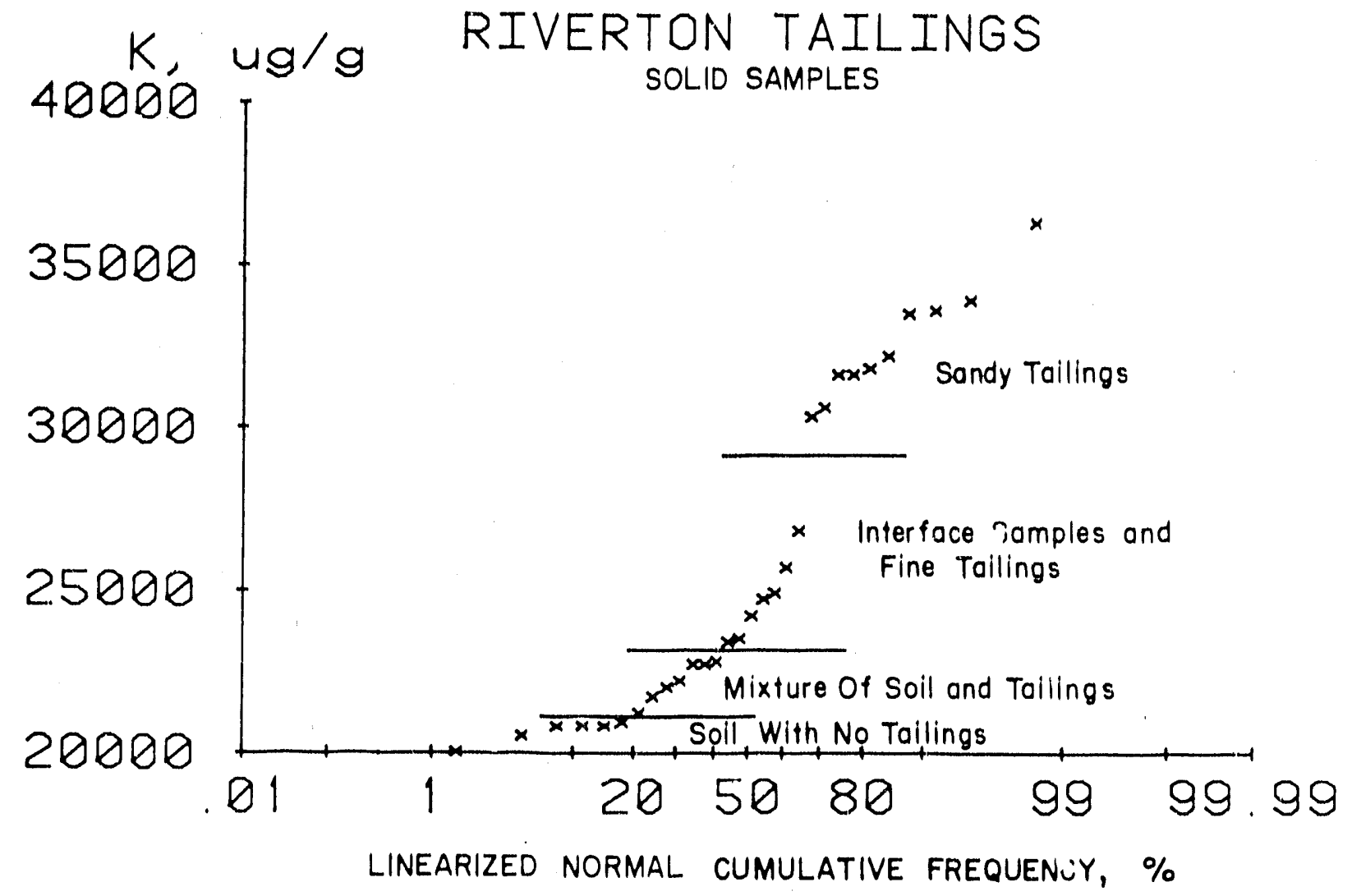

Figure 13. Linearized normal cumulative distribution of the potassium concentrations in the solid samples of tallings and cover. The potassium concentrations in the tailings are significantly greater than in the soils. Increasing potassium indicates an increase in the amount of tallings mixed with the cover. 
in the uranium ore are not disturbed in the milling process and, therefore, a near-equilibrium $\mathrm{Ra}-226 / \mathrm{Pb}-210$ ratio of 1.0 characterizes the tailings (Figure 14). Uncontaminated soils also contain a ratio of $\mathrm{Ra}-226$ and $\mathrm{Pb}-210$ concentrations of near 1.0 . The $\mathrm{Ra}-226 / \mathrm{Pb}-210$ ratios in the cover samples are consistently within the range found in the taflings or uncoirtaminated soils (Figure 14). This indicates that the bulk of Ra-226 and $\mathrm{Pb}-210$ in the cover above the background concentrations is due to the presence of tailings rather than chemical migration. If radium or lead underwent chemical migration, the isotopic ratio would be expected to deviate from equilibrium. A portion of $\mathrm{Ra}-226$ and $\mathrm{Pb}-210$ within the counting error of the isotope determinations may have migrated but this cannot be recognized with bulk solid analysis.

The fraction of cover material ascribable to tailings was computed algebraically according to the equation:

$$
C_{c}=x\left(C_{t}\right)+(1-x)\left(C_{s}\right)
$$

where $C_{c}, C_{t}$, and $C_{s}$ are the isotope concentrations in the cover samples, tailings, and uncontaminated soils, respectively, and $x$ and $(1-x)$ are the fractions of the cover assigned to the tailings and soils. The fraction of tailings was calculated for each cover sample for the isotopes, Ra-226, $\mathrm{Pb}-210$, Th-230, and $\mathrm{U}-238$ using mean isotope concentrations for tailings and uncontaminated soil (Table 4). Because of the consistent Ra-226/Pb-210 ratios in tha tailings and soil, the tailings fractions, as calculated from the Ra-226 and $\mathrm{Pb}-210$ data, are nearly equal. This fraction represents the maximum quantity of tailings present in the cover (Figures 15, 16, and 17). The differences between the fractions of tailings calculated on the basis of U-238 and Th-230 and the fractions of tailings calculated from $\mathrm{Pb}-210$ and $\mathrm{Ra}-226$ are probably due to chemical migration of uranium and thorium.

The distribution of the ratios of $T h-230$ ( $p C i / g)$ to total thorium (ppm) in the cover and tailings suggests similar results as the calculation of the fraction of tallings from isotope concentrations. Four populations comprise the normalized linear cumulative distribution of the Th-230/ Th-total in the cover and tailings (Figure 18). The tailings have a ratio between 5.6 and 11.8, in the sands and between 16.6 and 19.8 in the slimes, whereas the cover soils without tailings have a ratio of less than 1.0 . 


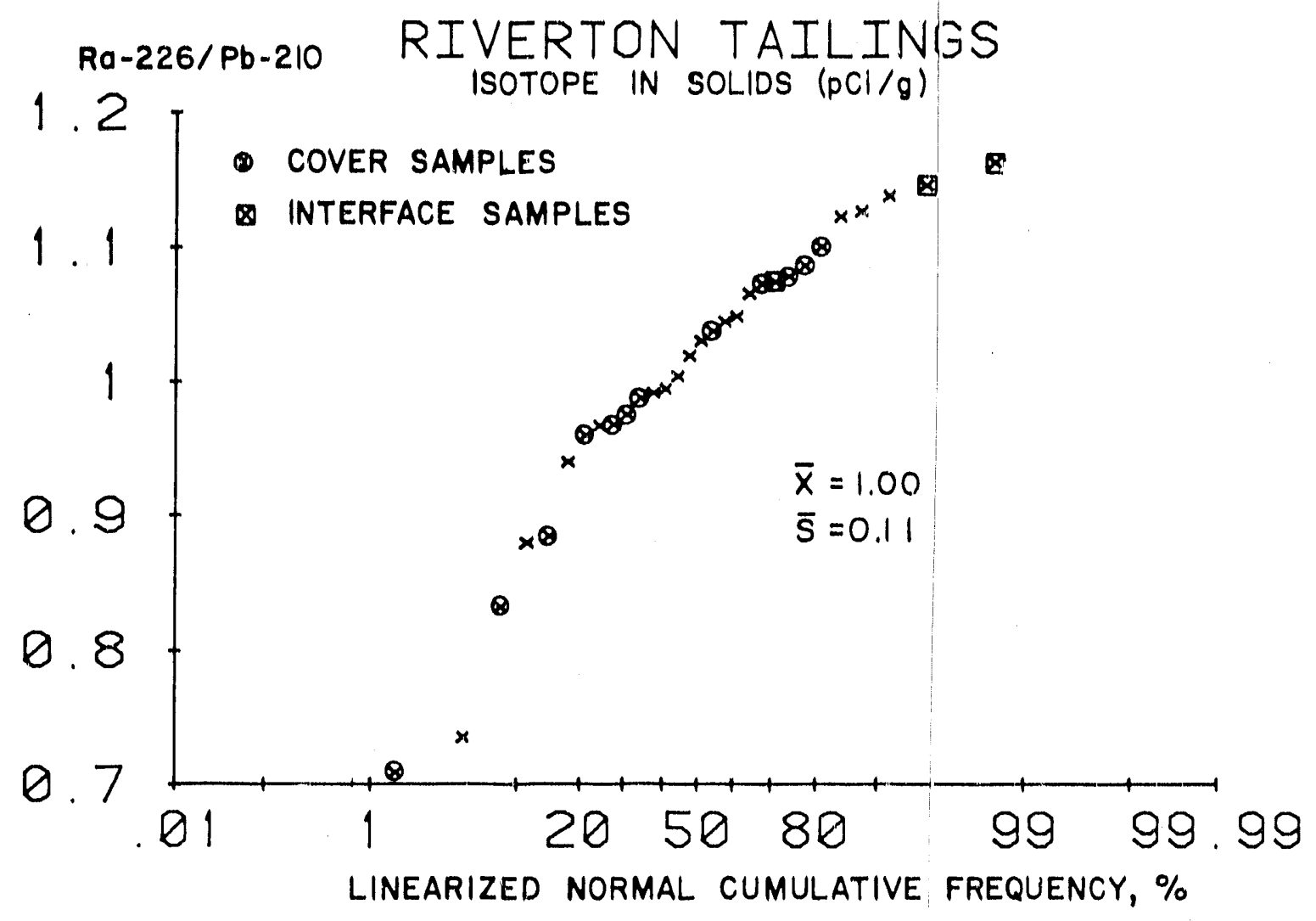

Figure 14. Linearized normal cumulative distribution of the Ra-226/ $\mathrm{Pb}-210$ ratios in solid samples from the tailings, cover, and interface. The ratios in the cover and tailings are not different, indicating that the $\mathrm{Fb}-2 \| 0$ and $\mathrm{Ra}-226$ in the cover is due to the presence of tailing!; and that differential movement of $\mathrm{Pb}-210$ and $\mathrm{Ra}-2.26$ (within the resolution of the isotope determinations) has not occurred. 
Table 4. Fraction of Isotopes in Cover and Interface Samples Contributed by the Presence of Tailings Material.1

\begin{tabular}{lllll}
\hline Sample No. & U-238 & Ra-226 & Pb-210 & Th-230 \\
\hline 164.01 & 0.88 & 0.069 & 0.069 & 0.23 \\
164.02 & 0.57 & 0.034 & 0.035 & 0.12 \\
164.03 & 0.35 & 0.033 & 0.030 & 0.070 \\
164.04 & 0.50 & 0.026 & 0.027 & 0.096 \\
164.05 & 1.6 & 0.40 & 0.35 & 1.2 \\
165.01 & 0.067 & 0.15 & 0.15 & 0.25 \\
165.02 & 0.21 & 0.21 & 0.20 & 0.43 \\
165.03 & 0.14 & 0.21 & 0.20 & 0.21 \\
165.04 & 0.13 & 0.18 & 0.17 & 3.3 \\
165.05 & 0.14 & 0.12 & 0.14 & 0.16 \\
165.06 & 1.1 & 0.80 & 0.70 & 0.15 \\
166.01 & 0.044 & 0.049 & 0.071 & 0.10 \\
166.02 & 0.026 & 0.046 & 0.055 & 1.2 \\
166.03 & 0.052 & 0.045 & 0.046 & 1.1 \\
166.04 & 0.94 & 1.2 & & \\
\hline
\end{tabular}

${ }_{1}$ Calculated on the basis of physical mixing using the mean concentrations of the isotopes in tailings and soils.

$\begin{array}{lrrrr}\bar{x} \text { tlgs } & 28.5 & 323 & 319 & 100 \\ \bar{x} \text { soii } & 1.5 & 1.5 & 1.5 & 1.5\end{array}$



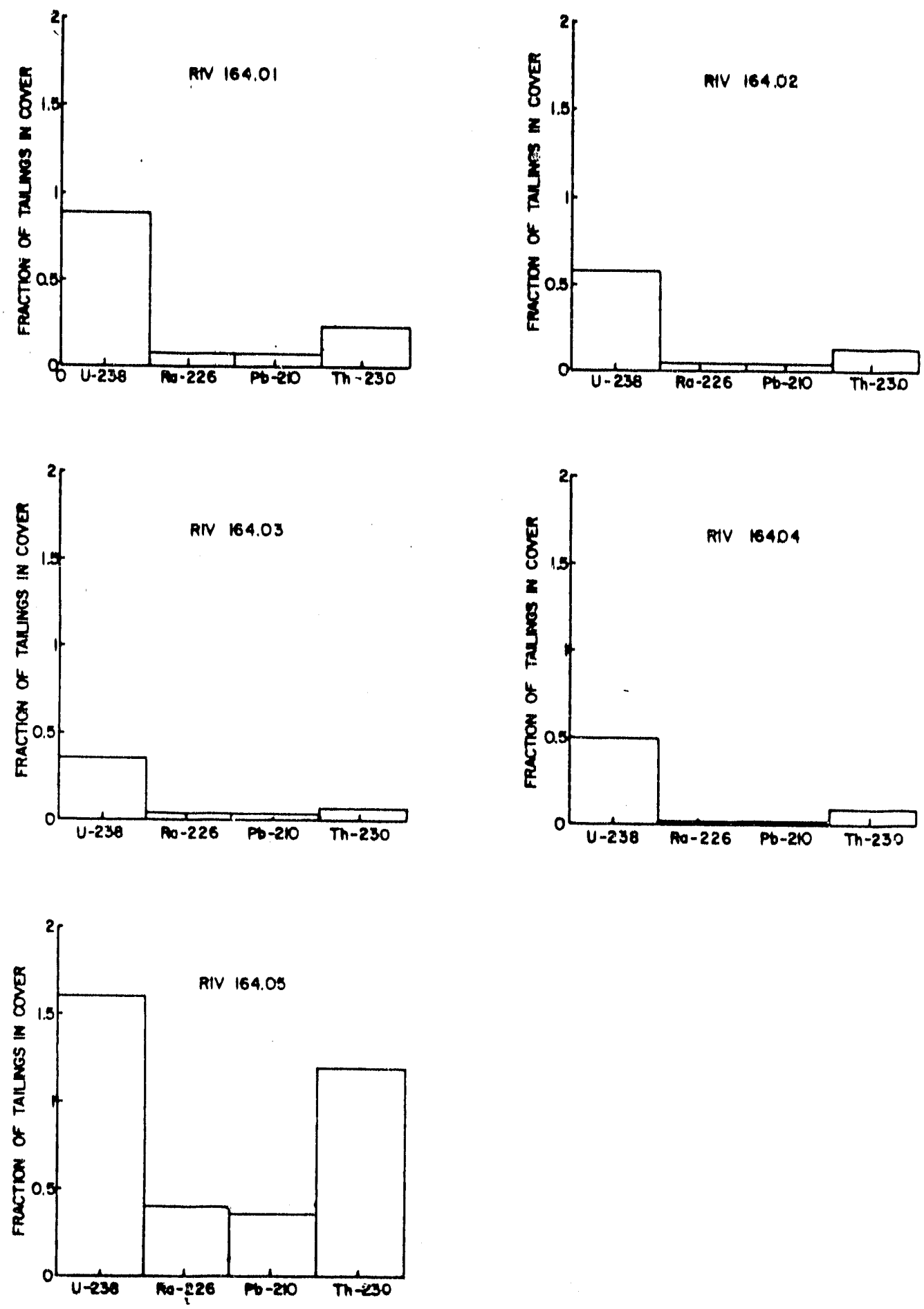

Figure 15. Fractions of isotopes in RIV 164 cover and interface samples contributed by the physical mixing of tailings, calculated from the isotope concentrations in the cover samples and an average isotope concentration in tailings and uncontaminated soil. Assuming the quantities of $\mathrm{Ra}-226$ and $\mathrm{Pb}-210$ are conservative, the fractions of isotopes in excess of $\mathrm{Ra}-226$ and $\mathrm{Pb}-210$ may be from chemical migration. 

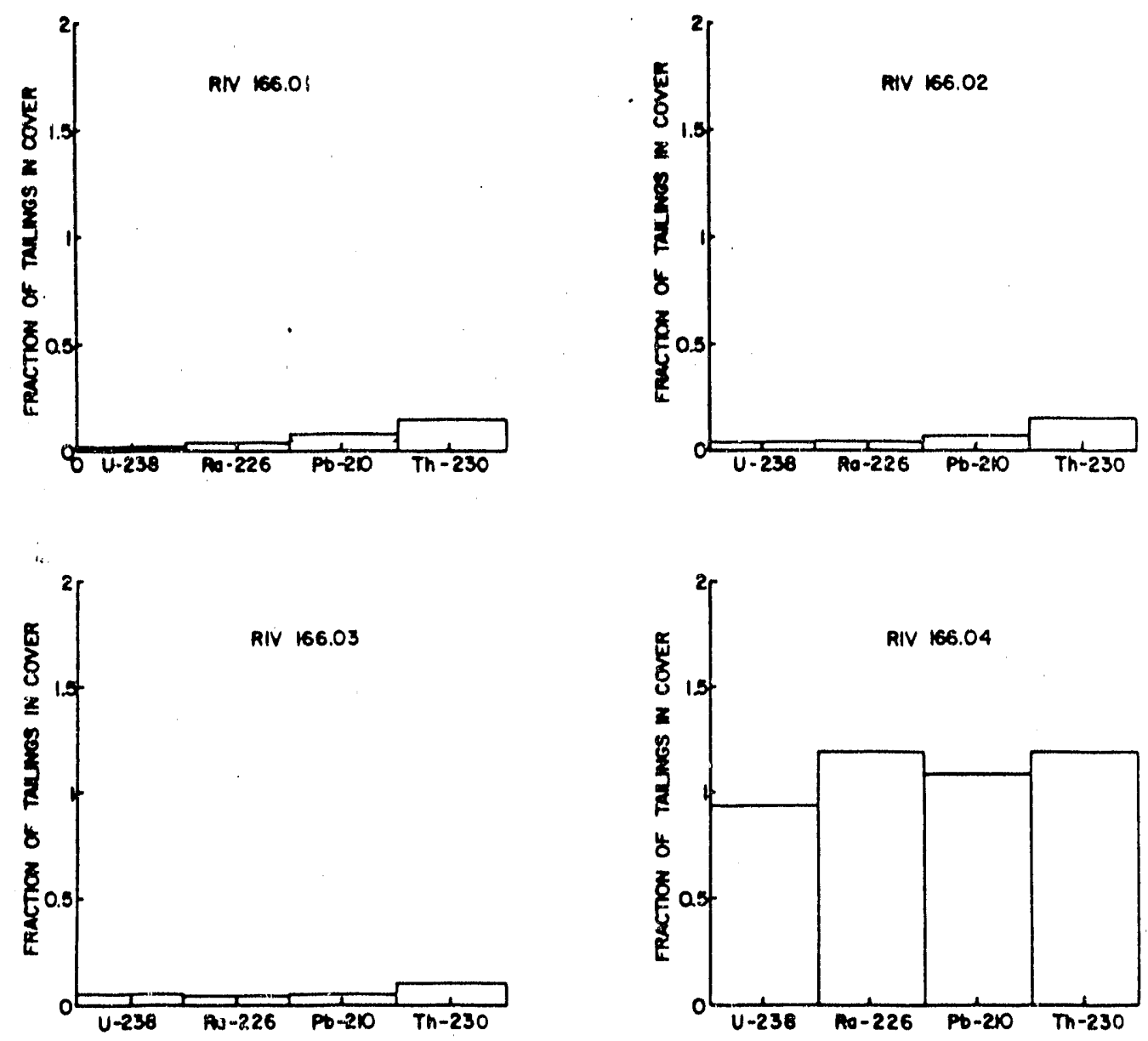

Figure 16. Fractions of isotopes in RIV 166 cover and interface samples contributed by the physical mixing of tailings, calculated from the isotope concentrations in the cover samples and an average isotope concentration in tailings and uncontaminated soil. Assuming the quantities of $\mathrm{Ra}-226$ and $\mathrm{Pb}-210$ are conservative, the fractions of isotopes in excess of Ra-226 and $\mathrm{Pb}-210$ may be from chemical migration. 

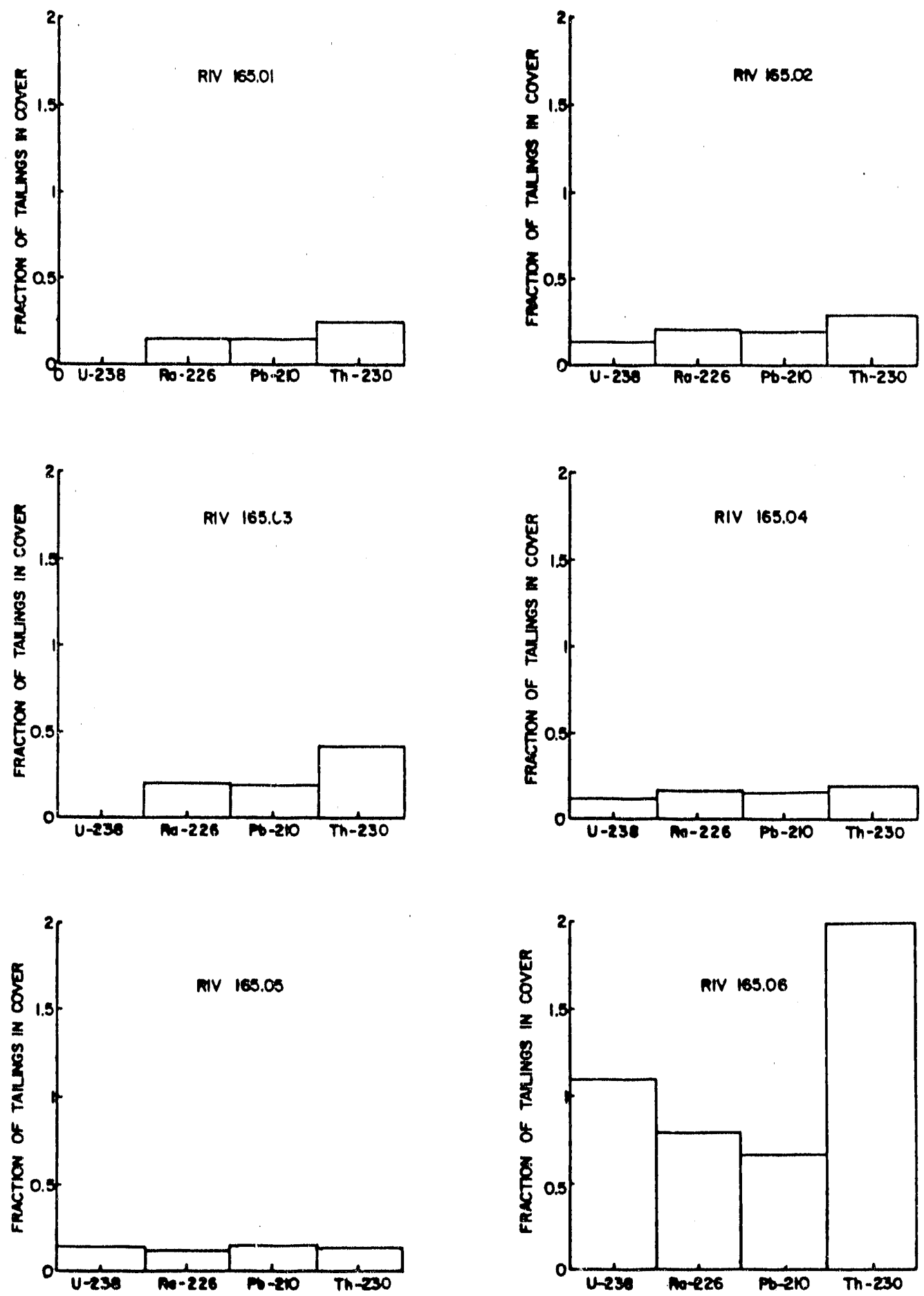

Figure 17. Fractions of isotopes in RIV 165 cover and interface samples contributed by the physical mixing of tailings, calculated from the isotope concentrations in the cover samples and an average isotope concentration in tailings and uncontaminated soil. Assuming the quantities of $R a-226$ and $P b-210$ are conservative, the fractions of isotopes in excess of $R a-226$ and $\mathrm{Pb}-210$ may be from chemical migration. 


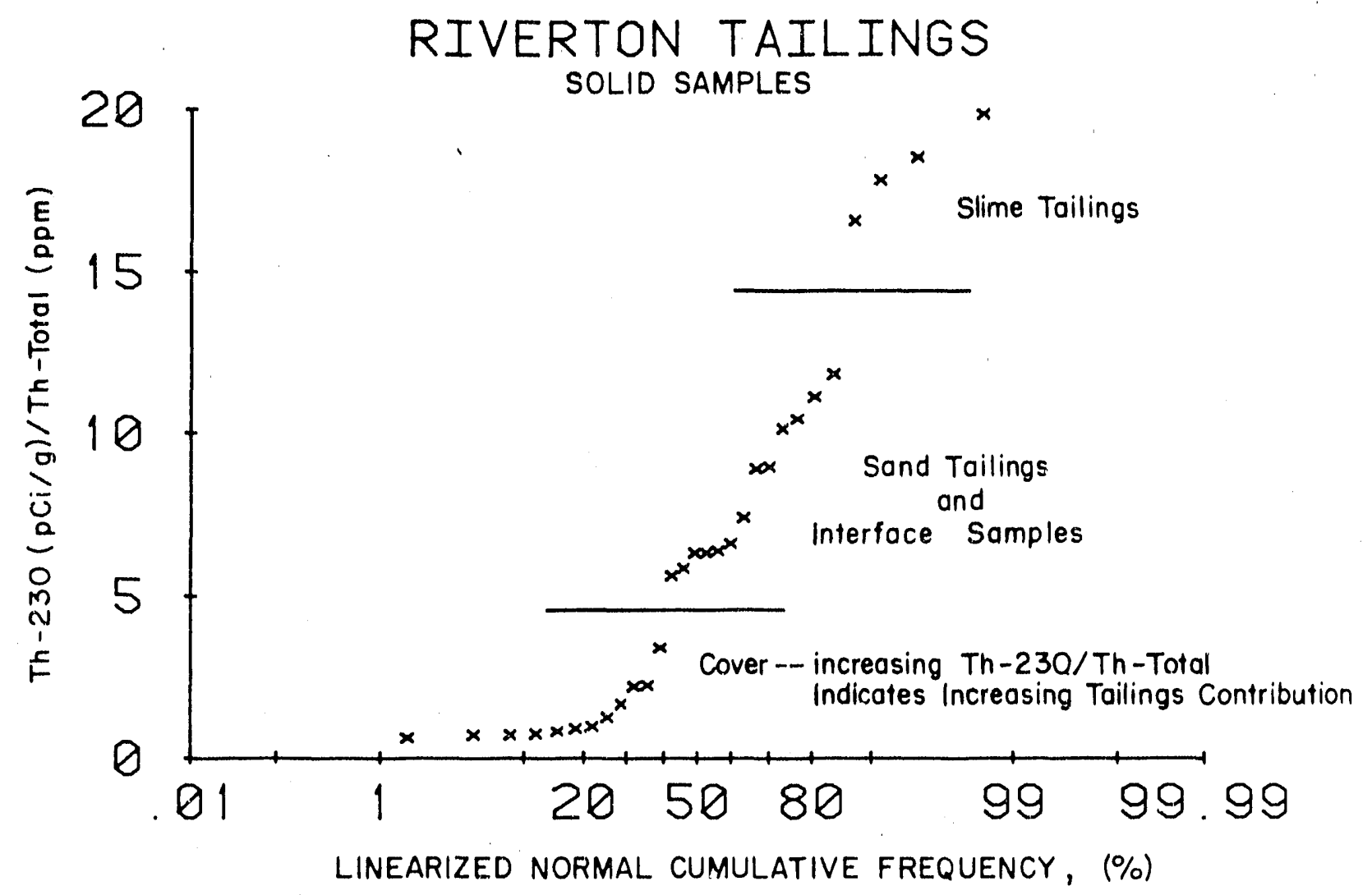

Figure 18. Linearized normal cumulative distribution of the Th-230/ Th-total ratios. The ratio is an order of magnitude larger in the tailings than in uncontaminated soils. The increasing ratio indicates an increasing contribution from tailings. 
The ratio increases as tailings are added to the cover soils. The ranking of samples in increasing Th-230/Th-total ratios coincides with the increasing fraction of tailings as calculated by the $\mathrm{Pb}-210$ and $\mathrm{Ra}-226$ with the exception of two samples.

\section{CHEMICAL MIGRATION}

\section{Migration of Uranium and Thorium}

The general conclusions from Figures 15, 16, and 17 are that uranium has migrated into the cover at site RIV 164 and thorium has migrated into the cover at sites RIV 164, RIV 165, and RIV 166. The linearized normal cumulative distributions of the ratios $\mathrm{Pb}-210 / \mathrm{Th}-230$ and $\mathrm{Pb}-210 / \mathrm{U}-238$ confirm the relationships shown by the box plots of the tailings fractions (Figures 15, 16, and 17). The $\mathrm{Pb}-210 / \mathrm{Th}-230$ ratios in the cover and interface samples are less than the ratios characteristic to the tailings (Figure 19). The $\mathrm{Pb}-210 / \mathrm{U}-238$ ratios in the cover samples are within the range characteristic of the tailings, except in the cover samples in RIV 164 where uranium enrichment has occurred. The cover samples with $\mathrm{Pb}-210 / \mathrm{U}-238$ ratios greater than the tailings ratios are depleted in uranium. The depletion may be due to tailings with lesser uranium concentrations mixed with the cover or a supression of the uranium by infiltration of surface precipitation.

The concentrations of $U-238$ and $T h-230$ in the cover deposited from chemical migration are calculated by deducting the contribution from the presence of tailings (fraction of tailings times the average concentration of the isotope in tailings) from the total isotope concentration (Table 5). The migration of $T h-230$ appears cunsistent in the covers from the three sites. The interface sample contains the greatest concentration which is overlain by a zone depleted in Th-230 and an enriched surface layer. This is a pattern typical for upward migration and accumulation on the surface in an insoluble phase. Uranium migrated only at RIV 164. The variations in the behavior of uranium at the three sites may be related to variations in the chemical environment of the cover. The mechanisms of mobility of thorium and uranium will be discussed in the next section on thermodynamic modeling. 

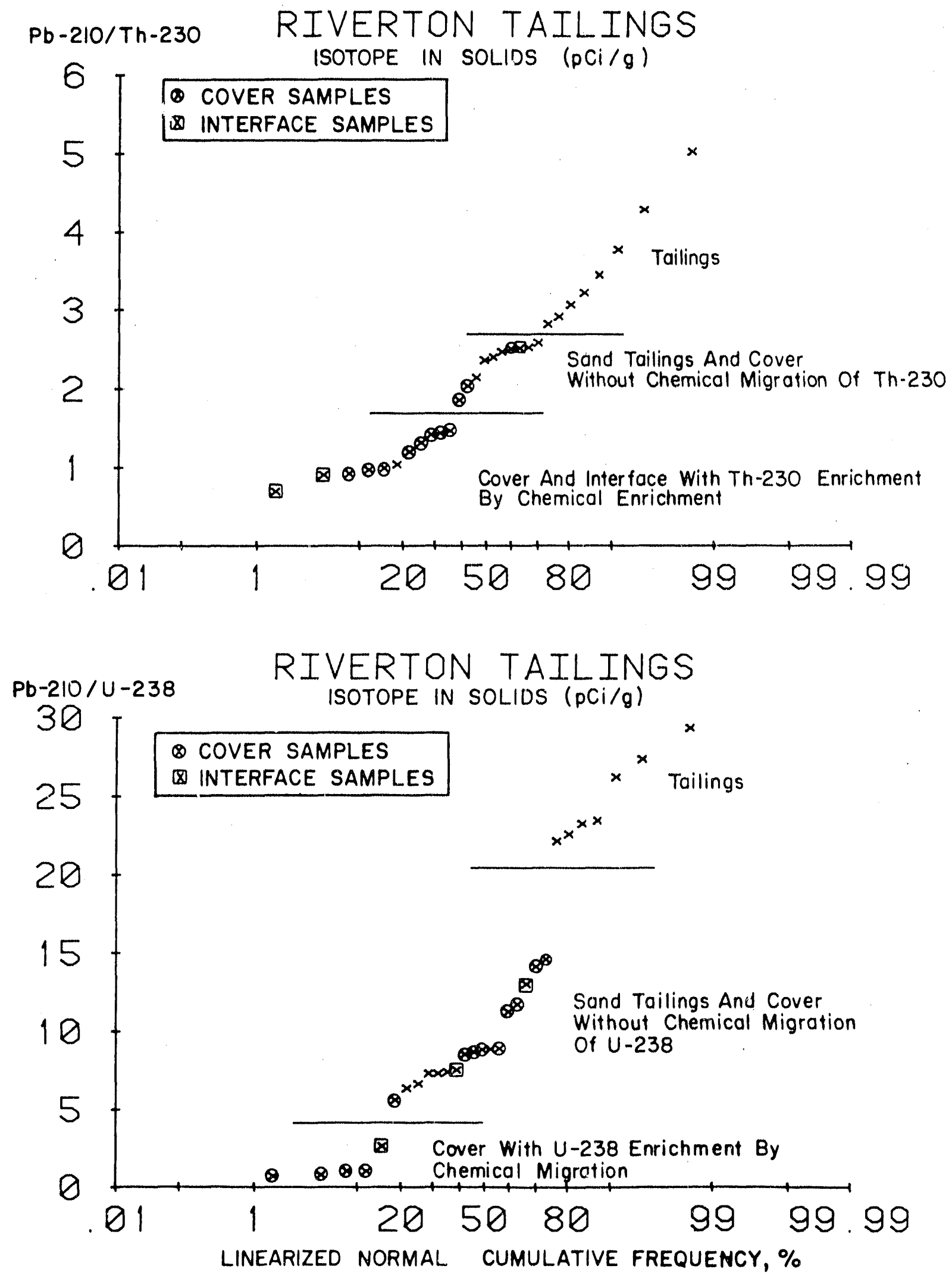

Figure 19. Linearized normal cumulative distributions of $\mathrm{Pb}-210 / \mathrm{Th}-230$ and $\mathrm{Pb}-210 / \mathrm{U}-238$ ratios in the tailings, cover, and interface. 
Table 5. Concentrations of Th-230 and U-238 in Cover Samples from Chemical Migration

\begin{tabular}{rrl} 
& $T h-230$ & U-238 \\
\hline 164.01 & 17 & 22 \\
.02 & 10 & 16 \\
.03 & 5 & 10 \\
.04 & 8 & 14 \\
.05 & 85 & 33 \\
165.01 & & \\
.02 & 11 & 0 \\
.03 & 23 & 1.2 \\
.04 & 10 & 0 \\
.05 & 4 & 0 \\
.06 & 2 & 1.9 \\
& 251 & 7.2 \\
166.01 & & 1.3 \\
.02 & 12 & 0.8 \\
.03 & 11 & 1.5 \\
.04 & 6 & 0
\end{tabular}


A characteristic difference between tailings, soil contaminated by chemical migration, and uncontaminated soil is the extractable fraction of the total quantity of an element. Normalized linear cumulative distributions of the extractable fraction of aluminum and uranium illustrate the chemical migration of uranium into the cover at RIV 164 (Figure 20). The extractable fractions of aluminum in the cover samples are within the range characteristic of the background, whereas the fraction of extractable aluminum in the interface samples are greater than in the cover samples which resemble the behavior characteristic of tailings. These data suggest that tailings dominate the interface samples but have no major influence on the behavior of the chemical composition of the water-extractable phase of the cover samples and that aluminum has not migrated from the tailings into the cover. This agrees with the calculated tailings fractions of 3 to 20 percent in the cover and 40 to 100 percent in the interface samples. The distribution of the extractable uranium fraction differs from the behavior of extractable aluminum. The fraction of extractable uranium in the cover resembles local soils except for the interface samples and the cover samples from RIV 164 which have extractable fractions similar to tailings. The resemblance to tailings in the interface samples is due to physical mixing; whereas in the cover of RIV 164, it is due to chemical migration of uranium.

\section{Migration of Radium}

Migration of radium evaluated by analysis of water and acid extracts, distinguishes the various chemical phases and, therefore, has greater resolution than the radium solid analysis. The total extractable quantity of radium in the cover exceeds that in the tailings. The concentrations of radium in the acid-soluble phase are much greater than the water-soluble concentrations in the cover, and nearly equal to the water-soluble concentrations in the tailings (Figure 21). Differences between the chemical form of radium in the cover and tailings account for the differences in extraction behavior. The extraction behavior of radium in the cover resembles carbonates and hydroxides, whereas in the tailings the behavior is typical of sulfate salts. The different chemical forms in the tailings and cover suggest migration of a water-soluble form from the tailings into 


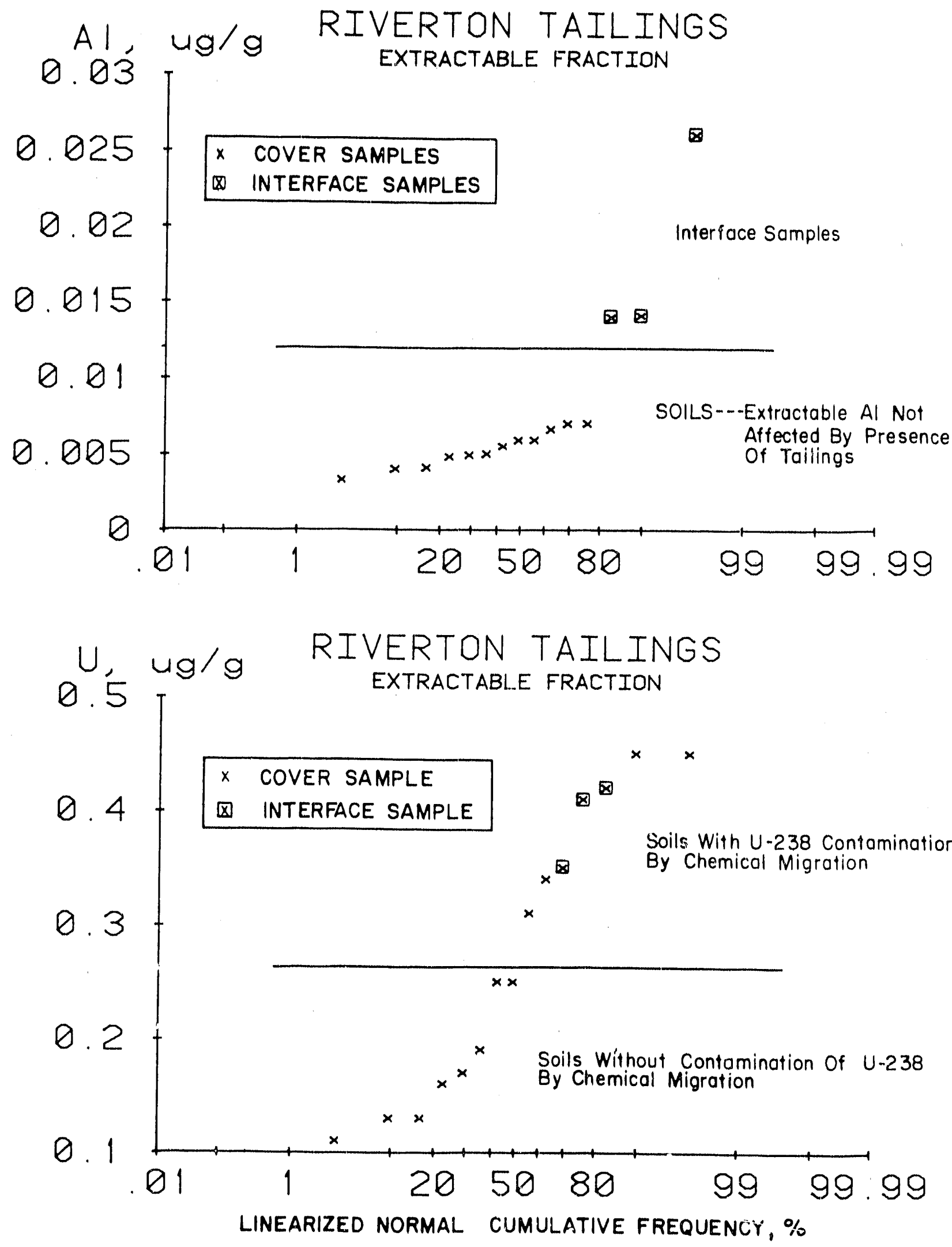

Figure 20. Linearized normal cumulative distributions of the extractable fractions of aluminum and uranium in the cover and interface samples. 
42
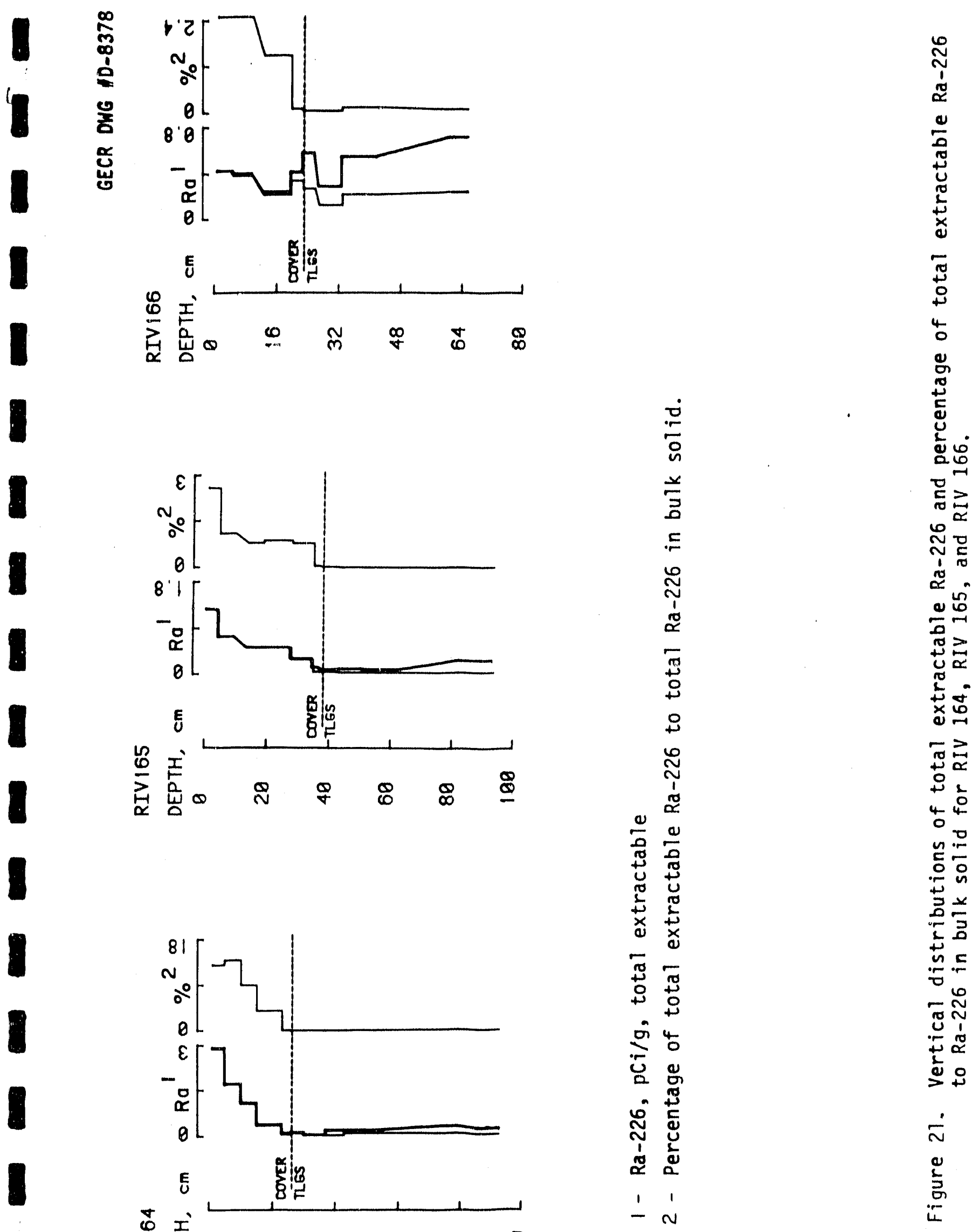
the cover, where it is immobilized in a water-insoluble form, such as carbonate salts or hydrous oxide precipitates.

The assumption that the acid-soluble radium in the cover represents the portion which underwent migration from the talings is probably valid, a)though no data exists on the acid-soluble concentrations in uncontaminated soils, which is necessary for absolute verification of the assumption. The profiles of the acid-soluble radium concentrations indicate that they represent the migration of radium. The concentrations of acid-soluble radium increase toward the surface, which is the pattern typical to upward migration and accumulation on the surface.

The percentage of total extractable $\mathrm{Ra}-226$ to $\mathrm{Ra}-226$ in the bulk solid indicates the maximum percentage of the Ra-226 in the cover due to migration (Figure 21). In all sample sequences through the cover, the percentage consistently increases toward the surface, representing the accumulation of radium with time. The percentage of total migration ranges between 0.73 and 14 , which is within the counting error of Ra-226 analysis in solid samples; and therefore explains why the chemicar migration of radium was not resolved in the analysis of the bulk solids.

The normalized linear cumulative distribution of acid-soluble radium in cover and interface samples distinguishes three statistical populations (Figure 22). The interface samples comprise the population of lowest radium concentrations. Apparently, the high concentrations of sulfate and the depressed $\mathrm{pH}$ from the presence of tailings prevent the solubility of radium. The intermediate population is comprised of the cover samples from RIV 166 and the lowermost cover samples from RIV 165 and RIV 164 with less than $0.5 \mathrm{pCi} / \mathrm{g}$ of soluble radium. Typical concentrations of extractable Ra-226 from uncontaminated soils is not available. Determination of the extent of contamination in the cover samples with extractable Ra-226 of less than $0.5 \mathrm{pCi} / \mathrm{g}$ requires determination of a background value of extractable Ra-226 and comparison with the extractable concentrations from the cover samples. The population with highest radium concentrations is the upper cover samples in RIV 164 and RIV 165, and most likely represents the accumulation of radium due to precipitation and occlusion under surface conditions. 
RIVERTON TAILINGS

$\mathrm{Ra} 226, \mathrm{pCl} / \mathrm{o}$

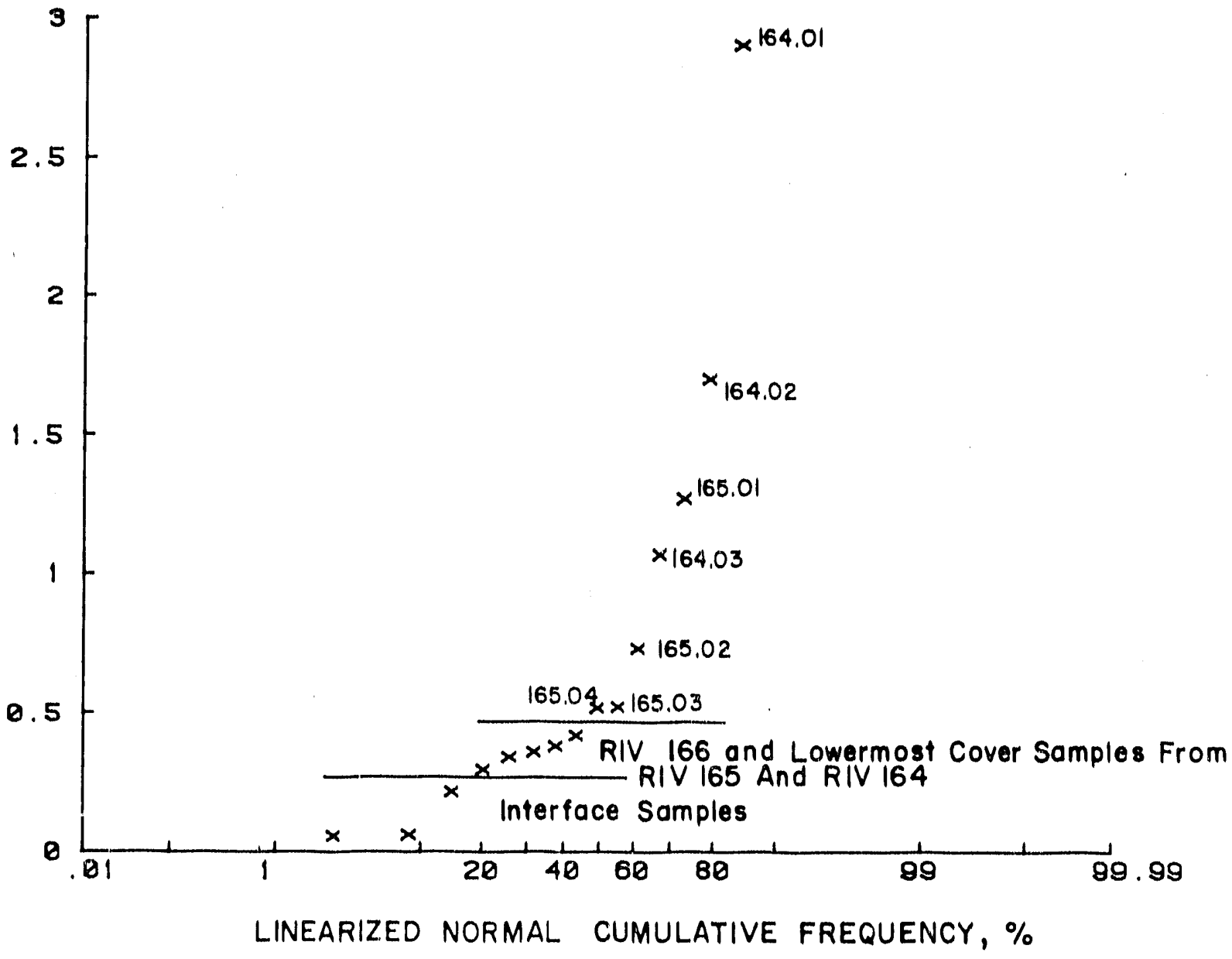

$\mathrm{HCl}$ Extracts of Cover a Interface Samples

$\times 164.01$

$x_{164.02}$

$$
x^{165.01}
$$

$\times 164.03$

165.02 
5 MECHANISMS OF MOBILIZATION AND RETARDATION OF ELEMENTS IN TAILINGS

INTRODUCTION

The upward migration of contaminants requires that the contaminant exists in a moblle form. Retardation of contaminants occurs when the components transfer from the mobile to immobile form by precipitation or adsorption mechanisms. If retardation mechanisms did not operate, migration of tailings solutions through the cover would produce identical distributions of all components. The transfer of components between moblle and immobile phases occurs by chemical processes. Thermodynamics govern precipitation reactions and the distribution of aqueous species. Other mechanisms of immobilization, especially important for trace elements, are adsorption, coprecipitation, and ocr.lusion by a solid substrate.

Uranium, thorium, and radium are mobile in the chemical environments of the tallings and are transported in varying degrees to the surface of the cover on the Riverton tailings. Although the concentrations of the isotopes in the pore waters of the tailings may be very low, accumulation of significant quantities of isotopes on the surface can occur. The water containing low concentrations moves to the surface where precipitation of the components occur. Some components precipitate as relatively watersoluble salts of chloride and sulfate and may be remobilized and leached downward by rain and snow melt. Other components, immobilized as insoluble hydrous oxides and carbonates, are water insoluble and do not undergo significant downward leaching.

Thorium shows the most consistent behavior in the upward migration between the three locations sampled. Thorium concentrations in the surface samples range from 10 to $25 \mathrm{pCi} / \mathrm{g}$. The migration of $\mathrm{Th}-230$ into the cover is significant because it decays to $\mathrm{Ra}-226$ which decays to radon gas [9]. Uranium exhibits the most inconsistent behavior among the three locations sampled. Accumulations of up to $22 \mathrm{pCi} / \mathrm{g}$ were present at one site; whereas, no accumulation was detected at the other two locations. The distribution of radium from migration resembles the distribution of uranium. The location with uranium migration has the greatest radium migration of $3 \mathrm{pCi} / \mathrm{g}$. The other locations have small quantities of radium accumulation, which cannot positively be attributed to migration. 
The chemical behavior of elements, thorium, uranium, and radium, will be discussed as relating to the mobility and retardation of the isotopes. Specific behavior of the elements in the chemical environment of the Riverton tallings and cover was evaluated by the state of chemical equilibrium of the water extracts as calculated with PHREEQE and by relating the quantities of precipitated iron, aluminum, manganese, and silica with the quantities of trace metals. The dominant aqueous species in the pore water of the tailings and cover are listed in Tables 6 and 7 . Species in the data base of PHREEQE included complexes of all the important anions, hydroxide, carbonate, sulfate, chloride, phosphate, and fluoride. Sulfate dominates the tailings pore water and has a significant control over many of the divalent elements in the cover.

\section{MOBILITY OF URANIUM, RADIUM, AND THORIUM}

Uranium occurs primarily in the uranous, U(IV), and uranyl, U(VI) states in the natural environment. Hexavalent uranium is generally considered mobile because it forms aqueous complexes with fluoride, sulfate, nitrate, and phosphate in acidic environments and with carbonate and hydroxide in neutral and alkaline pH environments. Uranium precipitates as oxides, silicates, and phosphates in the uranous state. The uranyl ion precipitates as hydroxides, carbonates, phosphates, vanadates, and silicates [10]. In the $\mathrm{Eh}$ and $\mathrm{pH}$ conditions of the tailings and the cover, the oxidized form complexed with sulfate predominates.

Uranium strongly interacts with organic compounds and is fixed by immobile organic matter and mobilized by soluble organic compounds. Experimental studies show fixation of uranium in soils with maximum adsorption on humic compounds, hydrous oxides of iron, silica, and manganese, and clay minerals at pH 5-6 [11]. In soils, the precipitation of calcite and apatite tends to occlude uranium by the substitution of $\mathrm{UO}_{2}{ }^{2+}$ for $\mathrm{Ca}^{2+}$ [12 and 13].

The results of equilibrium calculations of aqueous species and saiuration indexes (S.I.) of mineral phases show that $\mathrm{UO}_{2}\left(\mathrm{SO}_{4}\right)_{2}{ }^{-2}$ and $\mathrm{UO}_{2}+2$ dominate in the tailings, and $\mathrm{UO}_{2}\left(\mathrm{CO}_{3}\right)_{2}-2$ is the major soluble species in the cover (Tables 6 and 7). The low $\mathrm{pH}$, high Eh, and high sulfate 
concentrations prevent saturation of any mineral phase. At higher $\mathrm{pH}$ and carbonate conditions of solls, the autunite minerals $(\mathrm{Na}, \mathrm{K})_{2} \quad \mathrm{UO}_{2}\left(\mathrm{PO}_{4}\right)_{2}$, $\mathrm{UO}_{2}(\mathrm{OH})_{2}$, and $\left(\mathrm{UO}_{2} \mathrm{CO}_{3}\right)$ tend toward saturation as the moisture content decreases.

Radium. Inadequate data describing the solubility and immobilization of radium often leads to the generalization that radium is insoluble. However, high concentrations of radium in ground waters around uranium ore bodies suggest that natural water can mobilize radium from certain rock types [14]. Thermodynamic data for the aqueuus complexes and solid phases of radium with chloride, nitrate, and sulfate are available; however, other mechanisms such as coprecipitation and adsorption on clay minerals, hydrous oxides, and organic matter strongly influence the geochemical behavior of radium. Calculations with PHREEQE on the water extract data from the Riverton tailings indicate the dominant forms to be $\mathrm{Ra}^{2+}$ and $\mathrm{RaSO}_{4}$ in both the tailings and cover.

Various studies on the leaching of radium from acid-leached urarium mill tailings suggest that radium in mill tailings exists as a coprecipitate with sulfate minerals of barium, calcium, and strontium and may be sorbed on silicate minerals. Radium in uranium ore is oilly slightiy soluble in the sulfuric acid leaching circuit. Numerous determinations show that less than 0.2 percent of the radium in the ore dissolves. This may be due to a complex mechanism of dissolution from the ore follawed by precipitation of radium as sulfate minerals. Radium in uranium ore is soluble in $\mathrm{HCl}, \mathrm{HNO}_{3}$, and distilled water, because of the greater solubility of $\mathrm{RaCl}_{2}$ and $\mathrm{Ra}\left(\mathrm{NO}_{3}\right)_{2}$ as compared to $\mathrm{RaSO}_{4}$ at equal concentrations of the anion. The solubility in distilled water is highly dependent upon the liquid-to-solid ratio, suggesting a limiting solubility product $[15,16$, and 17].

Lime treatment of tailings slurry to neutralize the acid tends to increase the radium concentration in the aqueous phase [18]. The increase in radium coincides with a decrease in sulfate due to the precipitation of gypsum, which induces the dissolution of radium sulfate from the tailings according to the common ion effect. By analogy to the studies on radium in acid-leached tailings, Landa [14] suggests that alkaline earth carbonates 
Table 6. Dominant Aqueous Species in the Tailings Waters of Riverton Tailings Determined by Calculations of PHREEQE

\section{Element}

$$
\begin{aligned}
& \text { Al } \mathrm{Al}+3, \mathrm{Al}\left(\mathrm{SO}_{4}\right)_{4}^{-2} \\
& \text { As } \mathrm{H}_{2} \mathrm{AsO}_{4}- \\
& \mathrm{Ba} \quad \mathrm{Ba}^{+2}, \mathrm{BaSO}_{4} \mathrm{O} \\
& \mathrm{Ca} \quad \mathrm{Ca}+2, \mathrm{CaSO}_{4} \\
& \text { cd } \mathrm{Cd}^{+2}, \mathrm{CdCl}^{+}, \mathrm{CdSO}_{4} \\
& \mathrm{Cr} \quad \mathrm{Cr}+3 \\
& \mathrm{Fe} \quad \mathrm{FeSO}_{4}^{+}, \mathrm{Fe}\left(\mathrm{SO}_{4}\right)_{2}^{-}, \mathrm{Fe}^{+3}, \mathrm{Fe}^{+2}, \mathrm{FeSO}_{4}, \mathrm{FeCl}^{+2} \\
& \mathrm{~K} \quad \mathrm{~K}^{+}, \mathrm{KSO}_{4}^{-}, \mathrm{KCl} \\
& \mathrm{Mg} \quad \mathrm{Mg}^{+2}, \mathrm{MgSO}_{4} \\
& \mathrm{Mn} \mathrm{Mn}^{+2}, \mathrm{MnSO}_{4}, \mathrm{MnCl}^{+} \\
& \text {Mo } \mathrm{H}_{2} \mathrm{MOO}_{4} \\
& \mathrm{Na} \quad \mathrm{Na}^{+}, \mathrm{Na}_{2} \mathrm{SO}_{4}, \mathrm{NaSO}_{4}^{-}, \mathrm{NaCl} \\
& \mathrm{Ni} \quad \mathrm{Ni}^{+2}, \mathrm{NiSO}_{4}, \mathrm{NiCl}^{+} \\
& \mathrm{Pb} \quad \mathrm{Pb}+2, \mathrm{PbSO}_{4} \\
& \mathrm{Ra} \mathrm{Ra}^{+2}, \mathrm{RaSO}_{4} \\
& \text { Se } \mathrm{HSeO}_{3} \text { - } \\
& \mathrm{Si} \quad \mathrm{Si}(\mathrm{OH})_{4} \\
& \text { Th } T h\left(\mathrm{SO}_{4}\right)_{2}, \mathrm{Th}\left(\mathrm{SO}_{4}\right)_{3}^{-2}, \mathrm{Th}^{+4} \\
& \mathrm{U} \quad \mathrm{UO}_{2}+2, \mathrm{UO}_{2}\left(\mathrm{SO}_{4}\right)_{2}{ }^{-2}, \mathrm{UO}_{2} \mathrm{SO}_{4} \\
& v \quad \mathrm{VO}_{4}-3
\end{aligned}
$$


Table 7. Dominant Aqueous Species in the Cover Waters of Riverton Tailings Determined by Calculations of PHREEQE.

\section{Element}

\begin{tabular}{|c|c|}
\hline A1 & $\mathrm{Al}(\mathrm{OH})_{3}, \mathrm{Al}(\mathrm{OH})_{4}^{-}$ \\
\hline As & $\mathrm{AsO}_{4}-3$ \\
\hline $\mathrm{Ba}$ & $\mathrm{Ba}^{+2}, \mathrm{BaSO}_{4}$ \\
\hline $\mathrm{Ca}$ & $\mathrm{Ca}^{+2}$ \\
\hline$c d$ & $\mathrm{Cd}^{+2}, \mathrm{CdSO}_{4}$ \\
\hline $\mathrm{Cr}$ & $\mathrm{Cr}(\mathrm{OH})_{2}^{+}, \mathrm{CrO}_{4}-2$ \\
\hline $\mathrm{Fe}$ & $\mathrm{Fe}(\mathrm{OH})_{3} \mathrm{O}$ \\
\hline$k$ & $\mathrm{~K}^{+}, \mathrm{KSO}_{4}^{-}$ \\
\hline $\mathrm{Mg}$ & $\mathrm{Mg}^{2+}, \mathrm{IgSO}_{4}$ \\
\hline$M n$ & $\mathrm{Mn}^{2+}, \mathrm{MgSO}_{4}, \mathrm{MnCl}^{+}$ \\
\hline Mo & $\mathrm{MOO}_{4}-2$ \\
\hline $\mathrm{Na}$ & $\mathrm{Na}^{+}, \mathrm{NaSO}_{4}^{-}, \mathrm{NaCl}$ \\
\hline $\mathrm{Ni}$ & $\mathrm{Ni}+2, \mathrm{NiSO}_{4}$ \\
\hline$b$ & $\mathrm{~Pb}^{+2}, \mathrm{PbSO}_{4}$ \\
\hline $\mathrm{Ra}$ & $\mathrm{Ra}^{2+}, \mathrm{RaSO}_{4}$ \\
\hline $\mathrm{Se}$ & $\mathrm{SeO}_{3}-2$ \\
\hline Si & $\mathrm{Si}(\mathrm{OH})_{4}$ \\
\hline Th & $\operatorname{Th}(\mathrm{OH})_{4}, \operatorname{Th}\left(\mathrm{HPO}_{4}\right)_{3}-2$ \\
\hline$U$ & $\mathrm{UO}_{2}\left(\mathrm{CO}_{3}\right)_{2}-2, \mathrm{UO}_{2}\left(\mathrm{CO}_{3}\right)_{3}{ }^{-4}$ \\
\hline$v$ & $\mathrm{VO}_{4}-3$ \\
\hline
\end{tabular}


are probably involved in the immobilization of radium in alkaline-leached uranium mill tailings. Thermodynamic data does not exist on the stability of radium carbonates, but acid and water extracts of soils contaminated with radium from this study suggest that radium is immobilized in the acidsoluble phase, which may involve carbonate minerals.

Thorium. In aqueous systems of the natural environment only the Th(IV) oxidation state is known to exist. Because of its high charge density, it tends to form strong aqueous complexes with fluoride, sulfate, phosphate, chloride, and nitrate. Aqueous complexes allow significant levels of soluble thorium in waters containing great enough concentrations of anions. For example, in sulfuric acid leaching of uranium ore, about 20 percent of the thorium is released. Anionic complexes of thorium are most important in waters of 10w pH. As pH conditions increase, thorium hydrolizes and precipitates as thorium oxides or hydroxides. Thorium al so strongly sorbs to clay particles and to ferric oxides and hydroxides [14]. Experimental studies have shown that waters with a high organic content contain the greatest concentrations of soluble thorium [19].

The data from the Riverton tailings indicate that thorium is soluble in the tailings as sulfate complexes, $\mathrm{Th}\left(\mathrm{SO}_{4}\right)_{2}$ and $\mathrm{Th}\left(\mathrm{SO}_{4}\right)_{3}-2$ and soluble in the cover as $\mathrm{Th}(\mathrm{OH})_{4}$ and $\mathrm{Th}\left(\mathrm{HPO}_{4}\right)_{3}-2$. The presence of phosphate in soils from the addition of fertilizers or natural occurrences increases the concentrations of mobile thorium.

\section{RETARUATION OF ELEMENTS IN THE COVER}

Aluminosilicates such as feldspars and clay minerals in the soils of the cover weather incongruently, producing an acid-soluble Si-Al amoiphous material. The identity of this material is not known except that it is amorphous to $x$-ray diffraction and that it has a stoichiometry of nearly $1: 1$ aluminum to silicon (Figure 23). The aluminum is virtually water insoluble, whereas about one third of the total silicon is water soluble.

The Si-Al amorphous material actively retains trace elements especially divalent ions during its formation by either occulusion within the lattice or by sorbtion on the surface. Correlation of the concentrations in the acid extracts of radium with aluminum illustrates the effectiveness of the 


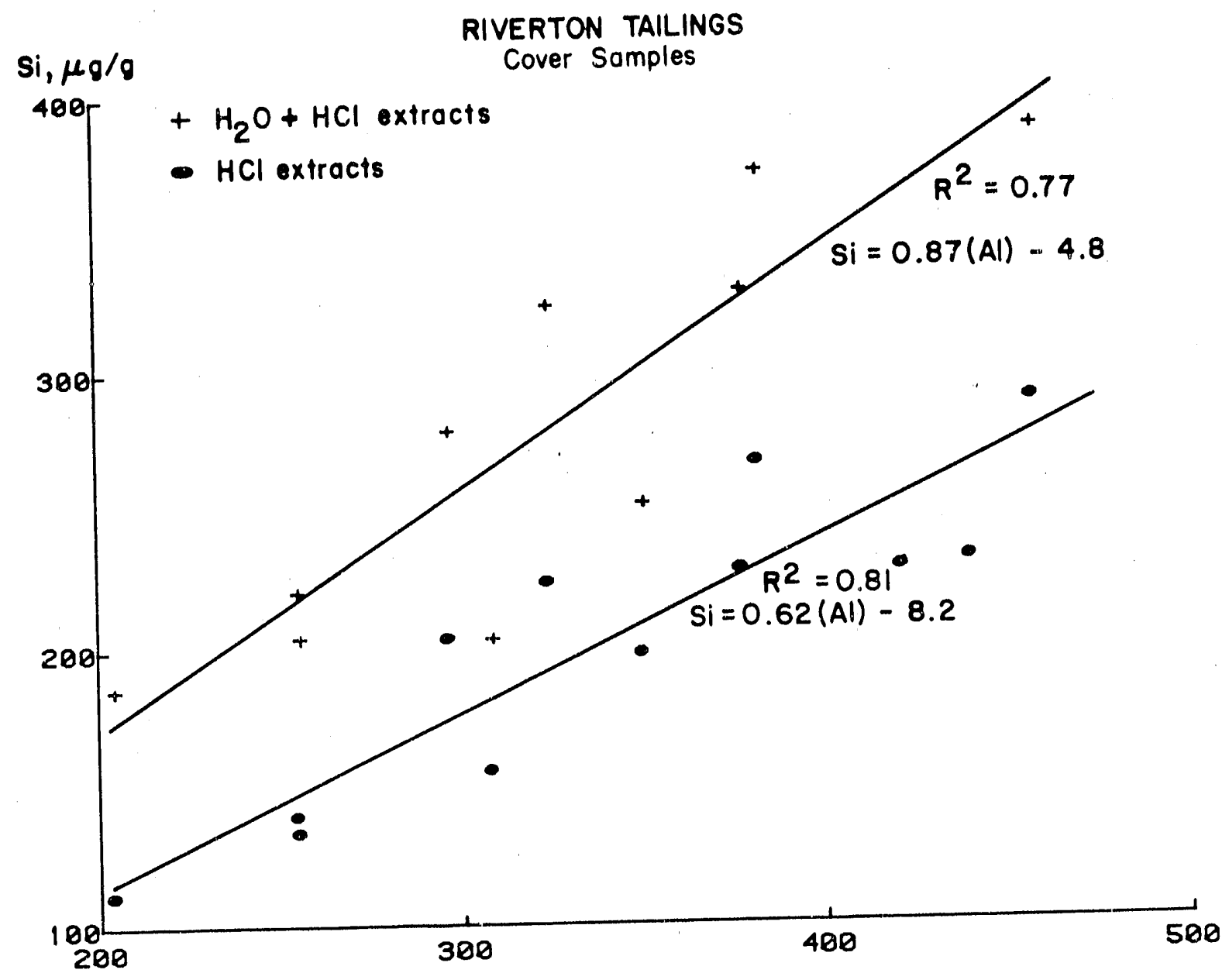

Al, $\mu g / 0$

Figure 23. Regression analys is of total extractable and $\mathrm{HCl}$ extractable $\mathrm{Al}$ and Si. The slopes of the regression lines indicate the stoichiometry of the aluminosilicates dissolving in the extractions. The water extract solubilizes $S i$ but not aluminum which suggest an incongruent reaction precipitating an acid soluble aluminum enriched material. 
Si-Al material to retard radium migration. The correlation of radium and aluminum shows three unique trends each corresponding to the cover samples from specific cores (Figure 24). Radium and aluminum correlate positively in the cover samples from RIV 165 and RIV 166 with correlation coefficients of greater than 0.99 . The concentrations of aluminum and radium regularly increase toward the surface in the cover of RIV 165 and RIV 166. This increase in aluminum indicates an increase in the rate of weathering of the aluminosilicate minerals and production of the amorphous $\mathrm{Al}-\mathrm{Si}$ material due to the increase in moisture and temperature toward the surface. The significant correlation may indicate a predictable relationship between the quantity of amorphous Al-Si material and the quantity of migrating radium it can retain.

There is no correlation between the acid-soluble aluminum and the total aluminum concentrations in the cover samples, which indicates that the increasing acid-soluble aluminum is independent of the source material. Also, the correlation line of RIV 165 is nearly parallel with the line describing the correlation for RIV 166 . The greater $y$-intercept in RIV 165 probably indicates a greater source of radium from the tailings mixed with the cover at this site. The parallel lines indicate similar mechanisms for the association of radium with aluminum at the two sampling sites.

The radium-aluminum relationship at RIV 164 differs from the relationships at RIV 165 and RIV 166 by the higher radium concentrations and the lower concentrations of acid-soluble aluminum. The low quantities of Al-Si amorphous material may have allowed the migration of higher quantities of radium to migrate to the surface. The surface samples of RIV 165 also fits into the low aluminum-high radium pattern of RIV 164 . When low quantities of amorphous aluminum are present, radium may precipitate as other acidsolubie phases, such as carbonates or adsorb on iron hydroxides.

This relationship between acid-soluble aluminum and radium may provide a feasible method to immobilize radium migrating into a cover emplaced on the tailings. Prior to emplacing a thick cover on the tailings, a thin cover of material with abundant amorphous aluminosilicates should be emplaced. Natural weathering processes will continue and further enhance the retardation properties of the amorphous aluminosilicates. 


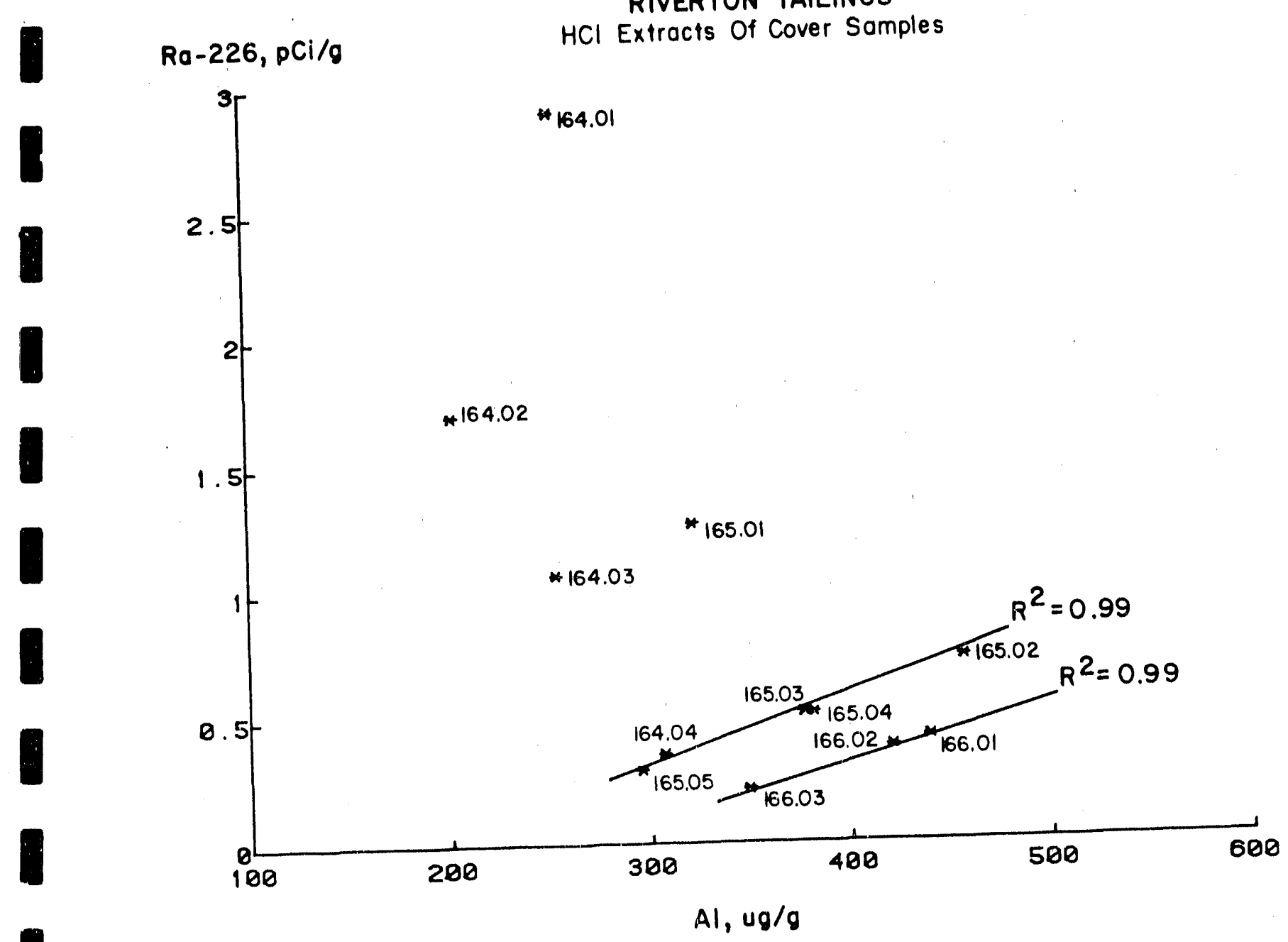

Figure 24. Regression analys is of Ra-226 and aluminum in the acid extracts of cover and interface. The correlation between Ra-226 and of cover and interface.
aluminum indicates retardation of Ra-226 by precipitation of
acid-soluble aluminum components. The parallel correlations of the samples in RIV 165 and RIV 165 indicate a similar mechanism. The high concentrations of $R a-226$ in the samples from RIV 164 may be related to the low concentrations of acid soluble aluminum. 
In addition to the amorphous aluminum material produced by weathering of aluminosilicate minerals, hydrous oxides of aluminum precipitate at the interface in greater quantities than in the cover (Figure 25). The vertical distributions of water and acid-soluble elements show the accumulation of aluminum at the interface, as well as many of the trace components. Iron hydroxide undoubtedly also precipitates at the interface because of the change from acidic conditions in the tailings to near neutral $\mathrm{pH}$ conditions in the soil; however, the vertical distributions do not show significantly greater concentrations at the interface than in the cover. However, observations of the interface zone in the trench prepared for sampling revealed a band of precipitates with the yellow-orange color of iron precipitates.

The precipitation of hydrous iron oxides also plays an important role of scavenging trace metals in the cover. The concentrations of trace metals in the acid extracts, cobalt, nickel, chromium, arsenic, vanadium, and uranium correlate with the acid-soluble iron and have correlation coefficients greater than 0.60 (Figures 26, 27, and 28). The surface samples are anomalously high in certain trace metals and were not included in the regression analysis for those metals. Uranium correlates with iron in the samples from RIV 164 where uranium has migrated. The samples from RIV 165 and RIV 166 that do not contain significant quantities of migrated uranium do not correlate with acid-soluble iron. 
Al, $u g / 9$

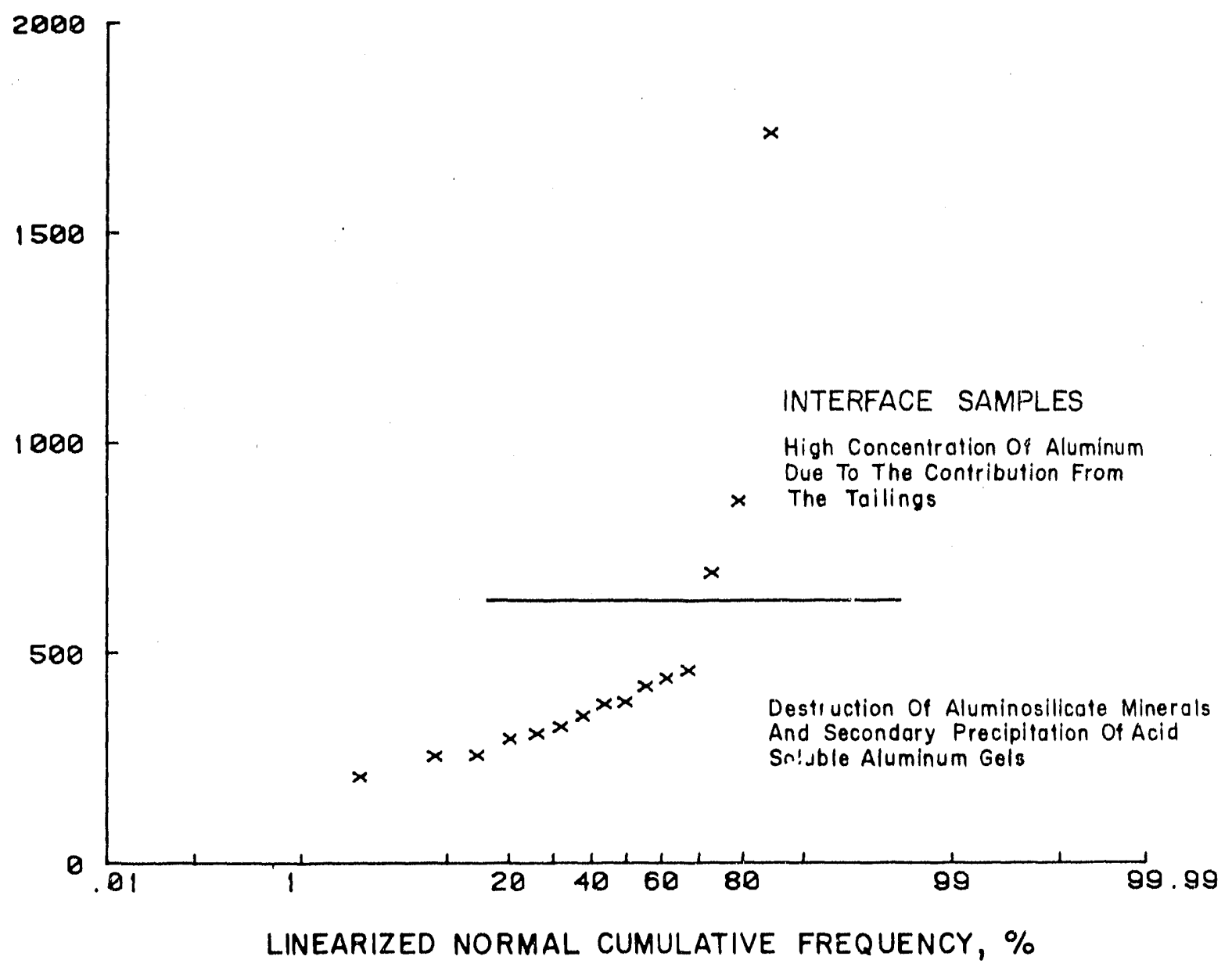

Figure 25. Linearized normal cumulative distribution of acid-soluble aluminum in cover and interface samples. The interface samples have high concentrations from the contribution of aluminum and acid from the tailings. Increasing acidsoluble aluminum in the cover indicates an increase in destruction of aluminosilicate minerals and the precipitation of aluminum gels. 

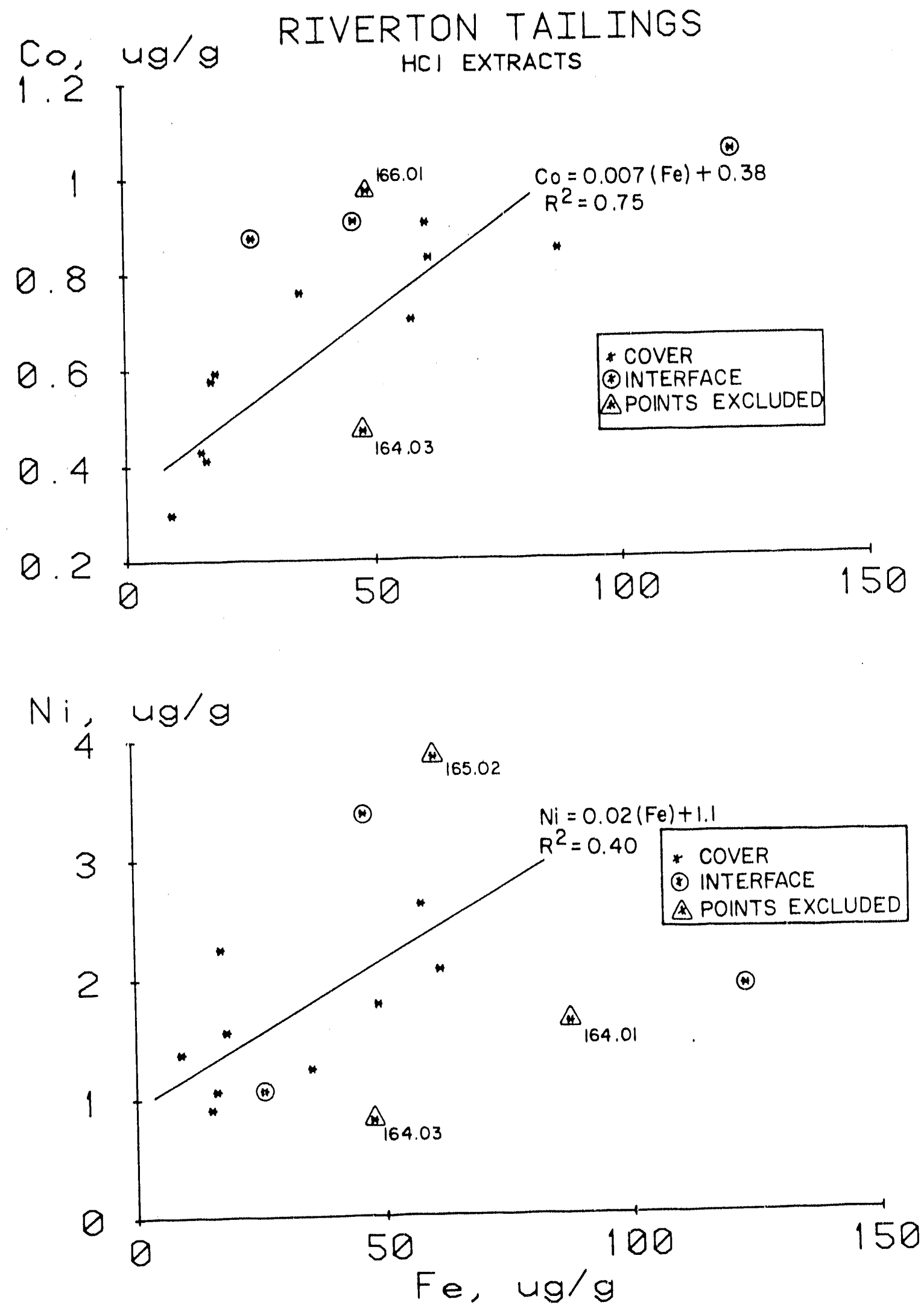

Figure 26. Regression analysis of acid-soluble iron against cobalt and nickel in cover and interface samples. 


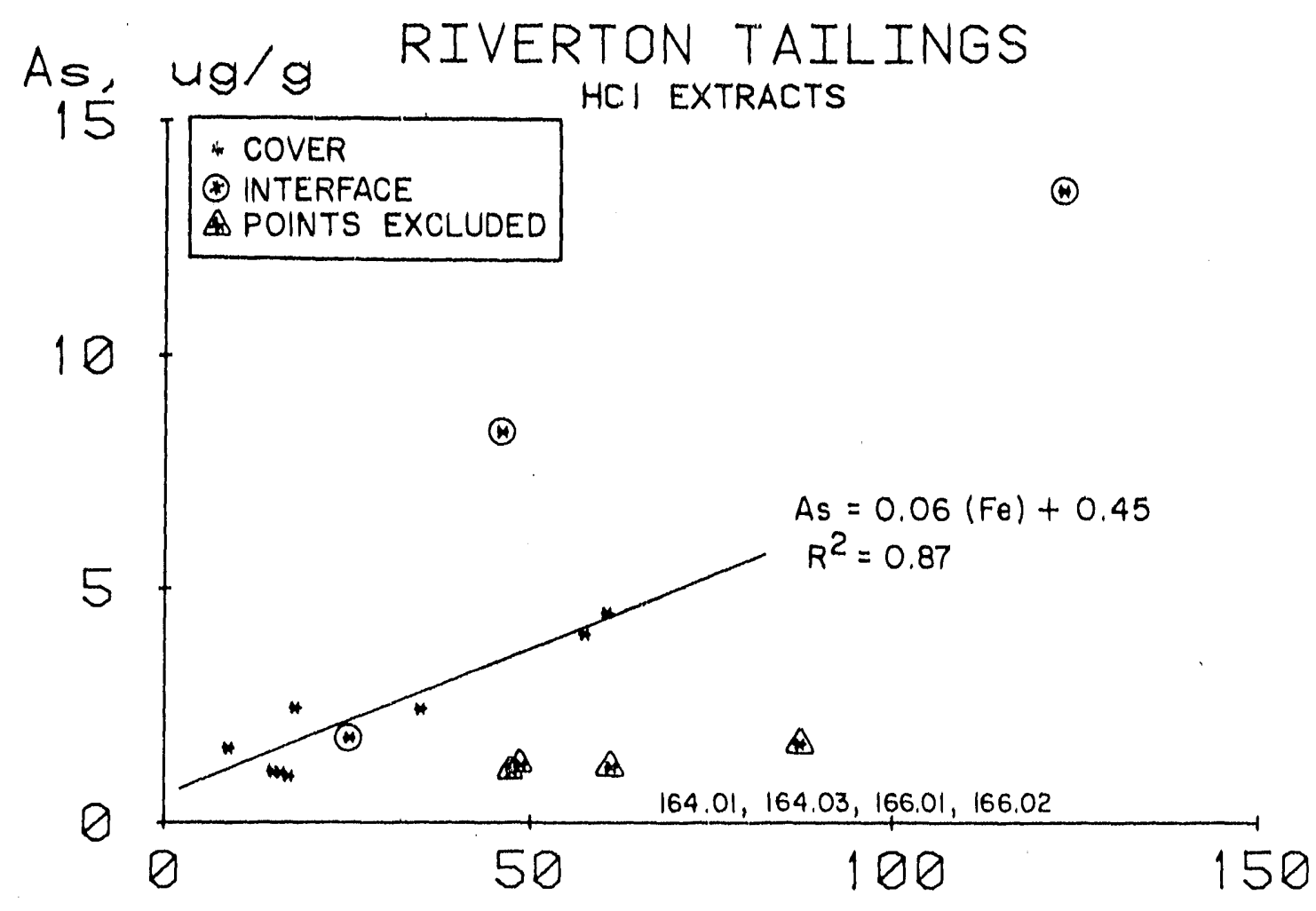

Cr, ug/g
1.5
$\left[\begin{array}{ll}* & \text { COVER } \\ 0 & \text { INTERFACE }\end{array}\right.$

(4)

(1)

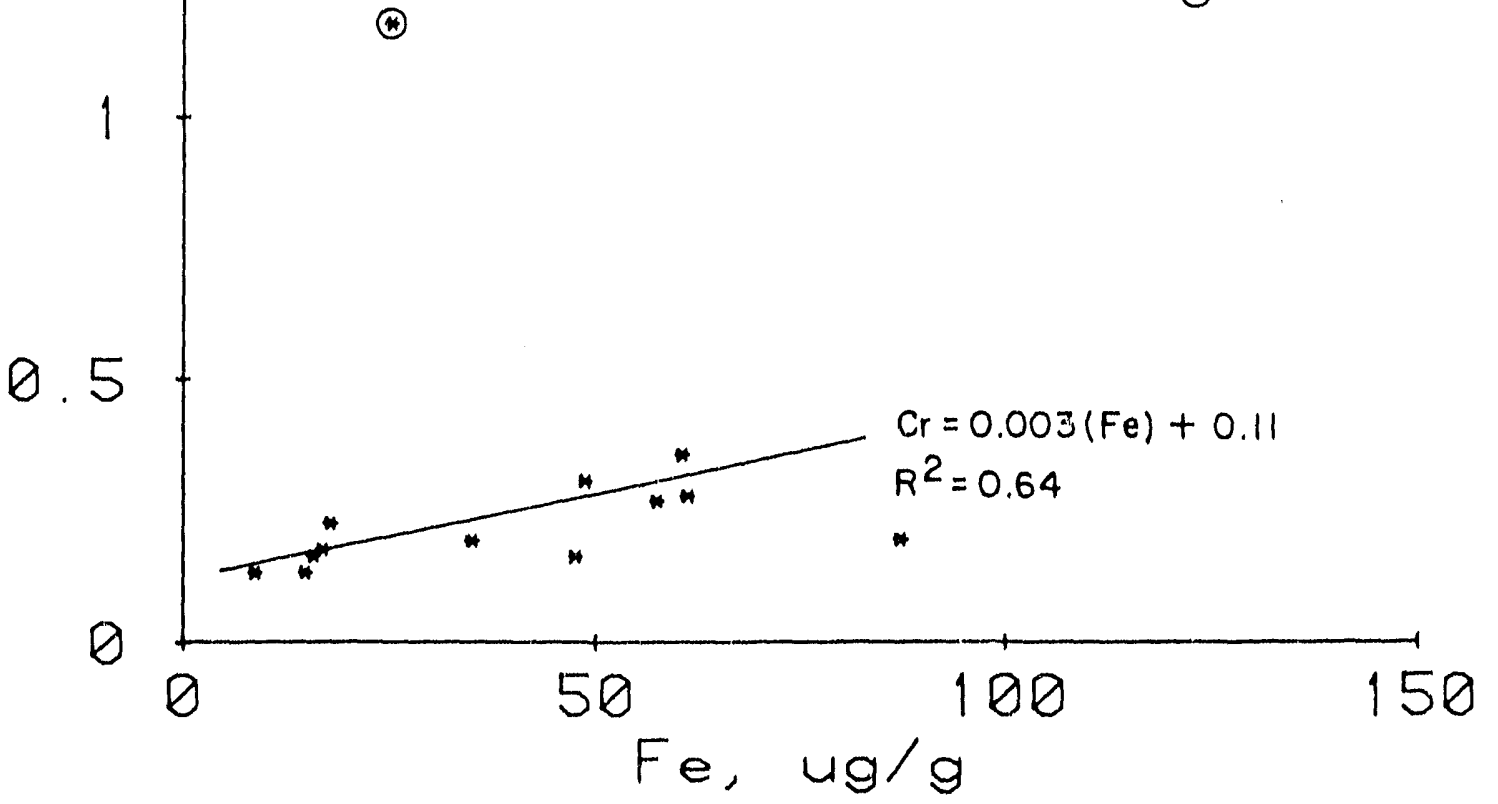

Figure 27. Regression analysis of acid-soluble iron against arsenic and chromium in cover and interface samples. 

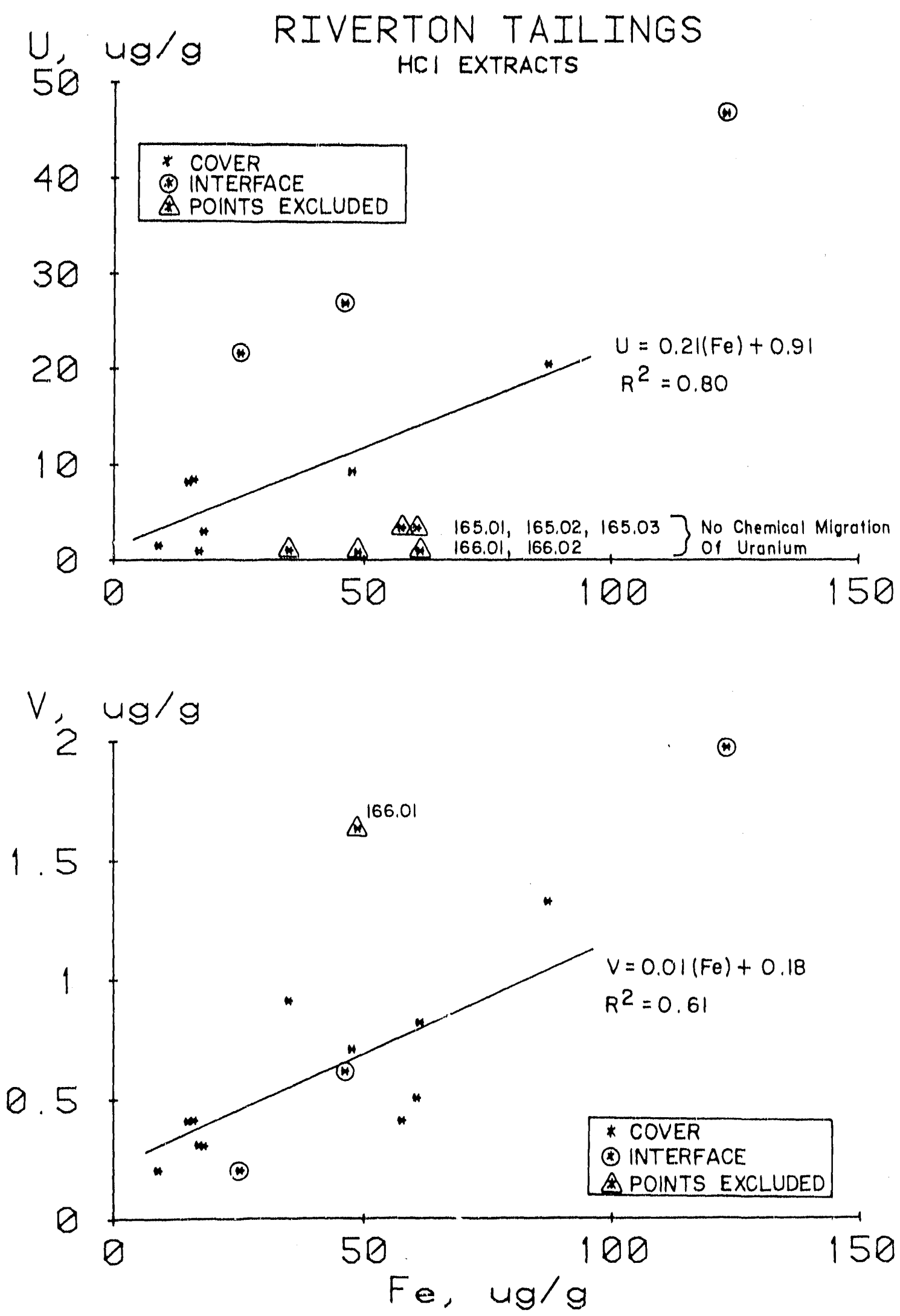

Figure 28. Regression analysis of acid-soluble iron against uranium and vanadium in cover and interface samples. 
6 THERMODYNAMIC MODELING OF MIXING OF TAILINGS SOLUTION WITH COVER

\section{INTRODUCTION}

Modeling the chemical reactions which occur upon migration of tallings solution into the cover requires determination of a representative source solution from the tallings and a solution representative of the pore water in the soils of the cover. The water extract solutions reflect the relative compositions of the pore waters ( $\mu \mathrm{g}$ of elentent per $\mathrm{g}$ of solid) and contain the components from the pore water and from the water-soluble precipitates. The composition of the pore water is determiend by concentrating the water extract solution accurding to the porosity and moisture saturation of the sample and by equilibrating the solution with the controlling mineral phases by calculations with PHREEQE. Equilibrating the solution with respect to appropriate mineral phases at saturation indexes typical of the environment adds or removes components to attain the specified saturation indexes. These calculations by PHREEQE result in a calculated solution which approximates the major chemical composition, $\mathrm{pH}$, and Eh of a typical pore water.

The minerals which control the composition of the pore water of the talings were determined by modeling the state of chemical equilibrium of pore waters sampled within the Riverton tailings with lysimeters by Lawrence Berkeley Laboratory [4]. The saturation indexes for minerals which control the composition of the aqueous phase are listed on Table 8. The saturation indexes for the various minerals are quite consistent throughout the tailings. The apparent supersaturation of gypsum and undersaturation of tauriscite $\left(\mathrm{FeSO}_{4} \cdot 7 \mathrm{H}_{2} \mathrm{O}\right), \mathrm{Fe}(\mathrm{OH})_{3}(\mathrm{aml})$, and epsomite $\left(\mathrm{MgSO}_{4} \cdot 7 \mathrm{H}_{2} \mathrm{O}\right)$ probably reflect processes not included in thermodynamic model such as kinetics, solid solutions, and formation of less-than-ideal crystal forms.

The minerals controlling the composition of pore water in the cover were determined from published data on chemical equilihrium in soils [20] and by comparison with the state of chemical equilibrium of the water extract in contact with the solid. The minerals: $\mathrm{Fe}(\mathrm{OH})_{3}$ (microcrystalline), manganite $(\mathrm{MnOOH}), \mathrm{Al}(\mathrm{OH})_{3}(\mathrm{am}), \mathrm{SiO}_{2}$ (gel), calcite, 


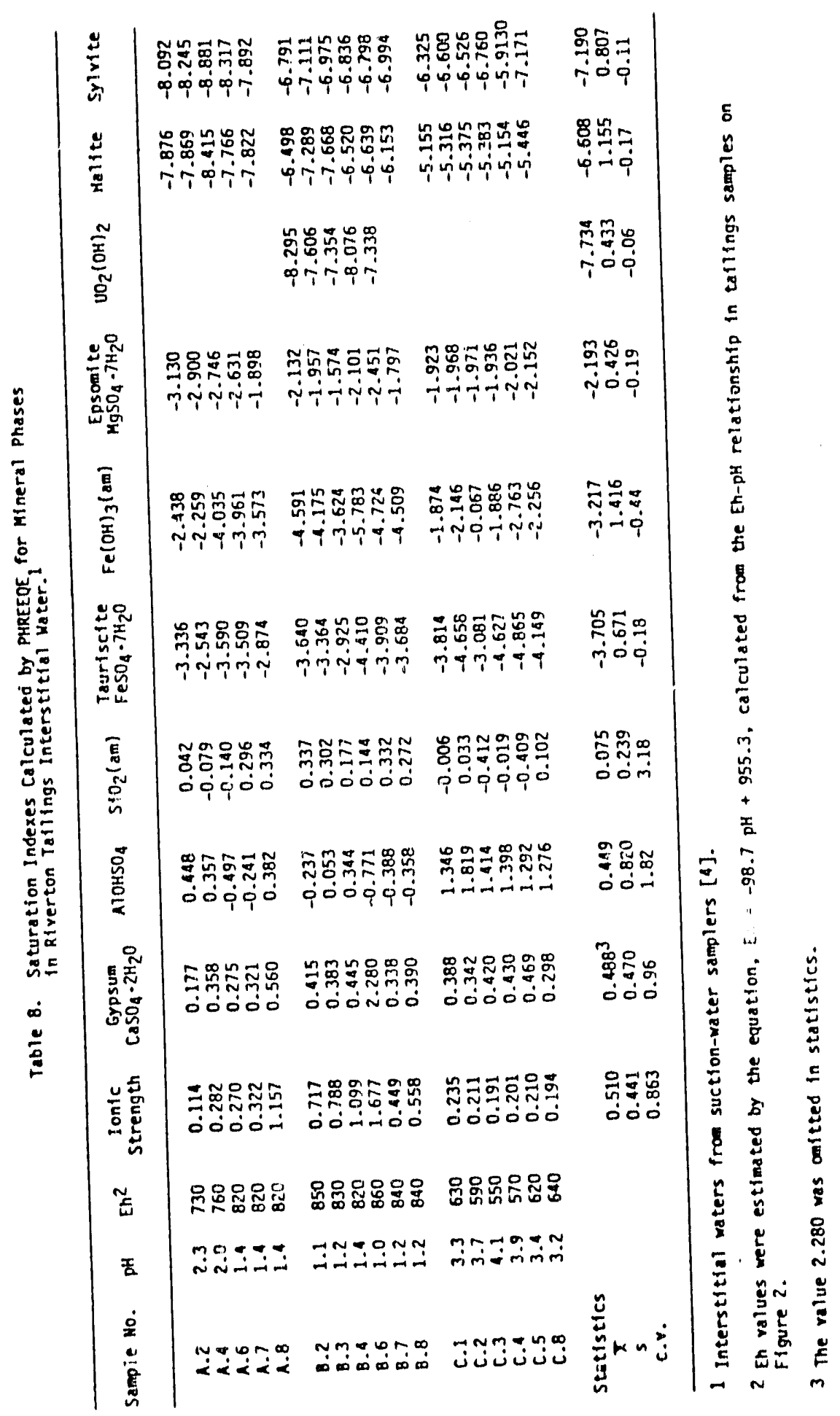


magnesite, $\mathrm{MnHPO}_{4}$, gypsum and fluorite, and carbon dioxide were determined to control the composition of the aqueous phase. In a carbonate environment, the concentration of solutic aiuminum may be controlled by minerals such as dawsonite $\left(\mathrm{NaAlCO}_{3}(\mathrm{OH})_{2}\right)$. The aluminum concentrations in equilibrium with amorphous aluminum hydroxide and dawsonite vary slightly, however, the results of modeling the migration of trace elements in the cover upon mixing of tallings and cover solutions are not sensitive to the ninor variations in aluminum concentrations. All of the minerals controlling the composition of the aqueous phase are near equilibrium with saiuration indexes of zero. Carbon dioxide has a saturation index equivaleni to the partial pressure. The partial pressure of $\mathrm{CO}_{2}$ has a significant relationship with $\mathrm{pH}$ and temperature and, therefore, affects the mobility of trace components.

For the calculations of the concentration of the water extract data, 50 percent porosity and $1.6 \mathrm{~g} / \mathrm{cm}^{3}$ bulk density were assumer. The calculations used are as follows:

$$
c=c \rho_{s} n_{e} / s
$$

where:

$$
\begin{aligned}
& c=\text { concentration in calculated solution }\left(\mu g_{e} \text { lement } / \mathrm{cm}^{3} \mathrm{H}_{2} \mathrm{O}\right) \\
& c=\text { concentration in water extract }\left(\mu \mathrm{gelement}_{\mathrm{e}} / \mathrm{g}_{\mathrm{soil}}\right) \\
& \rho_{\mathrm{s}}=\text { average bulk density }\left(\mathrm{g} / \mathrm{cm}^{3}\right) \\
& n_{e}=\text { effective porusity }\left(\mathrm{cm}^{3} \mathrm{soil}^{3} / \mathrm{cm}^{3} \text { void }\right) \\
& S=\text { moisture saturation }\left(\mathrm{cm}^{3} \text { void } / \mathrm{m}^{1} \mathrm{H}_{2} \mathrm{O}\right)
\end{aligned}
$$

The factors to concentrate the water extract data to account for variations in moisture content are as follows:

\begin{tabular}{cc} 
Saturation $(\%)$ & Factor \\
\hline 100 & $3 . ?$ \\
50 & 6.4 \\
40 & 8.0 \\
30 & 10.7 \\
20 & 16.0 \\
10 & 32
\end{tabular}


The multiplying factor required to convert $\mathrm{\mu g} / \mathrm{g}$ to $\mathrm{\mu g} / \mathrm{ml}$ in accordance with the porosity and moisture content of the tailings was confirmed by comparing the silicon concentrations in the water extracts $(\mu \mathrm{g} / \mathrm{g})$ with the silicon concentrations in solutions generated by PHREEQE, equilibrating the water extract data with mineral phases at the saturation indexes characteristic of the tailings pore waters. Silicon was used because the concentration of silicon in the water extracts reflects tl: concentration of silicon in the pore water of the tailings. Relatively small quantities of silicon in the solid phase of the tailings dissolves in the water extracts. The average ratio of the silicon concentrations in the tailings water extracts before and after equilibration with the mineral phases is 5 . This implies, that in order for the chemical composition of the water extracts to approximate that of tailings pore water, the water extract data are to be multiplied by about 5 to convert $\mu \mathrm{g} / \mathrm{g}$ to $\mu \mathrm{g} / \mathrm{ml}$. After the multiplication operation, the solutions are to be equilibrated with the major mineral phases to partition the quantity of components between the solid water-soluble phases and the pore water. Multiplication of the trace element concentrations in the water extracts by 5 gives the maximum concentration available for transport out of the tailings. A factor of 5 indicates a moisture saturation of about 64 percent in the tailings assuming 50 percent porosity and a bulk density of $1.6 \mathrm{~g} / \mathrm{cm}^{3}$.

The moisture content has orily a minor influence on the concentrations of components in the solution caiculated by PHREEQE because of the assumption that the solutions remain in equilibrium with the same set of mineral phases (Table 9). The primary effect of conceritrating the solutes by decreasing moisture content is the increase in activity coefficients of some aqueous species, especially divalent cations such as calcium and sulfate, thus increasing the concentration of solute necessary to maintain the chemical activity of the species, Changes in moisture content may influence the mobility of thorium, uranium, and radium (Table 10). The mobility of thorium may be influenced by changes in moisture content to a greater degree than uranium and radium. The variation between a saturation index (S.I.) of -0.25 and 0.86 at moisture contents of 100 to 10 percent may indicate migration of thorium during wetting and drying cycles. 
Table 9. Concentrations (ppm) of Elements in the Cover Pore Water at Varying Moisture Contents.

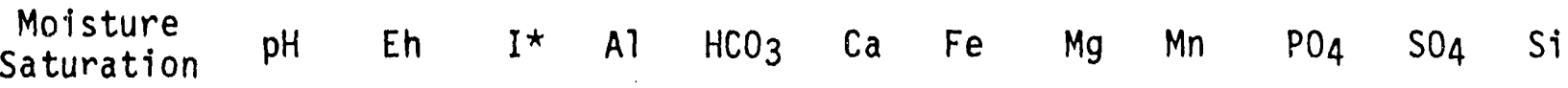

$\begin{array}{rrrrrrrrrrrrr}100 \% & 8.06 & 382 & .183 & 0.55 & 61 & 268 & 0.16 & 260 & 0.13 & 0.38 & 6810 & 89 \\ 50 \% & 8.13 & 378 & .292 & 0.66 & 83 & 242 & 0.15 & 232 & 0.12 & 0.53 & 11420 & 86 \\ 40 \% & 8.16 & 376 & .359 & 0.73 & 96 & 232 & 0.15 & 221 & 0.12 & 0.61 & 14600 & 84 \\ 30 \% & 8.18 & 375 & .440 & 0.83 & 112 & 221 & 0.14 & 210 & 0.11 & 0.71 & 18800 & 82 \\ 20 \% & 8.22 & 373 & .581 & 1.03 & 141 & 206 & 0.14 & 195 & 0.11 & 0.86 & 27100 & 78 \\ 10 \% & 8.26 & 370 & .904 & 2.0 & 215 & 178 & 0.12 & 169 & 0.10 & 1.16 & 50700 & 67\end{array}$

* Ionic Strength

Table 10. Thermodynamic Saturation Indexes of Minerals of Thorium, Uranium, and Radium at Varying Moisture Contents as

Calculated by PHREEQE.

\begin{tabular}{cccr}
$\begin{array}{c}\text { Moisture } \\
\text { Saturation }\end{array}$ & $\mathrm{ThO}_{2}$ & $\mathrm{UO}_{2}(\mathrm{OH})_{2}$ & $\mathrm{RaSO}_{4}$ \\
\hline $100 \%$ & -0.25 & 0.01 & -6.09 \\
$50 \%$ & 0.05 & 0.04 & -5.74 \\
$40 \%$ & 0.18 & 0.05 & -5.60 \\
$30 \%$ & 0.32 & 0.06 & -5.45 \\
$20 \%$ & 0.51 & 0.09 & -5.26 \\
$10 \%$ & 0.86 & 0.16 & -4.93
\end{tabular}


Uranium hydroxide maintains an equilibrium condition independent of the moisture content; whereas, radium sulfate remains undersaturated. Migration of thorium may be thermodynamically controlled; whereas, the mobility of uranium and radium is probably controlled by adsorption and coprecipitation reactions.

\section{CHARACTERISTICS OF THE COVER}

In the characterization of the cover, a temperature range between 5 and 35 degrees calsius and a range of partial pressure of $\mathrm{CO}_{2}$ (gas) from 10-2.0 to 10-4.0 were assumed to represent seasonal variations and the range of vegetative respiration in the root zone to conditions with no vegetation. High partial pressure (expressed as fugacity) of carbon dioxide gas $\left(\mathrm{pfCO}_{2}=2.0\right)$ represents conditions of high vegetative respiration rate; $\mathrm{pfCO}_{2}=3.5$ is the equilibrium state with the atmosphere. Whereas, $\mathrm{pfCO}_{2}=4.0$ indicales the absence of respiration. The variable parameters of temperature and the partial pressure of carbon dioxide gas influence the geochemical environment, which controls the properties of the cover material and the migration of trace metals. The probable range of the geochemical environment as expressed by $\mathrm{pH}$ and $\mathrm{Eh}$ is shown in Figure 29 . Comparison of measured and calculated conditions for the cover material shows close agreement.

The maintenance of equilibrium, $\mathrm{pH}$ buffering, and Eh poising of the aqueous phase with the solid phases requires the consumption and precipitation of solid phases participating in the reactions. Dissolutionprecilitation ractions, in turn, afiect the solid to void ratio of the cover material. The net cumulative changes will take place as function of the geochemical parameters and the direction and rate of water movement. The resulting net changes of calcite, $\mathrm{MnHPO}_{3}$, and volume are shown in Figures 30,31 , and 32 , respectively.

At a fixed $\mathrm{pfCO}_{2}$ dissolution of calcite to maintain equilibrium is affected by the temperature of the presailing environment and the $\mathrm{pH}$ as shown in Figure 30. The equilibrium $\mathrm{pH}$ conditiciss for the temperature range of 5 to 35 dearees Celsius and $\mathrm{pfCO}_{2}$ range of 2 to 4 varied between 7.3 and 8.5. High temperature and lower pH favors the dissolution of 


$$
\text { Eh-pH FIELD FOR }
$$

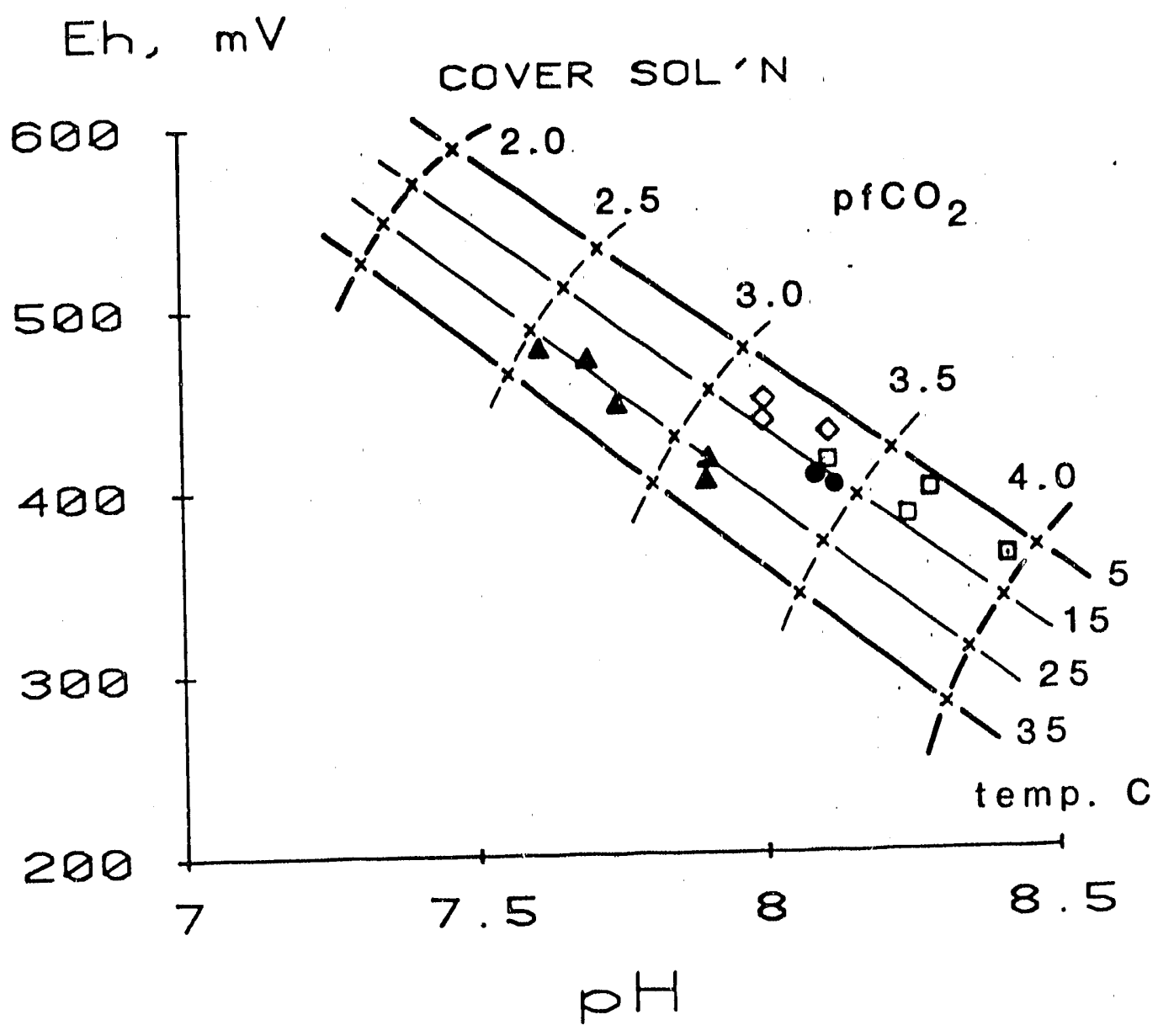

Figure 29. Eh-pH field calculated as the function of temperature and carbon dioxide fugacity $\left(\mathrm{pfCO}_{2}\right.$ means the negative logarithm of $\mathrm{CO}_{2}$ fugacity) and the solid phases maintaining equilibrium with solution (calcite, magnesite, silica gel, dawsonite, $\mathrm{MnHP}_{4}$, manganite, and microcrystalline ferric hydroxide). Samples from field are superimposed: $\diamond=$ RIV 166, $\Delta=$ RIV 165, $\square=$ RIV 164, and $=$ RIV 103. [1] 
CALCITE

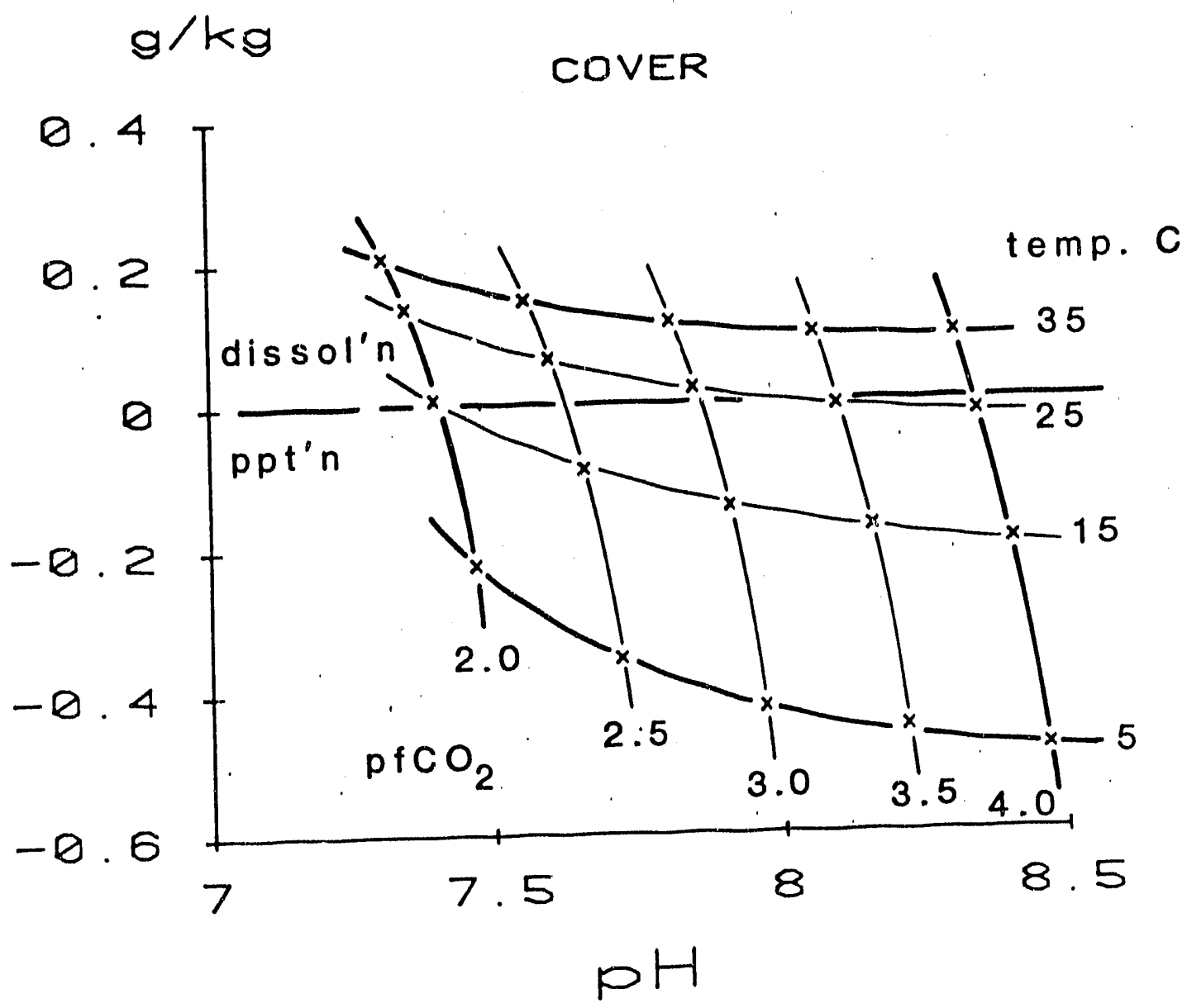

Figure 30. Behavior of calcite in cover as the function of temperature, $\mathrm{pfCO}_{2}$ and the corresponding $\mathrm{pH}$. Grams of calcite dissolved $(+)$ or precipitated $(-)$ per kilogram of solution. 


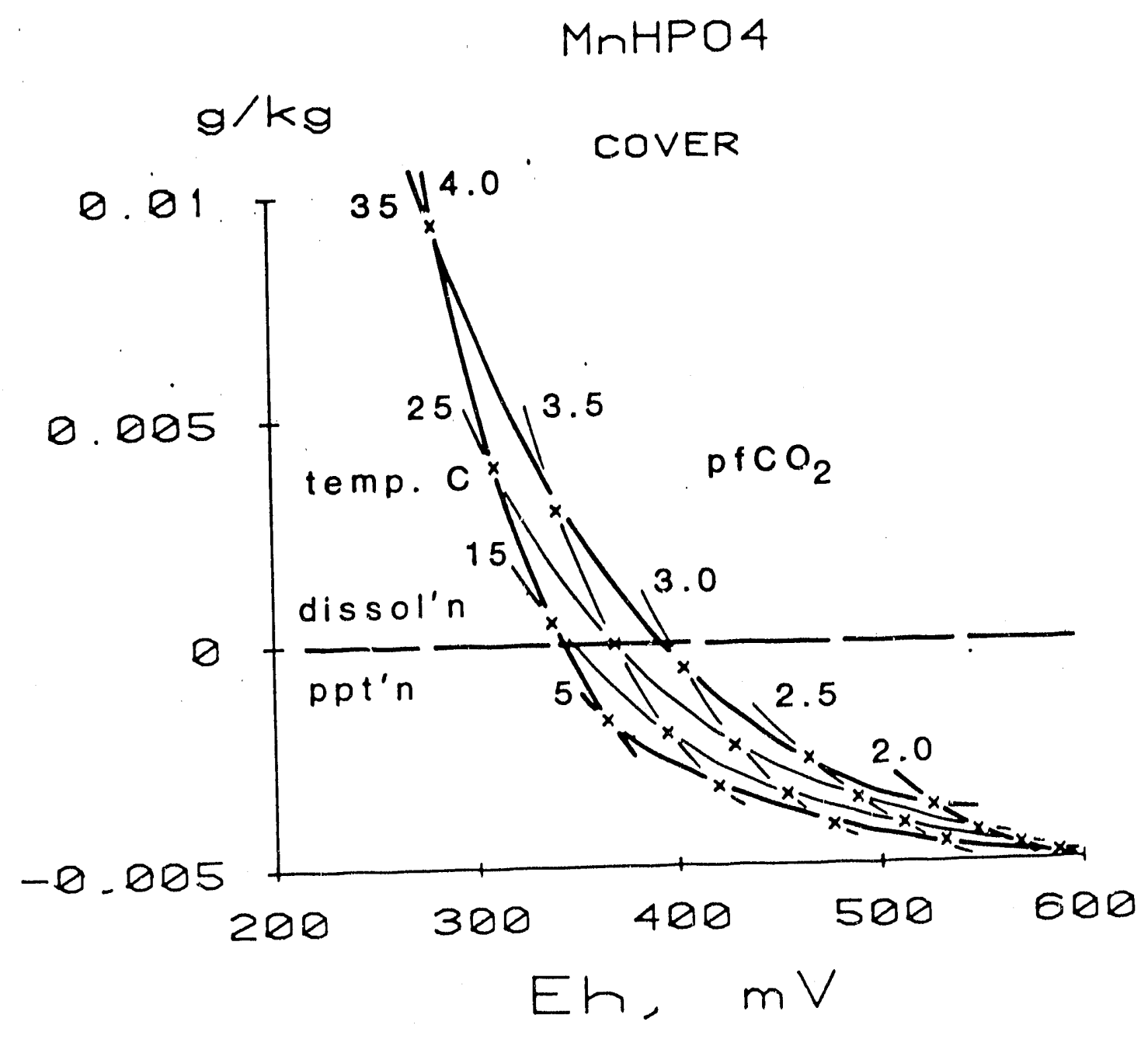

Figure 31. Behavior of $\mathrm{MnHPO}_{4}$ in cover as a function of temperature, $\mathrm{pfCO}_{2}$ and the corresponding $\mathrm{Eh}$. Grain of $\mathrm{MnHPO}_{4}$ dissolved $(+)$ or precipitated $(-)$ per kilogram of solution. 


\section{VOLUME CHANGE}

$$
\mathrm{cm}^{\wedge} 3 / \mathrm{kg}
$$

COVER

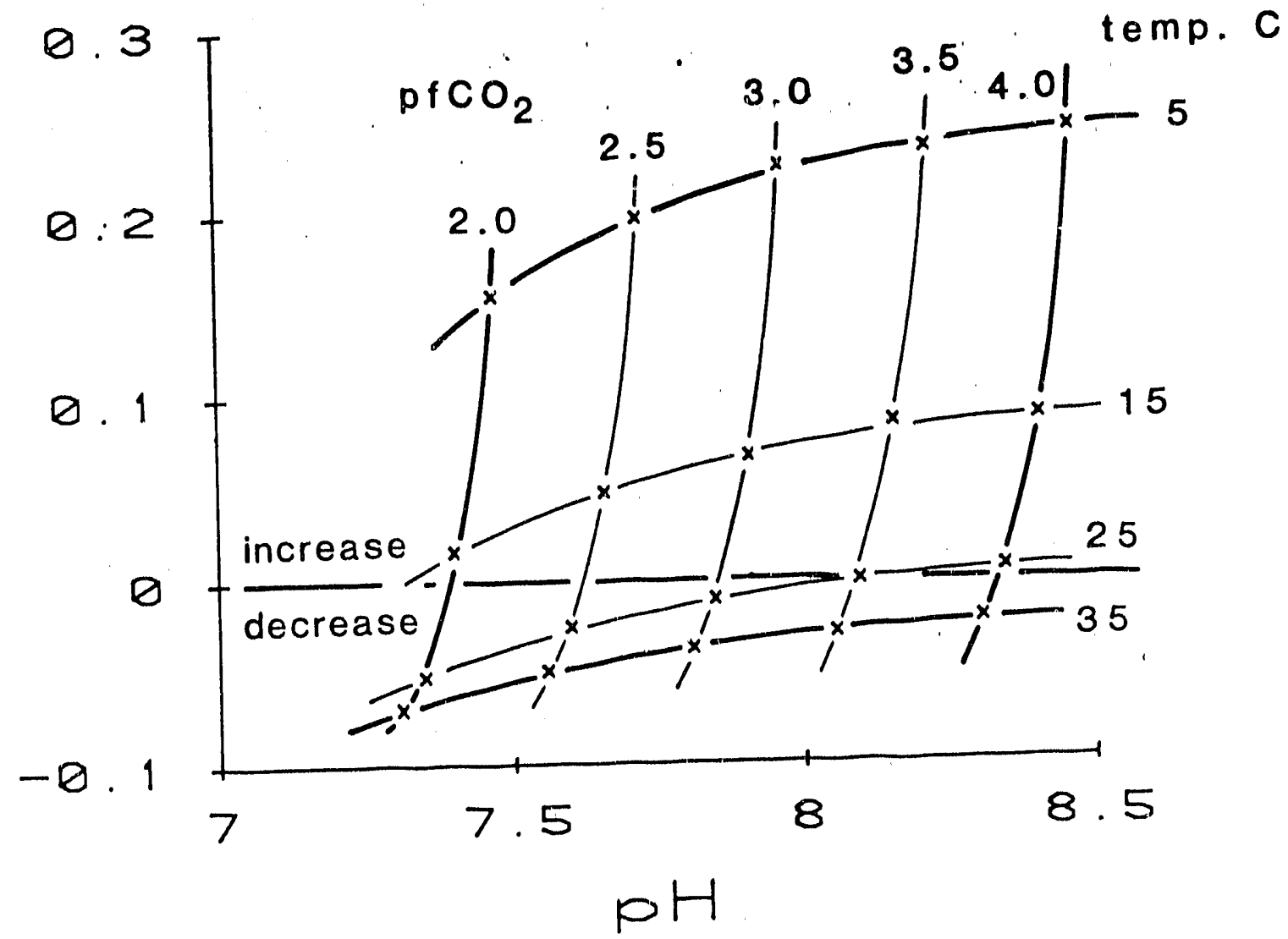

Figure 32. Pore volume change in cover as a function of temperature, $\mathrm{pfCO}_{2}$, and the corresponding $\mathrm{pH}$. $\mathrm{Cm}^{3}$ of pore volume increase $(+)$ or decrease (-) per kilogram of solution. 
calcite; whereas, lower temperature, high $\mathrm{pH}$, and low partial pressure causes the precipitation of calcite, providing a supply of calcium in the aqueous phase is available. If data describing the rate and quantity of water movement through the cover are available, the amount of calcite dissolved from or added to the solid phase can be calculated and the capacity in the cover to maintain equilibrium conditions governed by calcite can be estimated.

Coupled oxidation-reduction reactions of manganese and iron are the major electroactive component reactions, which poise the Eh of the system. The dominant manganese containing mineral, as inferred from acid extract data, is $\mathrm{MnHPO}_{4}$. Figure 31 shows the behavior of this solid as a function of temperature, partial pressure of carbon dioxide, and Eh. High temperature, low carbon dioxide fugacity, and lower Eh favor the dissolution of the solid phase, hence, decrease of the Eh of the system. Similarly to calcite, quantitative estimates of the capacity of manganese poising can be made if the appropriate hydrologic data are available.

The net result of volume change in the cover resulting from precipitation and dissolution of minerals as a function of the environmental parameters for a system where equilibrium is maintained is shown in Figure 32. The dissolution of gypsum and precipitation of calcite most significantly contribute to volume changes. Temperature has the greatest effect on changing the pore volume because of the influence on calcite equilibrium. Lower temperatures will increase pore volume through time, whereas, pore volume will tend to decrease with higher temperatures.

\section{INTERACTION OF TAILINGS SOLUTION WITH COVER}

Two cases of probable interactions of tailings solution with the cover were investigated.

1. The cover has no capacity for maintaining the original equilibrium condition.

2. The cover has the capacity for maintaining the original equilibrium conditions.

Within the 1-2 cm cover sample directly above the tailings interface, the first (1) relationship exists, despite the calcareous nature of the 
material used for the cover. These samples have low $\mathrm{pH} \quad\langle 6\rangle$ and high Eh ( $>480 \mathrm{mV}$ ) characteristic of the tailings material. Mineralogic evidence, the absence of calcite and the presence of natro-jarosite, gypsum, and hexahydrate suggests the following processes:

1. The rate and total quantity of acid addition to the cover had exceeded the rate of dissolution of calcite and Eh poising capacity of the minerals in the cover.

2. The capacity of the cover for maintaining original equilibrium conditions had been exhausted.

3. Precipitation of acid-producing minerals such as jarosites maintains acidic conditions, as well as increases Eh.

Mixing tailings solution with the cover in quantities great enough to exceed the buffer capacity of the soil affects the migration behavior of trace metals. The solubility of most components increase as the pH decreases. Furthermore, nearing or exceeding the isoelectric point toward the low pH side, recudes the adsorptive capacity of the substrate or shifts it to an anion adsorber. Addition of acid to the cover where no mineral control exists to maintain the original equilibrium profoundly lowers the $\mathrm{pH}$ (Figure 33). One micromole acid added to one kilogram of cover solution will reduce the $\mathrm{pH}$ from about 8 to about 4; two micromoles will reduce the $\mathrm{pH}$ to 3.

The second relationship where the mineralogy of the cover maintains the original equilibrium is generally the realistic situation for tailingscover interactions. Calculations were made for mixing tailings into cover solutions from $1: 99$ to $2: 3$ ratios considering the maintenance of equilibrium by calcite, magnesite, silica gel, dawsonite, $\mathrm{MnHPO}_{4}$ or bixbyte, and ferric hydroxide as a function of temperature and $\mathrm{pfCO}_{2}$. The chemical environment resulting from the mixing varies as a function of of temperature and $\mathrm{PfCO}_{2}$ (Figure 34 ). There is a tendency of lowering the Eh by a maximum $<100 \mathrm{mV}$ at high carbon dioxide partial pressure to a minimum $<20 \mathrm{mV}$ at low carbon dioxide partial pressure when the mixing ratio is 1:9, tailings to cover solution. The change in $\mathrm{pH}$ as a function of temperature and carbon dioxide partial pressure is negligible. Mixing of tailings and nontailings solutions does not significantly alter the 


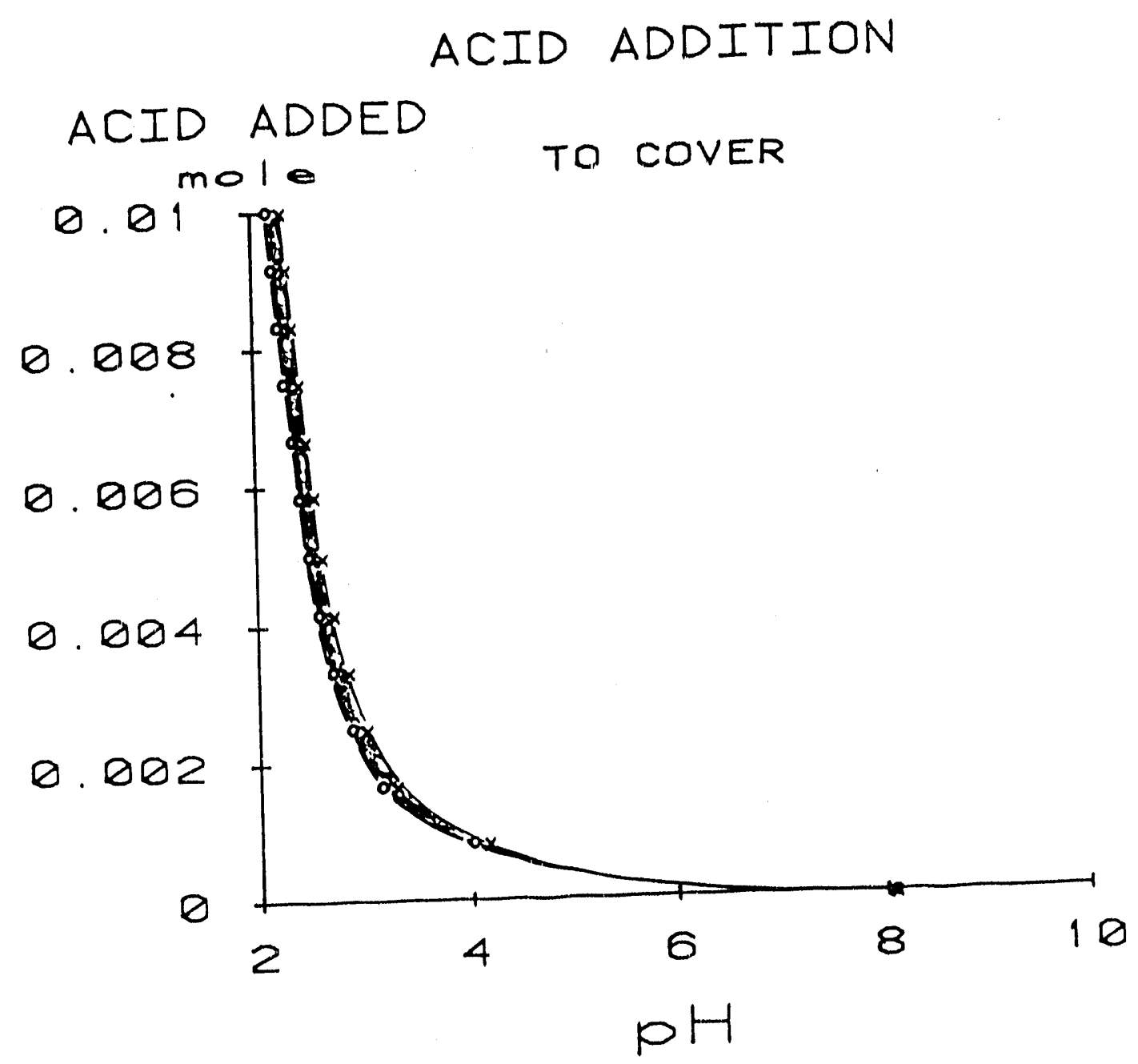

Figure 33. Change of $\mathrm{pH}$ as the function of acid addition to cover solution under conditions of no mineralogic buffer $0=5^{\circ} \mathrm{C}, \mathrm{x}=35^{\circ} \mathrm{C}$ temperatures. Acid added mole/kg of solution. 


\section{Eh-pH FIELD FOR}

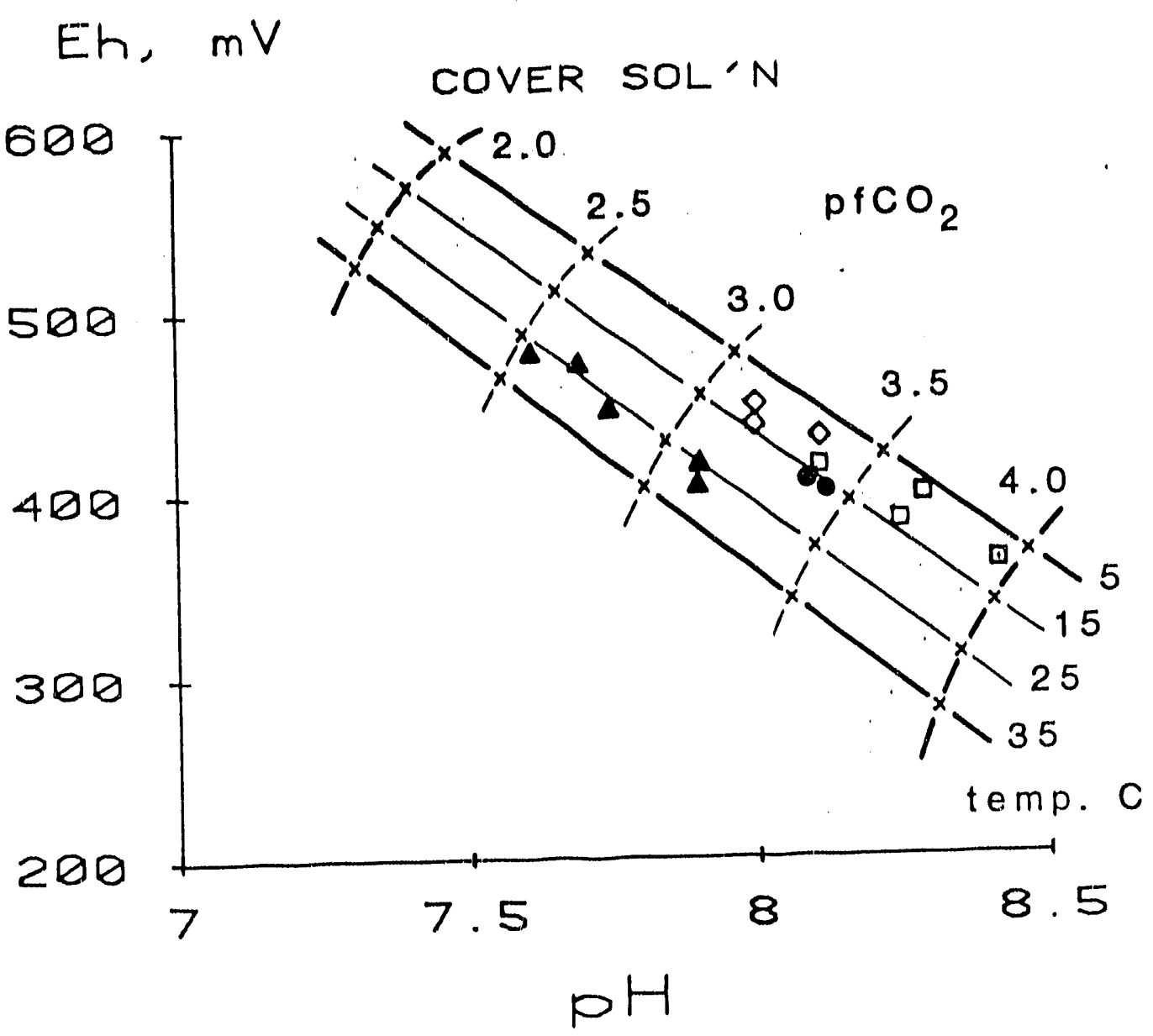

Figure 34. Eh-pH field and its shift from original position resulting from mixing tailings with cover solution in $1: 9$ ratio, as the function of temperature, $\mathrm{pfCO}_{2}$, and the corresponding $\mathrm{pH}$. 
components which are sensitive to Eh changes. The saturation indexes of the most mineral phases of the radioactive components (radium, thorium, and uranium) change little in the indicated chemical environment except for uranium.

Uranium is sensitive to the variations in the environmental conditions because of its oxidation-reduction behavior and formation of carbonate complexes (Figure 35). Low temperature and low partial pressure of carbon dioxide favor the precipitation of uranyl hydroxide. The dominant aqueous species is the negatively charged uranyl di-, and tri-carbonate, depending on the $\mathrm{pH}$. In the relatively high $\mathrm{pH}$ environment, the mineral substrate is mostiy a cation adsorber and the carbonate complexes of uranium are probabiy mobile.

As the mixing of solutions and the maintenance of original equilibrium conditions occur, the dissolution of calcite and the precipitation of gypsum should be considered. For $1: 9$ ratio of tailings solution mixing into the cover solution calcite dissoives in the range of 2.0 gram solid per $\mathrm{kg}$ of solution $\left(t=5^{\circ} \mathrm{C}\right.$ and $\left.\mathrm{pfCO}_{2}=4.0\right)$ and $2.3 \mathrm{~g} / \mathrm{kg}\left(t=35^{\circ} \mathrm{C}\right.$ and $\mathrm{pfCO}_{2}=2.01$. Because gypsum occupies less volume than calcite, the net pore volume reduction ranges between $0.55 \mathrm{~cm}^{3} / \mathrm{kg}$ of solvent $\left(t=35^{\circ} \mathrm{C}\right.$ and $\mathrm{pfCO}_{2}=2.01$ and $0.65 \mathrm{~cm}^{3} / \mathrm{kg}$ of solvent passing through the pore space. The significance of this process may be the enhancement of capiliary moisture movement, because with reduced pore space the capillary potential increases. 


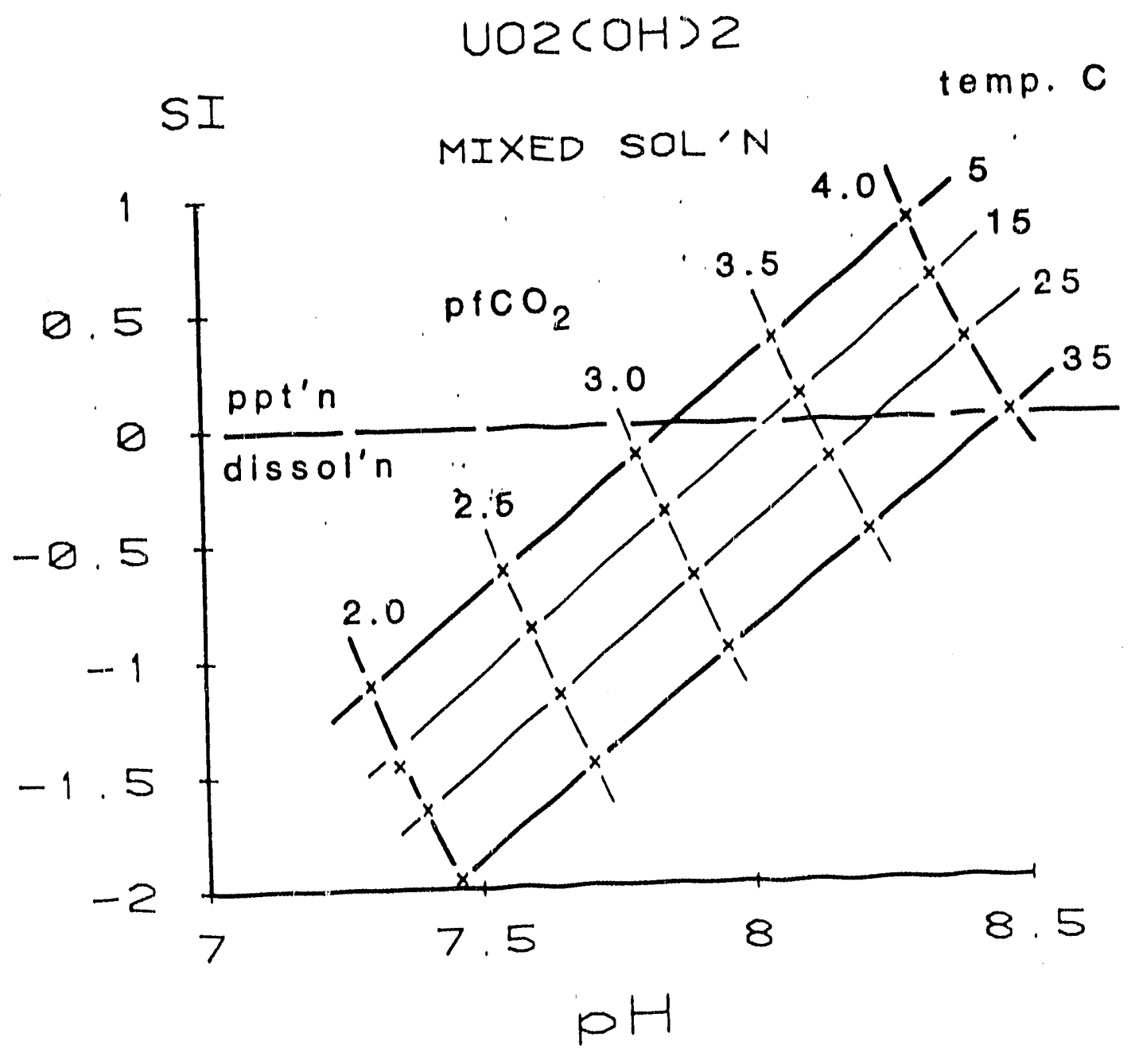
Figure 35. Changes in SI (saturation index) of $\mathrm{UO}_{2}(\mathrm{OH})_{2}$ as the function
of temperature, $\mathrm{pfCO}_{2}$, and the corresponding pH. Negative SI indicates dissolution, whereas positive indicates precipitation. 


\section{CONCLUSIONS}

The conclusions on the upward migration of salts and contaminants from tallings into an earthen cover are based upon a total of 30 samples taken from three locations through the cover into the tailings on the Riverton site. Data inciuded are chemical and isotope analysis of bulk solid, water extracts and acid extracts, and x-ray diffraction analysis. A general conclusion is that the study of contaminant migration must be preceded by a distinction between contamination from physical mixing and chemical migration. This was done by evaluation of conservative components such as potassium and $\mathrm{Pb}-210$ in the bulk solid. The quantity of tailings mixed in the cover sampled from the Riverton tailings varied between 3 and 20 percent. Varying quantities of thorium, uranium, radium, and molybdenum have contaminated the cover from chemical migration. Contaminants such as As, $\mathrm{Cr}, \mathrm{Ni}$, and $\mathrm{Se}$, which are sensitive to $\mathrm{PH}$ and $\mathrm{Eh}$ conditions, were immobilized at the interface between tallings and cover. The contamination from chemical migration was primarily transported by fluid gradients induced by evaporation. Thicker covers will minimize fluid gradients into the tallings; consequently, the role of capillary potentials for transporting contaminants will be increased.

The migration of Th-230 showed consistent behavior among the three sampling locations. The concentrations increased toward the surface within the range of 2 to $23 \mathrm{pCi} / \mathrm{g}$. The mobility of thorium appears to be controlled by the solubility of thorium oxides and hydroxides. The presence of phosphate from the addition of fertilizer forms aqueous thorium phosphate complexes and increases the soluble concentration. Thorium accumulates on the surface as oxides and hydroxides which become supersaturated due to evaporation.

The migration of uranium was inconsistent among the three sampling locations. The concentrations due to migration ranged between 10 and 22 $\mathrm{pCi} / \mathrm{g}$ at the location on the west end of the tailings pile; whereas, there was less than $2 \mathrm{pCi} / \mathrm{g}$ at the other two locations. At the $\mathrm{pH}$ and $\mathrm{Eh}$ conditions of the cover, uranium is available for migration as di- and tricarbonate complexes. Immobilization of uranium appears to be associated with the pres.rpitation of iron hydroxides. The details of the mobilization 
and immobilization mechanisms to explain the observations were not a part of this investigation. The migration of molybdenum follows the same pattern as uranium. The location on the west end of the site had concentrations of molybdenum from migration ten-fold greater than background concentrations. The greater magnitude of migration at the west end of the tailings may be related to the availability of water due to retention by a plastic liner near the base of the pile.

The distribution of radium showed some resemblance to the migration of uranium. The incation with high uranium concentrations had radium centrations dut migration up to i $\mathrm{pCi} / \mathrm{g}$; whereas, the other two locations had concenuations less than $1.5 \mathrm{pCi} / \mathrm{g}$. The distributions of radium increased toward the surface, typical of upward migration profiles. Radium sulfate is undersaturated in the cover, which indicates adsorption on various substrates and coprecipitation with $\mathrm{BaSO}_{4}$. The retardation of radium at the locations with less than $1.5 \mathrm{pCi} / \mathrm{g}$ appear to be associated with amorphous aluminosilicate components. The formation of amorphous alu "nosilicates from the weathering of primary silicate minerals, such as feldspars, may represant a feasible mechanism to retard the migration of radium. As natural weathering processes occurr through time, the immobilization of radium would be extended.

The major parameters affecting the mobility of contaminants were partial pressure of $\mathrm{CO}_{2}$ and temperature, which varies seasonally and with plant respiration. The partial pressure of $\mathrm{CO}_{2}$ influances the $\mathrm{pH}$ and the activities of bicarbonate and carbonate anions available foi complexing cations such as uranium.

The mo isture content, between 100 and 20 percent, did not significantly affect the concentrations of components in solution because of the assumption that the solutions remain in equilibrium with minerals in the solid phase. The saturation indexes of $\mathrm{ThO}_{2}$ vary significantly as a function of moisture content. The saturation index of $\mathrm{ThO}_{2}$ fluctuates positively and negatively from equilibrium, which indicates a potential for thorium oigration during wetting and drying cycles.

The migration of sulfate tailings solution into the cover dissnlves calcite and gypsum precipitates. Because of the molar volume diff nces 
between calsite and gypsum, the volume of the solid phase will increase, decreasing the pore volume. The decrease in pore volume will tend to increase the capillary potentials of moisture movement into the cover and needs to be considered in evaluation of capillary transport of water.

The results of modeling the mixing of tailings and nontailings did not show significant changes of the mobilities of contaminants except for uranium. Assuming an adequate quantity of calcite in the cover to buffer the acidity of the tailings solution, the only change in the chemical environment is a small decrease in Eh. The mobility of uranium is increased because of its electroactive nature and its tendency to form soluble carbonate complexes. 


\section{REFERENCES}

1. Markos, G. and K. J. Bush. Geochemical Investigation of UMTRAP Designated site at Riverton, Wyoming. GECR \#R-823. GECR, Inc., Rapid City, SD. Prepared for U.S. Department of Energy, UMTRAP Office, Cons:act No. DE-ACO4-82AL18797. DOE/UMT/0229. Albuquerque, NM, 1982.

2. Markos, G. and K. J. Bush. Geochemical Investigation of UMTRAP Designated Site at Grand Junction, Colorado. GECR \#R-824. GECR, Inc.: Rapid City, SD. Prepared for U.S. Department of Energy, UMTRAP office, Contract No. DE-ACO4-82AL18797. DOE/UMT/0231. Albuquerque, NM, 1982 .

3. Markos, G. and K. J. Bush. Geochemical Investigation of UMTRAP Designated Site at Shiprock, New Mexico. GECR \#R-825. GECR, Inc., Rapid City, SD. Prepared for U.S. Department of Energy, UMTRAP Office, Cortract No. DE-ACO4-82AL18797. DOE/UMT/0233. Albuquerque, NM, 1982 .

4. Narasimhan, T. N., R. M. Galbraith, A. White, A. Smith, H. Schmidt, B. Moed, and $T$. Tokunago. Hydro-geochemical Studies of Uranium Mill Tailings Piles at Riverton, Wyoming and Maybel1, Colorado. Annual Report for Fiscal 1981 DOE Contract No. DE-AC03-76SF0098. LBL-14486. Lawrence Berkeley Laboratory, Berkeley, CA, 1982.

5. Ford, Bacon and Davis Utah, Inc. Phase II - Title I Engineering Assessment of Inactive Uranium Mill Tailings, Riverton Site, Riverton Wyoming. Prepared for the U.S. Department of Energy, Contract No. E(05-1)-1658, 1977.

6. Bresler, E., B. L. MCNeal, and D. L. Carter. Saline and Sodic Soils, Principles - Dynamics - Modeling. Advanced Series in Agricultural Sciences 10. Springer-Verlag, New York, 1982.

7. Parkhurst, D. L., D. C. Thornstenson, and N. L. Plummer. PHREEQE--A Computer Program for Geochemical Calculations. U.S. Geological Survey, Water Resources Investigation 80-96, NTIS PB81-167801, 1980.

8. Markos, G. and M. Coffin. Research Notes and Computer Codes (unpublished). 1982.

9. Dressen, D. R., E. J. Cokal, P. D. O'Brien, E. F. Thode, L. E. Wangen, and J. M. Williams. Uranium Mill Tailings Conditioning Technology. Proceedings of a Symposium: Management of Wastes from Uranium Mining and Milling. Albuquerque, NM, May, 1982. IAEA and NEA.

10. Langmuir, D. Uranium Solution-Mineral Equilibria at Low Temperatures with Applications to Sedimentary Ore Deposits. Geochim. Cosmochim. Acta, Vol. 42, 1978, pp. 547-569.

11. Dement'yer, V. S. and N. G. Syromyatnikov. Conditions of Formation of a Sorption Barrier to the Migration of Uranium in an Oxidizing Environment. Geochemistry International, Vol. 5, 1968, pp. $394 \ldots 399$. 
REFERENCES

(Continued)

12. Bell, K. G. Deposition of Uranium in Salt-Pan Basins. USGS Prof. Paper 354-G, 1960, pp. 161-169.

13. Brown, J. R., W. S. Fyfe, F. Murray, and B. I. Kronberg. Immobilization of U-Th-Ra in Mine Wastes. Canadian Mining Journai, Vol. 102, No. 3, 1981, pp. 71-76.

14. Landa, E. Isolation of Uranium Mill Tailings and Their Component Radionuclides from the Biosphere - Some Earth Science Perspectives. Geological Survey Circular 814, 1980.

15. Shearer, Jr., S. D., and G. F. Lee. Leachability of Radium-226 from Uranium Mill Solids and River Sediments. Health Physics, Vol. 10, 1964, pp. 217-227.

16. Havlik, B., B. Nycova, and J. Grafova. Radium-226 Liberation from Uranium Ore Processing Mill Waste Solids and Uranium Rocks into Surface Streams - II. Health Physics, Vol. 14, 1968, pp. 423-430.

17. Havlik, B., B. Nycova, and J. Grafova. Radium-226 Liberation from Uranium Ore Processing Mill Waste Solids and Uranium Rocks into Surface Streams - 1. Health Physics, Vol. 14, 1968, pp. 417-422.

18. Ring, R. J., D. M. Levins, and F. J. Gee. Radionuclides in Process and Waste Streams at an Operating Uranium Mill. Proceedings of a Symposium Management of Wastes from Uranium Mining and Milling. Albuquerque, NM, May, 1982. IAEA and NEA.

19. United States Environmental Protection Agency. Radionuclide Interactions with Soil and Rock Media. Volume I: Processes Influencing Radionuclide Mobility and Retention, Element Chemistry and Geochemistry, Conclusions and Evaluation. EPA 52016-78-007, Office of Radiation Programs, Las Vegas, NV, Facility, 1978.

20. Lindsey, W. L. Chemical Equilibria in Soils. Wiley-Interscience, New York, 1979. 


\section{APPENDIX A}

METHODS USED BY BENDIX FIELD ENGINEERING CORPORATION FOR CHEMICAL AND ISOTOPIC ANALYSIS 
APPENDIX A

METHODS USED BY BENDIX FIELD ENGINEERING CORPORATION

FOR CHEMICAL AND ISOTOPIC ANALYSIS

WATER AND HCl EXTRACTS:

\section{Determination}

Aluminum

Aresenic

Barium

Calcium

Cadmium

Cobalt

Chromium

Iron

Potassium

Magnesium

Manganese

Molybdenum

Sodium

Nickel

Lead

Selenium

Silicon

Strontium

Uranium (total)

Vanadium

Chloride

Fluoride

Phosphate

Sulfate

Thorium (total)

210 Lead
226 Radium

$$
\begin{aligned}
& \text { EPA }^{2}-206.2 \\
& \text { EPA }-208.1 \\
& \text { EPA }-215.1 \\
& \text { EPA }-213.2 \\
& E P A-219.2 \\
& E P A=218.2 \\
& E P A-236.1 \\
& E P A-258.1 \\
& E P A-242.1 \\
& E P A-243.2 \\
& E P A-273.1 \\
& E P A-249.2 \\
& E P A-239.2 \\
& E P A-270.2
\end{aligned}
$$

\section{SOILS OR TAILINGS:}

Aluminum

Silicon

Iron

Manganese

Potassium

Uranium

210 Radium

210 Lead

230 Thorium

234 Thorium

234 Uranium
23 Uranium

$E P A-904.0^{9}$
Method

Inductively Coupled Plasma Emission ${ }^{2}$

Heated Graphite - Atomic Absorption

Flame Atomic Absorption

Flame Atomic Absorption

Heated Graphite - Atomic Absorption

Heated Graphite - Atomic Absorption

Heated Graphite - Atomic Absorption

Flame Atomic Absorption

Flame Atomic Absorption

Heated Graphite - Atomic Absorption

Heated Graphite - Atomis Absorption

Inductively Coupled Plasma Emission

Flame Atomic Absorption

Heated Graphite - Atomic Absorption

Heated Graphite - Atomic Absorption

Heated Graphite - Atomic Absorption

Inductively Coupled Plasma Emişsion

Atomic Absorption Spectrometry

Fluorometric with Scintrex UA- $3^{4}$

Inductively Coupled Plasma Emission

Ion Chromatography 5

Ion Chromatography

Standard Methods--Colorimetric--Method $424^{6}$

Ion Chromatography

Inductively Coupled Plasma Emission After

Solvent Extraction

Liquid Scintillation Counting ${ }^{8}$

Atomic Absorption Spectroscopy 10

Atomic Absorption Spectroscopy

Atomic Absorption Spectroscopy

Atomic Absorption Spectroscopy

Atomic Absorption Spectroscopy

Fused-Pellet-Fluorometric

Gama Spectroscopy

Liquid Scintillation Counting ${ }^{8}$

Alpha Spectroscopy

Alpha Spectroscopy

Alpha Spectroscopy

Alpha Spectroscopy 


\section{FOOTNOTES}

1

ICP/5000 Inductively Coupled Plasma System. Perkin-Elmer Corporation, January 1981.

Winge, R. K., Peterson, J. V., and V. A. Fassel, 1979, Inductively Coupled Plasma--Atomic Emission Spectroscopy: Prominent Lines, Applied Spectroscopy, Vol. 33, No. 3.

2

United States Environmental Protection Agency, Methods for Chemical Analysis of Water and Wastes, EPA-600/4-79-020.

3

United States Geological Survey, Techniques of Water-Resources Investigations of the United States Geological Survey, Book, Chapter A1, Methods for Determination of Inorganic Substances in water ind Fluvial Sediments, Shangstad, M. W., Fishman, M. J., Friedman, L. C., Erdmann, D. E., and S. S. Durican, editors. U.S. Government Printing Office, 1979.

Korte, N. E. and R. B. Chessmore, 1980, Interference Effects of Inorganic Ions in Natural Waters When Using the Scintrex UA-3 Uranium Analyzer. United States Department of Energy Open-File Report, GJBX-109(80).

5

Swee, B. W., Hall, G. E. M., and D. J. Koop, 1978, Analysis of Fluoride, Chloride, Nitrate, and Sulphate in Natural Waters Using Ion Chromatography, Journal of Geochemical Exploration, Vol. 10, pp. 245258.

6

American Public Health Association, American Water Works Association, Water Pollution Control Federation, 1981. Standard Methods for the Examination of Water and Wastewater, American Public Health Association, 1015 Fifteenth Street, N.W. "Washington, DC 20005.

7

Extraction and ICP parameters are detailed in - Korte, N., Hollenbach, M., and S. Donivan, 1983, The Determination of $U, T h, Y, Z r$, and $H f$ in Zircon, Analytica Chimica Acta, Vol. 146, pp. 267-270.

Fairman, W. D. and J. Sedlet, 1968, Direct Determination of Lead-210 by Liquid Scintillation Counting, Analytical Chemistry, Vol. 40, No. 13, p. 2004.

9

United States Environmental Protection Agency, Prescirbed Procedures for Measurement of Radioactivity in Drinking Water, EPA-600/4-80-032.

10

Samples dissolved by acid digestion. Analysis follows procedures in reference 2 .

11 Centanni, F. A., Russ, A. M. and M. A. DeSesa, 1956, Fluorometric Determination of Uranium: Analytical Chemistry, Vol. 28, pp. 16511657 . 


\section{FOOTNOTES (CONTINUED)}

12

Gamma Spectroscopy Manual in preparation. Method Summary: Samples are grgund and sealed in a can for 20 days to permit daughter in-growth. $\mathrm{Ra}$ is quantitated based on gamma emission from $214 \mathrm{Bi}$.

13

Donivan, S., Hollenback, M. and N. Korte, 1982, The Determination of Uranium and Thorium Isotopes in Water, Rock, and Soll Samples by Alpha Spectrometry. United States Department of Energy, Open-File Report, GJBX-121(82). Specific details of our procedures are listed in our procedure manual. The manual is undergoing revision currently. Copies should be available in September, 1983. 


\section{APPENDIX B}

CHEMICAL DATA FROM RIVERTON TAILINGS SITE 


\section{APPENDIX B}

CHEMICAL DATA FROM RIVERTON TAILINGS SITE

Table B-1. Data for Solid Samples: Riverton, Wyoming Table B-2. Data for Water Extracts: Riverton, Wyoming Table B-3. Data for $\mathrm{HCl}$ Extracts: Riverton, Wyoming

\section{NOTES ON APPENDIX}

The locations of the site numbers are shown on Figure 1 of the text. Descriptions of the three-digit codes for sample types in the data tables are as follows:

$\begin{array}{ll}120 & \text { TAILINGS - solid } \\ 130 & \text { TAILINGS - water extract } \\ 140 & \text { TAILINGS - HCl extract } \\ 520 & \text { COVER - solid } \\ 530 & \text { COVER - water extract } \\ 540 & \text { COVER - HCl extract }\end{array}$


TAELE B-1 [lata for salid samples; RIVEFTON, WYOMING

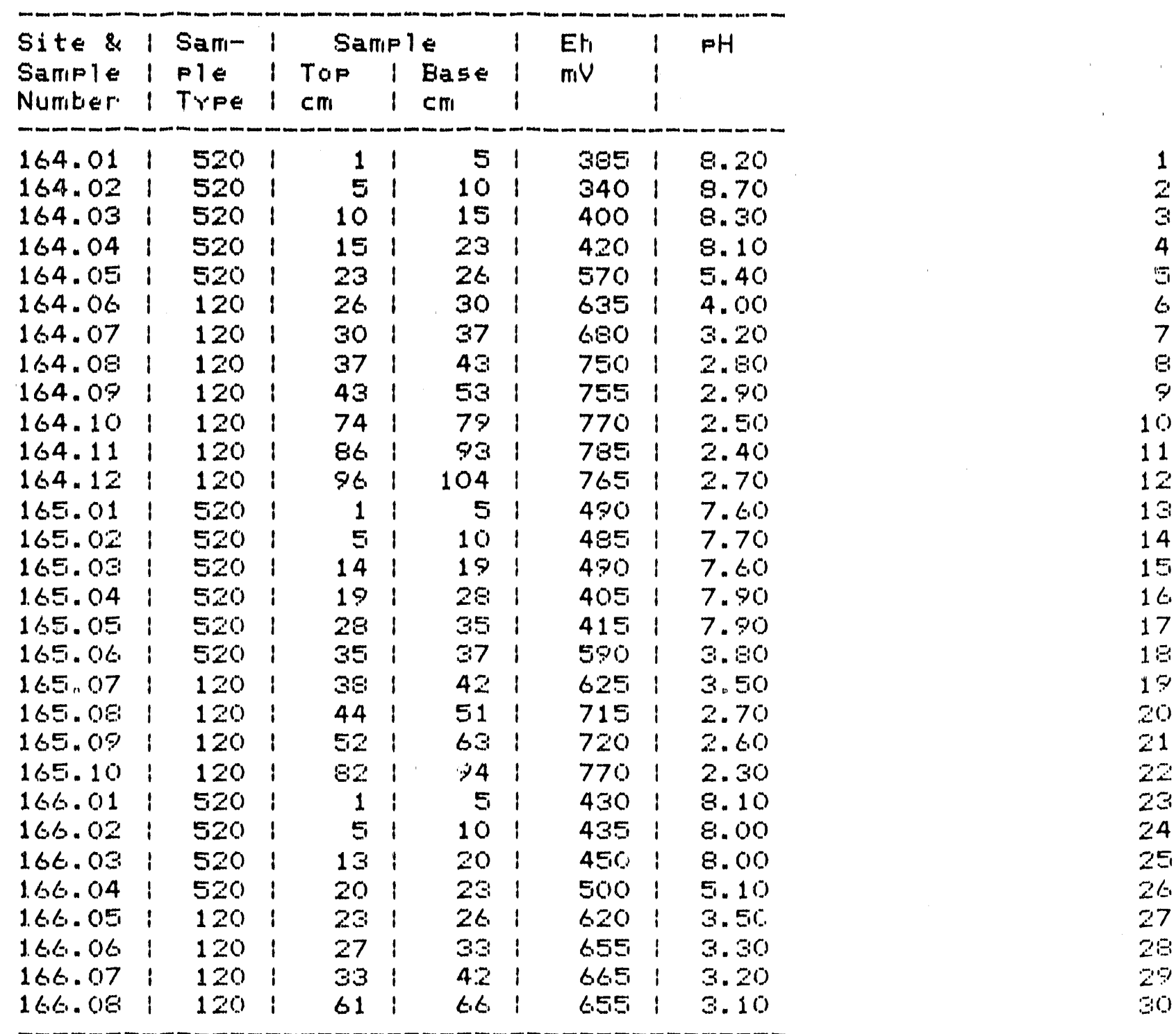

NOTE: Zero value indicates ria determiration was made. 
TABLEB-1 (continuation)

\begin{tabular}{|c|c|c|c|c|c|c|c|c|c|c|}
\hline $\begin{array}{c}A 1 \\
u g / 9\end{array}$ & 1 & $\begin{array}{c}S i \\
\omega g / g\end{array}$ & 1 & $\begin{array}{c}\mathrm{Fe} \\
\mathrm{ug} / \mathrm{g}\end{array}$ & $\begin{array}{l}1 \\
1\end{array}$ & $\begin{array}{c}M r_{1} \\
u g / g\end{array}$ & $\begin{array}{l}1 \\
1 \\
1\end{array}$ & $\begin{array}{c}K \\
u g / g\end{array}$ & $\begin{array}{l}1 \\
1 \\
1\end{array}$ & \\
\hline $6.32 E+004$ & 1 & $3.21 E+005$ & 1 & $2.37 E+0014$ & 1 & $3.70 E+002$ & 1 & $2.17 E+004$ & 1 & 1 \\
\hline $6.15 E+004$ & 1 & $3.32 E+005$ & 1 & 2. $40 E+004$ & 1 & $3.95 \varepsilon+002$ & 1 & $2.05 E+004$ & 1 & 2 \\
\hline $6.42 E+004$ & 1 & $3.11 E+005$ & 1 & $2.41 E+004$ & $i$ & $3.90 E+002$ & $i$ & 2. $08 E+004$ & 1 & \\
\hline $6.36 E+004$ & 1 & $3.09 E+005$ & 1 & 2. $40 E+004$ & 1 & $3.90 E+002$ & 1 & $2.07 E+004$ & 1 & 4 \\
\hline+004 & 1 & $E+005$ & 1 & $2.47 E+004$ & 1 & $2.60 E+002$ & 1 & $2.68 E+004$ & 1 & 5 \\
\hline $5.72 E+004$ & 1 & 3.33E+005 & 1 & $2.22 E+004$ & 1 & $9.50 E+001$ & 1 & $3.16 E+004$ & 1 & 6 \\
\hline $5.58 E+004$ & 1 & $3.29 E+005$ & 1 & 2. $80 E+0014$ & $i$ & $7.5 O E+001$ & 1 & $3.39 E+004$ & 1 & 7 \\
\hline $6.02 E+004$ & 1 & $3.16 \mathrm{E}+005$ & 1 & $3.76 E+004$ & 1 & 1. $40 E+002$ & 1 & $3.06 E+004$ & 1 & 8 \\
\hline $5.65 E+004$ & 1 & $3.27 E+005$ & 1 & $2.95 E+004$ & 1 & $1.20 E+002$ & 1 & $3.36 E+004$ & 1 & 9 \\
\hline $6.22 E+004$ & 1 & 3. $26 E+005$ & 1 & 1. $38 E+0014$ & 1 & $8.00 E+001$ & 1 & 3. $16 . E+004$ & 1 & 0 \\
\hline $6 E+004$ & 1 & $2.62 E+005$ & 1 & $2.78 E+0044$ & ! & $1.65 E+002$ & 1 & $2.42 E+0014$ & 1 & 1 \\
\hline 5. $010 E+004$ & 1 & 3. $82 E+005$ & 1 & 2. $80 E+003$ & 1 & 4. $00 E+001$ & 1 & $3.63 E+00.4$ & 1 & 12 \\
\hline $6.49 E+0014$ & 1 & $3.11 E+005$ & 1 & $2.31 E+004$ & 1 & $3.60 E+002$ & 1 & $2.22 E+004$ & 1 & 13 \\
\hline $6.57 E+0014$ & 1 & $3.12 E+005$ & 1 & $2.29 E+004$ & 1 & $3.40 E+002$ & 1 & $2.27 E+004$ & i & 14 \\
\hline $6.52 E+004$ & 1 & $3.16 \mathrm{E}+005$ & 1 & $2.31 E+004$ & 1 & $3.35 E+002$ & 1 & $2.27 E+004$ & 1 & 15 \\
\hline $6.40 E+004$ & 1 & $3.20 E+005$ & 1 & $2.43 E+004$ & i & $3.65 E+002$ & 1 & $2.20 E+0014$ & 1 & 16 \\
\hline $6.18 E+0014$ & 1 & $3.28 E+005$ & 1 & $2.11 E+004$ & 1 & $3.30 E+002$ & 1 & $2.34 E+004$ & 1 & 17 \\
\hline $6.32 E+004$ & $i$ & $3.07 E+005$ & i & $2.56 E+0014$ & i & $2.20 E+002$ & 1 & $2.49 E+004$ & 1 & 19 \\
\hline $5.80 E+0$ & 1 & $3.46 E+005$ & 1 & $1.44 E+004$ & 1 & $8.50 E+001$ & 1 & $3.18 E+004$ & 1 & 19 \\
\hline $7.72 E+0014$ & 1 & $3.13 E+005$ & 1 & $1.78 E+004$ & 1 & $9.50 E+0011$ & 1 & $3.03 E+004$ & 1 & 20 \\
\hline $7.77 E+004$ & $i$ & $3.13 E+005$ & 1 & $1.65 E+004$ & $!$ & $9.00 E+001$ & 1 & $3.22 E+004$ & 1 & 21 \\
\hline $8.65 E+004$ & 1 & $2.83 E+005$ & 1 & $2.91 E+004$ & 1 & $1.10 E+002$ & 1 & $2.57 E+004$ & 1 & 22 \\
\hline $6.32 E+004$ & $i$ & $3,16 E+005$ & 1 & $2.36 E+004$ & 1 & $3.75 E+002$ & 1 & $2.08 E+004$ & 1 & 23 \\
\hline $6.40 E+004$ & 1 & $3.10 E+005$ & 1 & 2. $36 E+004$ & 1 & $3.95 E+002$ & i & $2.00 E+004$ & 1 & 24 \\
\hline $6.42 E+004$ & 1 & $3.16 E+005$ & 1 & $2.25 E+004$ & 1 & $3.65 E+002$ & i & 2. $08 E+0104$ & 1 & 25 \\
\hline $6.76 E+004$ & 1 & $2.87 E+005$ & 1 & $2.56 E+004$ & ! & $3.10 E+002$ & i & $2.28 E+004$ & 1 & $2 t$ \\
\hline $8.14 E+004$ & 1 & $2.84 E+005$ & 1 & $2.82 E+004$ & 1 & 8. $00 E+001$ & 1 & $2.35 E+004$ & 1 & 27 \\
\hline 8. $60 E+004$ & 1 & $2.77 E+005$ & 1 & $3.52 E+004$ & i & $7.00 E+001$ & 1 & $2.47 E+004$ & $i$ & 28 \\
\hline $6.99 E+004$ & 1 & $3.45 E+005$ & 1 & $9.50 E+003$ & i & $5.50 E+001$ & ! & $3.35 E+0014$ & 1 & 29 \\
\hline $9.90 E+0014$ & 1 & $2.69 E+005$ & $i$ & $3.53 E+004$ & i & $9.50 E+001$ & i & $2.12 E+004$ & 1 & 30 \\
\hline
\end{tabular}




\begin{tabular}{|c|c|c|c|}
\hline $\begin{array}{c}u \\
u g / g\end{array}$ & 1 & $\begin{array}{c}\text { Th-Total } \\
\text { ug/g }\end{array}$ & $\begin{array}{l}1 \\
1 \\
1\end{array}$ \\
\hline $7.20 E+001$ & 1 & 1. $10 E+001$ & 1 \\
\hline 5. $10 E+001$ & 1 & 1. $90 \mathrm{E}+001$ & 1 \\
\hline $3.30 E+001$ & 1 & $1.20 E+001$ & 1 \\
\hline 4. $50 E+001$ & 1 & 1. $90 E+001$ & 1 \\
\hline $1.33 E+002$ & 1 & $1.90 E+001$ & 1 \\
\hline $7.80 E+001$ & 1 & 1. $70 E+001$ & 1 \\
\hline $6.60 E+001$ & 1 & 1. $10 E+001$ & 1 \\
\hline $1.06 E+002$ & 1 & $1.30 E+001$ & 1 \\
\hline $6.30 E+001$ & 1 & 1. $00 E+001$ & 1 \\
\hline $1.00 E+002$ & 1 & $1.30 E+001$ & 1 \\
\hline $1.63 E+002$ & 1 & 1. $70 E+001$ & 1 \\
\hline $1.80 E+001$ & 1 & 1. $10 E+001$ & 1 \\
\hline 1. $00 E+001$ & 1 & 2. $10 E+001$ & 1 \\
\hline $2.20 E+001$ & 1 & 1. $30 E+001$ & $i$ \\
\hline 1. $60 E+001$ & 1 & 1. $40 E+001$ & 1 \\
\hline 1. $50 E+001$ & 1 & $2.20 E+001$ & 1 \\
\hline 1. $60 E+001$ & 1 & 1. $60 E+001$ & 1 \\
\hline $9.00 E+001$ & $i$ & 2. 80E+0101 & $i$ \\
\hline $3.30 E+001$ & 1 & $8.00 E+000$ & 1 \\
\hline $6.90 E+001$ & 1 & 1. $20 E+001$ & 1 \\
\hline $7.20 E+001$ & 1 & 1. $40 E+001$ & 1 \\
\hline $1.24 E+002$ & 1 & 1. $90 E+001$ & 1 \\
\hline $8.00 E+000$ & $i$ & 1. $80 E+001$ & 1 \\
\hline $7.00 E+000$ & 1 & $2.00 E+001$ & i \\
\hline $9.00 E+000$ & 1 & 1. $50 E+001$ & 1 \\
\hline $8.10 E+001$ & 1 & $2.20 E+001$ & 1 \\
\hline 1. $06 E+002$ & i & $1.80 E+001$ & 1 \\
\hline $1.06 E+002$ & 1 & $1.80 E+001$ & $i$ \\
\hline $4.80 E+001$ & 1 & $O O E+C O D 1$ & $i$ \\
\hline $1.75 E+002$ & 1 & $4.00 E+001$ & 1 \\
\hline
\end{tabular}


TABLE B-1(continuation)

\begin{tabular}{|c|c|c|c|c|c|c|c|c|}
\hline $\begin{array}{r}\mathrm{Ra}-226 \\
\mathrm{pC1/g}\end{array}$ & $\begin{array}{l}1 \\
1 \\
1\end{array}$ & $\begin{array}{r}T h-230 \\
\mathrm{pCi} / \mathrm{g}\end{array}$ & 1 & $\begin{array}{r}\mathrm{Pb}-210 \\
\mathrm{pCt} / \mathrm{g}\end{array}$ & 1 & $\begin{array}{l}\mathrm{U}-234 \\
\mathrm{pCi} / \mathrm{g}\end{array}$ & 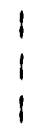 & $\begin{array}{l}U-238 \\
\mathrm{pCi} / \mathrm{g}\end{array}$ \\
\hline 001 & 1 & $E+001$ & & $E+001$ & 1 & $2.20 E+001$ & 1 & $E+001$ \\
\hline 001 & 1 & +001 & & +001 & . & 1 & . & 01 \\
\hline 001 & 1 & +000 & & $E+001$ & 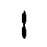 & $0 E+000$ & 1 & +001 \\
\hline 000 & 1 & $E+001$ & & $E+001$ & 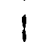 & $40 E+001$ & . & $E+001$ \\
\hline 002 & 1 & $=002$ & & +002 & 1 & $E+001$ & 1 & +001 \\
\hline 002 & 1 & +002 & & +002 & 1 & $O E+001$ & 1 & +001 \\
\hline 002 & 1 & +001 & & $E+002$ & 1 & $50 E+001$ & 1 & $E+001$ \\
\hline 002 & 1 & & & $E+002$ & 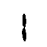 & $70 E+001$ & & +001 \\
\hline 002 & 1 & +001 & & +002 & 1 & +001 & 1 & +001 \\
\hline 002 & 1 & +001 & & +002 & 1 & $3.70 E+001$ & 1 & +001 \\
\hline 002 & 1 & $E+002$ & & $E+002$ & 1 & $O E+001$ & 1 & +001 \\
\hline 002 & 1 & & & +002 & 1 & 00 & & 1000 \\
\hline 001 & 1 & +001 & & +001 & 1 & $=000$ & & +000 \\
\hline 6.8 & 1 & +001 & & $E+001$ & 1 & $8.00 E+000$ & 1 & +000 \\
\hline-001 & 1 & 001 & & 1 & 1 & $=000$ & & +000 \\
\hline 001 & 1 & & & 1 & 1 & 00 & & .000 \\
\hline 0,01 & 1 & 1.2. & 1 & 1 & 1 & 00 & & +000 \\
\hline 002 & 1 & +002 & & $5+002$ & 1 & $.50 E+001$ & & +001 \\
\hline .002 & 1 & +001 & & $E+002$ & 1 & $70 E+001$ & & $E+001$ \\
\hline 002 & 1 & & & $E+002$ & 1 & $30 E+001$ & & +001 \\
\hline .002 & 1 & & & 2 & 1 & 11 & & 001 \\
\hline 0002 & 1 & 3. & & 2 & 1 & $7.40 E+001$ & & +001 \\
\hline+001 & 1 & +001 & & $E+001$ & 1 & $3.30 E+000$ & $i$ & $2.70 E+000$ \\
\hline+001 & 1 & & 1 & 1. & & & & 000 \\
\hline 004 & 1 & 1. & & 1. & 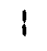 & 0 & & +000 \\
\hline+002 & 1 & +002 & 1 & $3.51 E+002$ & 1 & $3.30 E+001$ & & +001 \\
\hline .003 & 1 & 2 & & $E+C$ & 1 & $6.20 E+001$ & & $E+001$ \\
\hline+002 & 1 & & & $E+C$ & r & $80 E+101$ & & $E+001$ \\
\hline+002 & 1 & $=0022$ & & $E+002$ & 1 & $3.00 E+001$ & & $E+001$ \\
\hline+002 & 1 & $E+002$ & & $E+002$ & & 7. $600 E+001$ & & $5.80 E+001$ \\
\hline
\end{tabular}


TAELE B-2 Data for water extracts; RIVERTON, WYOMING

\begin{tabular}{|c|c|c|c|c|c|c|c|c|c|c|c|}
\hline $\begin{array}{l}\text { Site \& } \\
\text { Sample } \\
\text { Number }\end{array}$ & i & $\begin{array}{l}\text { Sam- } \\
\text { Ple } \\
\text { Trpe }\end{array}$ & $\begin{array}{l}i \\
i\end{array}$ & $\begin{array}{l}\text { Sal } \\
\text { Top } \\
\mathrm{cm}\end{array}$ & $\begin{array}{l}\text { np } 1 \\
! \\
!\end{array}$ & $\begin{array}{l}\text { Ease } \\
\text { cm }\end{array}$ & $\begin{array}{l}i \\
i \\
i\end{array}$ & $\begin{array}{l}\text { Eh } \\
\text { mV }\end{array}$ & $\begin{array}{l}i \\
i \\
i\end{array}$ & $\mathrm{PH}$ & \\
\hline 164.01 & $i$ & 530 & $i$ & 1 & ! & 5 & $i$ & 410 & i & 7.90 & 1 \\
\hline 164.02 & $i$ & 530 & $i$ & 5 & $i$ & 10 & i & 385 & i & 8.10 & 2 \\
\hline 164.03 & $i$ & 530 & : & 10 & $i$ & 15 & $i$ & 370 & $i$ & 8.00 & 3 \\
\hline 164.04 & $i$ & 530 & $i$ & 15 & $i$ & 23 & $i$ & 355 & $i$ & 7.80 & 4 \\
\hline 164.05 & i & 530 & $i$ & 23 & 1 & 26 & $i$ & 455 & i & 6.50 & 5 \\
\hline 164.06 & i & 130 & $!$ & 26 & $i$ & 30 & $i$ & 535 & $i$ & 4.00 & $\theta$ \\
\hline 164.07 & i & 130 & $i$ & 30 & 1 & 37 & $i$ & 670 & i & 3.20 & 7 \\
\hline 164.08 & i & 130 & 1 & 37 & 1 & 43 & $i$ & 700 & i & 2.80 & 8 \\
\hline 164.09 & i & 130 & $i$ & 43 & $i$ & 53 & i & 710 & $i$ & 2.80 & 9 \\
\hline 164.10 & i & 130 & $i$ & 74 & $i$ & 79 & i & 715 & i & 2.30 & 10 \\
\hline 164.11 & $i$ & 130 & $i$ & 86 & $i$ & 93 & i & 715 & $i$ & 2.30 & 11 \\
\hline 164.12 & i & 130 & $i$ & 96 & $i$ & 104 & $i$ & 715 & $i$ & 2.50 & 12 \\
\hline 165.01 & ! & 530 & $i$ & 1 & $i$ & 5 & $i$ & 435 & $i$ & 7.90 & 13 \\
\hline 165.02 & i & 530 & $i$ & 5 & i & 10 & i & 440 & $i$ & 7.80 & 14 \\
\hline 165.03 & i & 530 & i & 14 & i & 19 & i & 410 & $i$ & 7.70 & 15 \\
\hline 165.04 & i & 530 & i & 19 & $i$ & 28 & $i$ & 405 & i & 7.80 & 16 \\
\hline 165.05 & i & 530 & i & 28 & $i$ & 35 & $i$ & 470 & $i$ & 7.60 & 17 \\
\hline 165.06 & i & 530 & $i$ & 35 & $i$ & 37 & $!$ & 540 & $i$ & 4.20 & 18 \\
\hline 165.07 & i & 130 & i & 38 & $i$ & 42 & i & 620 & $i$ & 3.50 & 19 \\
\hline 165.08 & i & 130 & i & 44 & $i$ & 51 & i & 695 & i & 2.70 & 20 \\
\hline 165.09 & i & 130 & i & 52 & $i$ & 63 & i & 700 & $i$ & 2.50 & 21 \\
\hline 165.10 & i & 130 & i & 82 & i & 94 & $!$ & 740 & $i$ & 2.20 & 22 \\
\hline 166.01 & i & 530 & $i$ & 1 & i & 5 & $i$ & 380 & ! & 8.10 & 23 \\
\hline 166.02 & i & 530 & i & 5 & $i$ & 10 & $i$ & 385 & i & 8.10 & 24 \\
\hline 166.03 & i & 530 & $i$ & 13 & i & 20 & ! & 380 & ! & 7.80 & 25 \\
\hline 166.04 & i & 530 & i & 20 & i & 23 & i & 465 & i & 6.20 & 26 \\
\hline 166.05 & $\mathbf{i}$ & 130 & i & 23 & i & 26 & i & 635 & i & 3.20 & 27 \\
\hline 166.06 & i & 130 & $i$ & 27 & i & 33 & i & 655 & i & 3.00 & 28 \\
\hline 166.07 & i & 130 & $i$ & 33 & 1 & 42 & i & 655 & i & 3.10 & 29 \\
\hline 166.08 & i & 130 & $i$ & 61 & i & 66 & i & 635 & ! & 2.80 & 30 \\
\hline
\end{tabular}

NOTE: Zero value indicates no determination was made. Negative sign indicates below analytical detection limit. 
TABLEB-2(coritiruation)

\begin{tabular}{|c|c|c|c|c|c|c|c|c|c|c|}
\hline $\begin{array}{c}A 1 \\
u \Omega / g\end{array}$ & $\vdots$ & $\begin{array}{c}\text { As } \\
U g / 9\end{array}$ & $\begin{array}{l}: \\
i \\
i\end{array}$ & $\begin{array}{c}\mathrm{Ba} \\
\mathrm{ug} / \mathrm{g}\end{array}$ & 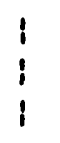 & $\begin{array}{c}\mathrm{Ca} \\
\mathrm{ug} / \mathrm{g}\end{array}$ & $:$ & $\begin{array}{c}C d \\
\cup g / g\end{array}$ & 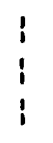 & \\
\hline 000 & i & 01 & $i$ & 001 & i & $E E+003$ & $\mathbf{i}$ & $-1.00 E-001$ & 1 & 1 \\
\hline-1 & $i$ & 01 & $i$ & 01 & $i$ & $O E+002$ & i & $-1.00 E-001$ & $\boldsymbol{r}$ & \\
\hline-1. & $i$ & $1.60 E-001$ & $i$ & $4.00 E-001$ & $i$ & $7.90 E+002$ & $i$ & $-1.00 E-001$ & $i$ & 3 \\
\hline$-1.0 O E+000$ & $i$ & $-1.00 E-001$ & $i$ & $3.30 E-001$ & $i$ & $2.68 E+003$ & $i$ & $-1.00 E-001$ & $i$ & \\
\hline$-1.0 O E+O O O$ & $i$ & $-1.00 E-001$ & i & $2.10 E-001$ & i & $50 E+003$ & $i$ & $-1.00 E-001$ & $i$ & 5 \\
\hline 1.8 & 1 & $1.60 E-001$ & i & 1. $6 O E-001$ & $i$ & 5. $80 E+003$ & $i$ & $-1.00 E-001$ & $i$ & \\
\hline 5.5 & $i$ & 7.6OE-001 & $i$ & $-1.00 E-001$ & $i$ & $5.80 E+003$ & $i$ & $-1.00 E-001$ & $i$ & \\
\hline 1.6 & $i$ & $1.45 E+000$ & $i$ & $1.20 E-001$ & $i$ & $5.40 E+003$ & $!$ & $-1.00 E-001$ & $i$ & 8 \\
\hline 1. $20 E+003$ & $i$ & $9.60 E-001$ & $i$ & $1.20 E-001$ & $i$ & $5.60 E+003$ & $i$ & $-1.00 E-001$ & $i$ & 9 \\
\hline 603 & $i$ & $O E+001$ & $i$ & $\bar{E}-001$ & $i$ & +003 & $i$ & $O E-001$ & $i$ & 10 \\
\hline $3.90 E+003$ & $i$ & 2. $10 E+001$ & $i$ & $-1.00 E-001$ & i & 4. $20 E+003$ & $i$ & $E-001$ & $i$ & 11 \\
\hline+002 & $i$ & $7.30 E+000$ & i & $1.90 E-001$ & $i$ & $=003$ & ; & $-1.00 E-001$ & i & 12 \\
\hline$E+O 0 O$ & $i$ & $\overline{D E}-001$ & $i$ & $6.90 E-001$ & ! & $8.30 E+002$ & i & $-1.00 E-001$ & $i$ & 13 \\
\hline$-1.00 E+000$ & $i$ & 7. $30 E-001$ & i & $3.70 E-001$ & i & $5.30 E+003$ & $i$ & $-1.00 E-001$ & 1 & 14 \\
\hline$-1.00 E+000$ & $i$ & $6.50 E-001$ & i & $2.40 E-001$ & $i$ & $5.20 E+003$ & $i$ & $-1.00 E-001$ & 1 & 15 \\
\hline$-1.00 E+000$ & $i$ & -001 & $i$ & 1.8 & $i$ & 4. & $i$ & -1 & $i$ & 16 \\
\hline$-1.00 E+000$ & 1 & $2.50 E-001$ & $i$ & $2.10 E-001$ & i & 3.2 & 1 & -1 & $i$ & 17 \\
\hline 2.00 & 1 & $8.00 E-002$ & $i$ & -001 & $i$ & $5.10 E+003$ & $i$ & $-1.00 E-001$ & $i$ & 18 \\
\hline 4. $00 E+00 Z$ & $i$ & $5.50 E-001$ & i & $-1.00 E-001$ & $i$ & $5.40 E+003$ & $i$ & $-1.00 E-001$ & $i$ & $1 \%$ \\
\hline 1. $6 O E+003$ & $i$ & 1. $38 E+000$ & $i$ & $-1.0 Q E-001$ & i & $4.84 E+003$ & $i$ & $-1.00 E-001$ & $i$ & 20 \\
\hline $2.40 E+003$ & $i$ & 1.96E+000 & $i$ & $-1.00 E-001$ & $i$ & $4.15 E+003$ & $i$ & $-1.00 E-001$ & $i$ & 21 \\
\hline $3.20 E+003$ & 1 & $105+001$ & ! & $-1.00 E-001$ & $i$ & $=003$ & $i$ & $=-001$ & 1 & 20 \\
\hline$-1.00 E+000$ & 1 & $1.60 E-001$ & i & $7.20 E-001$ & $i$ & +002 & $i$ & $-1.00 E=001$ & 1 & 23 \\
\hline$-1.00 E+000$ & $i$ & $1.10 E-001$ & i & $5.40 E-001$ & $i$ & $5.60 E+002$ & $i$ & $-1.00 E-001$ & $i$ & 24 \\
\hline$-1.00 E+000$ & $i$ & $-1.00 E-001$ & i & $2.90 E-001$ & i & $2.10 E+003$ & $!$ & $-1.00 E-001$ & i & 25 \\
\hline$-1.00 E+000$ & 1 & $-1.00 E-001$ & i & 1. 50E-001 & $i$ & $4.89 E+003$ & $i$ & $-1.00 E-001$ & 1 & 26 \\
\hline & $i$ & 3 ond and & & $-1.00 E-001$ & $!$ & $3.93 E+003$ & i & $-1.00 E-001$ & 1 & 27 \\
\hline & & & $i$ & & i 5 & 4.2 & $i$ & $-1.00 E-001$ & & $2 E$ \\
\hline$O O E+002$ & i & $3.60 E-001$ & i & $-1.00 E-001$ & $i$ & $5.40 E+003$ & $!$ & $-1.00 E-001$ & 1 & 29 \\
\hline $8.00 E+002$ & 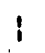 & $8.90 E-001$ & $i$ & $-1.00 E-001$ & $i$ & $4.38 E+003$ & ! & $-1.00 E-001$ & ! & 30 \\
\hline
\end{tabular}


TABLE B-2(continuation)

\begin{tabular}{|c|c|c|c|c|c|c|c|c|c|}
\hline $\begin{array}{c}C 1 \\
49 / 9\end{array}$ & $!$ & $\begin{array}{c}\mathrm{Ca} \\
\mathrm{ug} / \mathrm{g}\end{array}$ & $\begin{array}{l}: \\
\vdots \\
1\end{array}$ & $\begin{array}{c}\mathrm{Cr} \\
\mathrm{ug} / \mathrm{g}\end{array}$ & $\begin{array}{l}1 \\
1 \\
1\end{array}$ & $\begin{array}{c}F \\
u g / g\end{array}$ & $\begin{array}{l}\mathbf{1} \\
\mathbf{1} \\
\mathbf{z}\end{array}$ & $\begin{array}{c}F \theta \\
\omega g / g\end{array}$ & $\begin{array}{l}\mathbf{1} \\
\mathbf{1}\end{array}$ \\
\hline$-1.00 E+002$ & $i$ & -1 & i & $E-001$ & $!$ & 1. OOE +00O & $i$ & $-1.00 E+000$ & $i$ \\
\hline$-1.00 E+002$ & $i$ & $-1.00 E-001$ & $i$ & $-1.00 E-001$ & $i$ & 2. OOE +000 & i & $-1.00 E+000$ & $i$ \\
\hline$-1.00 E+002$ & in & $-1.00 E-001$ & $i$ & $-1.00 E-001$ & $i$ & $4.00 E+000$ & i & 1. $.00 E+000$ & $i$ \\
\hline$-1.00 E+002$ & $i$ & $-1.00 E-001$ & $i$ & $-1.00 E-001$ & $i$ & 4.0 & $i$ & $-1.00 E+000$ & $i$ \\
\hline$-1.0 \mathrm{OE}$ & $i$ & .001 & $i$ & 001 & $i$ & -1.0 & i & $-1.00 E+000$ & $i$ \\
\hline$-1.00 E+002$ & $i$ & $.20 E-001$ & i & $-1.00 E-001$ & $i$ & 4. OOEt & 1 & 1. $.00 E+000$ & 1 \\
\hline$-1.00 E+002$ & 1 & $9.10 E-001$ & $!$ & 001 & i & 0 & 1 & 01 & 1 \\
\hline$-1.00 E+002$ & 1 & 2. $27 E+000$ & i & 1. $13 E+000$ & $i$ & -1.0 & i & 02 & $i$ \\
\hline$-1.00 E$ & $i$ & $1.77 E+000$ & i & 1. $.02 E+000$ & $i$ & 1.00 & $i$ & 1. $.59 E+002$ & $i$ \\
\hline $1.0 O E$ & $i$ & 4. $3 S E+000$ & $i$ & $3.63 E+000$ & $i$ & -1.0 & i & $=003$ & 1 \\
\hline$-1.00 E+002$ & $i$ & $5.70 E+000$ & $i$ & \%. 16E+000 & i & $-1 \cdot c$ & i & +003 & 1 \\
\hline$-1.0 O E$ & $i$ & $7.20 E-001$ & i & $6.50 E$ & i & -1.00 & $i$ & 1. $63 E+003$ & $i$ \\
\hline$-1.00 \mathrm{E}$ & 1 & $-1.00 E-001$ & $i$ & $-1.00 E-001$ & $i$ & 2.00 & i & $-1.00 E+000$ & ! \\
\hline$-1.00 E+002$ & $i$ & $-1.00 E-001$ & $i$ & $-1.00 \bar{E}-001$ & $i$ & $4.00 E+00 O$ & i & $1.00 E+000$ & 1 \\
\hline$-1.00 E$ & $!$ & $-1.00 E-001$ & i & $-1.00 E$ & $i$ & $3.00 E+000$ & i & $-1.00 E+000$ & $i$ \\
\hline $3.50 E+002$ & $i$ & $-1.0 O E-001$ & i & $-1.00 E-001$ & $i$ & $3.0 O E+000$ & i & $-1.00 E+000$ & 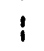 \\
\hline $3.10 E+002$ & $i$ & $-1.00 E-001$ & 1 & $-1.00 E-001$ & i & $4.00 E+000$ & i & $-1.00 E+000$ & $i$ \\
\hline $7.70 E+002$ & $i$ & $7.50 E-001$ & 1 & $-1.00 E-001$ & $\mathbf{i}$ & 7.0 & i & $E+000$ & i \\
\hline $5.30 E$ & $i$ & 7. & i & 2. & $i$ & 3. & i & 00 & $!$ \\
\hline 1. $33 E$ & $i$ & $2 n 39 E+C$ & $i$ & 1. B1Et & i & 4.0 & ! & $7.20 E+001$ & $!$ \\
\hline 5.600 & i & $3.12 E+$ & i & $2.93 E-1$ & i & $3.00 E+000$ & i & $1.50 E+002$ & ! \\
\hline $2.10 \mathrm{E}$ & $i$ & G. $84 E+000$ & $i$ & $6.59 \mathrm{E}+$ & $i$ & $-1.00 E+000$ & 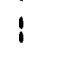 & $2.08 E+003$ & i \\
\hline$-1.00 E+002$ & $i$ & $-1.00 E-001$ & $i$ & $-1.00 E-001$ & $i$ & 2. OOE +000 & i & $-1.00 E+000$ & i \\
\hline$-1.00 E+002$ & $i$ & $-1.00 E-001$ & $!$ & $-1.00 E-001$ & 1 & $6.00 E+000$ & i & $1.00 E+000$ & i \\
\hline$-1.00 E+002$ & $i$ & $-1.00 E-001$ & $i$ & $-1.00 E-001$ & i & 1. $20 E+001$ & i & $-1.00 E+000$ & i \\
\hline$-1.00 E+002$ & $i$ & $-1.00 E-001$ & 1 & $-1.00 E-001$ & 1 & 1. $.00 E+000$ & i & $-1.00 E+000$ & i \\
\hline$-1.00 E+002$ & $i$ & $9.201 E-001$ & $i$ & $2.80 E-001$ & 1 & 4. OOE+OOO & i & $2.00 E+000$ & 1 \\
\hline$-1.00 E+002$ & 1 & 1. $50 E+000$ & ! & $5.00 E-001$ & i & $4.00 E+000$ & i & $5.00 E+000$ & i \\
\hline$-1.00 E+002$ & $i$ & $9.60 E-001$ & i & $3.40 E-001$ & ! & $3.00 E+000$ & $:$ & $5.00 E+000$ & i \\
\hline$-1.00 E+002$ & 1 & $2.10 E+000$ & i & $6.70 E-001$ & $\mathbf{i}$ & $4.00 E+000$ & i & $5.00 E+001$ & i \\
\hline
\end{tabular}


TABLEB-2 (caritinuatiar)

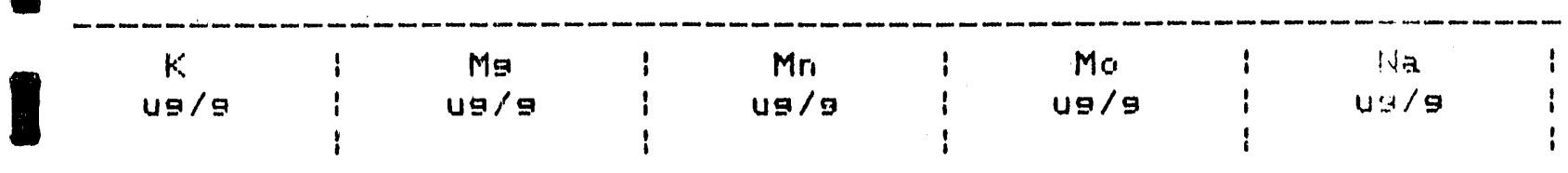

1. $48 E+002$

$9.40 E+001$

$9.00 E+001$

$9.90 E+001$

2. $90 E+001$

1. $20 E+001$

$3.00 E+000$

4. OOE +OOO

4. $00 E+000$

3. $00 E+000$

1. $00 E+000$

5. $00 E+000$

1. $70 E+002$

1. $24 . E+002$

1. $22 \mathrm{E}+002$

1. $24 E+002$

1. $09 E+002$

2. $80 E+001$

1. $00 E+001$

1. $30 E+001$

1. $00 E+001$

4. $.00 E+000$

1. $32 E+002$

1. $00 E+002$

1. $43 \mathrm{E}+002$

5. $40 E+001$

$3.50 E+001$

3. $50 E+001$

2. $30 E+001$

$3.60 E+001$
2. 10E +002

1. $80 E+002$

$3.20 E+002$

1. $01 E+003$

$9.10 E+002$

$6.70 E+002$

5. $10 E+002$

8. $40 E+002$

5. $20 E+002$

1. $22 \mathrm{E}+003$

1. $43 E+003$

1. $50 E+002$

8. $00 E+001$

3. $80 E+002$

$6.30 E+002$

1. $04 E+003$

1. $04 \mathrm{E}+003$

1. $08 E+003$

5. $40 E+002$

$9.40 E+002$

$7.40 E+00 Z$

$\% .20 E+002$

8. $00 E+001$

1. $6 O E+O 02$

7. $50 \mathrm{E}+002$

$6.60 E+002$

5. $20 E+002$

4. $00 E+002$

2. $00 E+002$

$3.50 E+002$

$-1.00 E+000$
$-1.00 E+000$
$-1.00 E+000$
$-1.00 E+000$
$5.00 E+000$
$1.60 E+001$
$1.80 E+001$
$4.40 E+001$
$3.20 E+001$
$8.90 E+001$
$1.01 E+002$
$1.30 E+001$
$-1.00 E+000$
$-1.00 E+000$
$-1.00 E+000$
$-1.00 E+000$
$-1.00 E+000$
$2.40 E+001$
$1.40 E+001$
$4.20 E+001$
$4.90 E+001$
$3.00 E+001$
$-1.00 E+000$
$-1.00 E+000$
$-1.00 E+000$
$4.00 E+000$
$1.20 E+001$
$1.80 E+001$
$1.20 E+001$
$2.30 E+001$
-1

4. $90 \mathrm{E}-001$

$6.40 \mathrm{E}-001$

8. $90 E-001$

7. $1 \mathrm{OE}-001$

1. $08 E+000$

1. $40 \mathrm{E}-001$

4. 50E-001

3.5OE-001

3. $70 E-001$

$2.90 E+000$

$3.35 E+000$

3. $6.0 E-001$

1. $30 \mathrm{E}-001$

3. $20 E-001$

3. $70 \mathrm{E}-001$

$6.20 E-001$

4. $40 E-001$

$-1.00 E-001$

$-1.00 E-001$

$-1.00 E-001$

$-1.00 E-001$

4. $00 E-001$

1. $30 E-001$

2. $40 E-001$

1. $60 \mathrm{E}-001$

4. $60 \mathrm{E}-001$

$-1.00 E-001$

$-1.00 E-001$

$-1.00 E-001$

1. $80 E-001$
2. $00 E+002$

4. $10 \mathrm{E}+002$

$7.90 E+002$

1. $05 E+003$

6. OOE+0O2

4. $10 E+002$

2. $40 E+002$

1. $70 E+002$

4. $00 E+001$

$6.00 E+001$

$6.00 E+001$

2. $00 E+001$

4. $00 E+001$

1. $70 E+002$

4. $50 \mathrm{E}+002$

1. $6.9 \mathrm{E}+003$

$1.67 E+003$

1. $39 \mathrm{E}+003$

6. $70 \mathrm{E}+002$

$9.30 E+002$

$4.00 E+002$

7. $00 E+001$

5. $00 E+001$

1. $60 E+002$

$3.10 \mathrm{E}+002$

$3.40 E+002$

4. $10 E+002$

3. $60 \mathrm{E}+002$

1. $50 E+002$

2. $30 E+002$
1

2

3

4

5

6

7

8 
TABLE B-2 (continuation)

\begin{tabular}{|c|c|c|c|c|c|c|c|c|c|c|}
\hline $\begin{array}{c}\mathrm{Ni} \\
\mathrm{ug} / \mathrm{g}\end{array}$ & $\begin{array}{l}i \\
i\end{array}$ & $\begin{array}{c}P P_{i} \\
\text { ug/g }\end{array}$ & $i$ & $\begin{array}{r}\mathrm{PQ14} \\
\mathrm{ug} / \mathrm{g}\end{array}$ & $\begin{array}{l}i \\
i \\
i\end{array}$ & $\begin{array}{c}\text { Se } \\
\text { Ugis }\end{array}$ & $\begin{array}{l}i \\
i \\
i\end{array}$ & $\begin{array}{c}S i \\
U g / g\end{array}$ & $\begin{array}{l}i \\
i \\
i\end{array}$ & \\
\hline $1.00 E-001$ & 1 & $E-001$ & $i$ & $-3.00 E+000$ & $i$ & $1.80 E-001$ & i & $6.90 E+001$ & I & 1 \\
\hline 001 & $i$ & & $i$ & 00 & $i$ & 01 & $i$ & $30 E+001$ & $i$ & 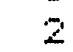 \\
\hline 01 & 1 & -1 & $i$ & $\bar{E}+000$ & $i$ & 2. $00 E-001$ & $i$ & $8.00 E+001$ & $!$ & 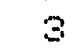 \\
\hline$-1.0 O E$ & 1 & $O E-001$ & i & $E+000$ & $i$ & $3.40 E-001$ & i & $4.60 E+001$ & $i$ & $T$ \\
\hline $5.50 E-001$ & $i$ & $-1.00 E-001$ & i & $-3.00 E+00 \%$ & $i$ & $7.50 E-001$ & $i$ & $1.10 E+001$ & $i$ & 5 \\
\hline 1. $.9 E+000$ & $i$ & $-1.00 E-001$ & 1 & $E+000$ & $i$ & 5. SOE-001 & i & $2.10 E+001$ & 1 & 6 \\
\hline 2.5 & $i$ & -1 & i & $E+000$ & i & $E-001$ & i & 1 & i & 7 \\
\hline+000 & $i$ & $E-001$ & ! & $E+000$ & $i$ & $E-001$ & i & 1 & $i$ & $\Xi$ \\
\hline+000 & $i$ & -1. & i & -3. & i & $=-001$ & i & $1 .<$ & i & 9 \\
\hline $1.1 B E+001$ & 1 & $-1.00 \mathrm{E}-001$ & i & 2. & $i$ & 1. & $i$ & 4. & i & 10 \\
\hline 1. $21 E+001$ & $i$ & $-1.00 E-001$ & $i$ & 4. OOE+ & $i$ & $\therefore 6$ & i & 4. & $i$ & 11 \\
\hline+000 & $i$ & $-1.00 E-001$ & $i$ & $E+000$ & $i$ & 1.4 & i & 00 & 1 & 12 \\
\hline$-1.00 E-001$ & $i$ & $-1.00 E-001$ & 1 & $-3.00 E+000$ & i & 2. $30 E-001$ & 1 & 9.5 & i & 13 \\
\hline$-1.00 E-001$ & 1 & -1.0 OCE -001 & $i$ & $E+000$ & i & $3.70 E-001$ & 1 & $\$ .70 E+$ & $i$ & 14 \\
\hline$-1.00 E-001$ & 1 & $O E-O 01$ & $i$ & $E+000$ & $!$ & $4.40 E-001$ & i & 1. $.04 E+002$ & $i$ & 15 \\
\hline$-1.00 E-001$ & 1 & $-1.00 E-001$ & 1 & $-3.00 E+000$ & 1 & $1.74 E+000$ & 1 & 1. $.0 O E+002$ & 1 & 16 \\
\hline$-1.00 E-001$ & $i$ & $-1.00 E-001$ & 1 & $-3.00 E+000$ & $i$ & 1. $7 \mathrm{BE}+000$ & 1 & $7.40 E+001$ & $!$ & 17 \\
\hline $3.21 E+000$ & 1 & $-1.00 E-001$ & $i$ & $-3.00 E+000$ & $i$ & $7.50 E+000$ & $i$ & $4.10 E+001$ & $i$ & 19 \\
\hline $2.47 E+000$ & $!$ & -1.8 & 1 & $E+000$ & $i$ & $3.40 E+000$ & $i$ & 1. $30 E+001$ & $i$ & $1 \%$ \\
\hline 7.59 & : & -1.8 & 1 & $E+000$ & $i$ & 6.7 & 1 & $4.70 E+001$ & 1 & 20 \\
\hline $9.23 E+000$ & $i$ & $-1 \cdot 0$ & 1 & -3 & 1 & 1.7 & $i$ & 1 & 1 & 21 \\
\hline 1. $74 E+C$ & i & -1.0 & i & +000 & i & $3.07 E+000$ & i & 4. OOEA & $i$ & 22 \\
\hline$-1.00 E-001$ & i & $-1.00 E-001$ & ! & $-3.00 E+000$ & $i$ & 1. $20 E-001$ & 1 & $5.70 E+001$ & i & 23 \\
\hline 01 & i & $-1.00 E-001$ & i & $-3.00 E+000$ & 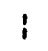 & $9.00 E-002$ & ! & 01 & $i$ & 24 \\
\hline$-1.00 E-6$ & i & $-1.00 E-001$ & ! & $E+000$ & i & 1. $40 E-001$ & : & 01 & 1 & 25 \\
\hline $5.70 E-001$ & 1 & $-1.00 E-001$ & i & $-3.00 E+000$ & ! & $5.80 E-001$ & $i$ & $2.30 E+001$ & $i$ & 26 \\
\hline$E+000$ & $i$ & $O E-001$ & 1 & $O E+000$ & i & 1. $07 E+000$ & i & $4.00 E+C$ & $i$ & 27 \\
\hline $4.3 \% E+000$ & $i$ & -1.0 & $i$ & $O E+000$ & 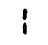 & $1.13 \mathrm{E}+000$ & 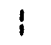 & 4. $30 E+001$ & 1 & $2 \theta$ \\
\hline $3.4 \Xi E+000$ & $i$ & $-1.00 E-001$ & $i$ & $-3.00 E+000$ & i & $6.10 E-001$ & i & $2.50 E+001$ & i & 29 \\
\hline $6.32 E+000$ & $i$ & $-1.00 E-001$ & $i$ & $-3.00 E+000$ & i & $1.24 E+000$ & i & $4.80 E+001$ & i & 30 \\
\hline
\end{tabular}


TABLE B-2(coritiruation)

\begin{tabular}{|c|c|c|c|c|c|c|c|c|c|c|}
\hline $\begin{array}{r}504 \\
\mathrm{ug} / 9\end{array}$ & $i$ & $\begin{array}{c}S F \\
u g / 9\end{array}$ & $\begin{array}{l}\mathbf{1} \\
\mathbf{i}\end{array}$ & $\begin{array}{l}U \\
U 9 / 9\end{array}$ & $i$ & $\begin{array}{c}U \\
u g / g\end{array}$ & $\vdots$ & 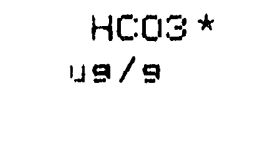 & $\begin{array}{l}\vdots \\
\vdots \\
i\end{array}$ & \\
\hline $3.72 E+003$ & $i$ & $4.30 E+000$ & $\mathbf{i}$ & 1. $20 E+001$ & i & 2.00E-001 & $i$ & 1. $10 E+002$ & : & 1 \\
\hline $2.97 E+003$ & $?$ & $2.70 E+000$ & $i$ & $7.66 E+000$ & & $3.00 E-001$ & $i$ & $1.00 E+001$ & i & 2 \\
\hline $4.72 E+00 \Xi$ & $i$ & $3.5 O E+000$ & i & $5.85 E+000$ & ; & 3. OOE-001 & $i$ & $6.80 E+001$ & $\mathrm{i}$ & - \\
\hline 1. $04 E+004$ & $i$ & $8.60 E+000$ & $i$ & $7.00 E+000$ & I & 2. OOE-001 & 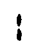 & $2.76 E+003$ & $i$ & 4 \\
\hline $1.45 E+004$ & $i$ & $5.20 E+000$ & i & $8.00 E+000$ & , & $-1.00 E-001$ & $i$ & $6.10 E+003$ & $i$ & \\
\hline 1. $50 E+004$ & $i$ & $4.40 E+000$ & $i$ & 1. $50 E+001$ & $i$ & $-1.00 E-001$ & $i$ & $0.00 E+000$ & : & 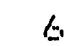 \\
\hline $1.51 E+004$ & $i$ & $4.10 E+000$ & i & $1.70 E+001$ & : & $3.00 E-001$ & i & $0.00 E+000$ & i & 7 \\
\hline $2.65 E+004$ & $i$ & 4. $70 E+000$ & $i$ & $3.50 E+001$ & $!$ & $1.90 E+000$ & $i$ & $0.00 E+000$ & $i$ & $E$ \\
\hline $2.17 E+004$ & 1 & $5.10 E+000$ & : & $2.60 E+001$ & : & $6.00 E-001$ & $i$ & $0.00 E+000$ & ; & $\%$ \\
\hline $3.74 E+004$ & $i$ & $5.50 E+000$ & $!$ & $1.04 E+002$ & i & 7. $10 \mathrm{E}+000$ & $i$ & $0.00 E+000$ & $i$ & 10 \\
\hline $4.60 E+004$ & $i$ & $3.90 E+000$ & ; & $1.22 E+002$ & : & $8.40 E+000$ & $i$ & $0.00 E+000$ & i & 11 \\
\hline 1. $79 E+004$ & $i$ & $3.60 E+000$ & i & 1. $20 E+001$ & 1 & $3.00 E-001$ & : & $0.00 E+000$ & 1 & 12 \\
\hline $2.26 \bar{E}+003$ & $i$ & $2.31 E+000$ & $i$ & $1.90 E-001$ & $i$ & 1.0OE-001 & $i$ & 2. $15 E+004$ & $i$ & 13 \\
\hline $1.41 E+004$ & 1 & $1.03 E+001$ & $i$ & $8.50 E-001$ & i & $-1.00 E-001$ & $i$ & $6.00 E+002$ & $i$ & 14 \\
\hline $1.45 E+004$ & 1 & $1.04 E+001$ & $i$ & $6.60 E-001$ & $i$ & $1.00 E-001$ & $i$ & 1. $.80 E+003$ & : & 15 \\
\hline 1.72E+004 & $i$ & 1. $30 E+001$ & i & $7.60 E-001$ & i & $3.00 \mathrm{E}-001$ & $i$ & $9.30 E+002$ & i & 16 \\
\hline $1.4 \% E+004$ & $i$ & 1. $02 E+001$ & : & $6.20 E-001$ & $i$ & $2.00 E-001$ & $i$ & $2.60 E+002$ & $i$ & 17 \\
\hline 1. $8: E+004$ & $i$ & 4. $30 E+000$ & i & $1.60 E+001$ & : & $-1.00 \mathrm{E}-001$ & i & 5. $80 E+004$ & ! & 18 \\
\hline 1. $75 E+004$ & $i$ & $2.30 E+000$ & $i$ & 1. $6.0 E+001$ & : & $1.00 E-001$ & $i$ & $0.00 E+000$ & i & 19 \\
\hline $2.54 E+004$ & $i$ & $3.40 E+000$ & i & $3.10 E+001$ & i & $2.00 E-001$ & $i$ & $0.00 E+000$ & $i$ & 20 \\
\hline $2.08 E+004$ & . & $3.30 E+000$ & ; & $4.10 E+001$ & $i$ & 4. OOE-OO1 & $i$ & $0.00 E+000$ & : & 21 \\
\hline $3.66 E+0014$ & i & $3.50 E+000$ & $i$ & $8.60 E+001$ & i & 1. $60 \mathrm{E}+000$ & $i$ & $0.00 E+000$ & $i$ & 22 \\
\hline $1.53 E+003$ & $i$ & $2.50 E+000$ & $i$ & $2.90 E-001$ & i & $3.00 E-001$ & $i$ & $2.30 E+001$ & i & 23 \\
\hline $2.29 E+003$ & $i$ & $3.10 E+000$ & $i$ & $2.20 \mathrm{E}-\mathrm{CO} 1$ & i & $3.00 E-001$ & $i$ & $1.00 E+001$ & i & 24 \\
\hline $3.20 E+003$ & $i$ & $\because .60 E+000$ & $i$ & $5.60 E-001$ & $i$ & $2.00 E-001$ & $i$ & 5. $80 E+002$ & $i$ & 25 \\
\hline $1.29 E+004$ & i & $6.70 E+000$ & $i$ & $1.09 E+000$ & $i$ & $2.00 E-001$ & ! & $4.78 E+003$ & 1 & 26 \\
\hline $1.31 E+0044$ & $i$ & $4.60 E+000$ & i & $1.40 E+001$ & , & 1. $.00 E-001$ & i & $0.00 E+000$ & 1 & 27 \\
\hline 1. $56 E+004$ & $i$ & $4.40 E+000$ & 1 & $2.20 E+001$ & i & 1. $00 \mathrm{E}-001$ & $i$ & $0.00 E+000$ & : & 29 \\
\hline 1. $56 E+004$ & 1 & 3. EOE + 000 & $i$ & 1. $30 E+001$ & i & 1.OOE-OO1 & $i$ & $0.00 E+000$ & $i$ & 29 \\
\hline 1. $6.4 E+004$ & 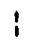 & $2.70 E+000$ & $i$ & $3.20 E+001$ & i & 7.00E-001 & i & $0.00 E+000$ & i & 30 \\
\hline
\end{tabular}

* Calculated as the missing an:on in the charge balance. 
TAELE $B-2$ (cont iruatian)

\begin{tabular}{|c|c|c|c|c|c|}
\hline I & $\begin{array}{r}\mathrm{Th}-230 \\
\mathrm{pCi} / \mathrm{g}\end{array}$ & $\begin{array}{l}i \\
\vdots \\
i\end{array}$ & $\begin{array}{c}\text { Ra- } 6 \\
u g / g\end{array}$ & $i$ & \\
\hline & $6.00 E-003$ & i & $2.00 E-002$ & $!$ & 1 \\
\hline & $9.00 E-003$ & $i$ & $-1.00 E-002$ & $!$ & 2 \\
\hline & $1.00 E-002$ & 1 & $-1.00 E-002$ & i & 3 \\
\hline & 1. $10 \mathrm{E}-002$ & 1 & $-1.00 E-002$ & i & 4 \\
\hline & $1.10 E-002$ & 1 & $-2.00 E-002$ & $i$ & 5 \\
\hline & $1.50 E-002$ & $i$ & $-2.00 E-002$ & 1 & $\Leftrightarrow$ \\
\hline & $1.30 E-001$ & 1 & $-2.00 E-002$ & 1 & 7 \\
\hline i & $3.30 \mathrm{E}-002$ & $i$ & 1. $50 \mathrm{E}-001$ & i & 9 \\
\hline ! & $3.00 E-001$ & $i$ & $3.30 E-002$ & 1 & $F$ \\
\hline ! & $1.50 E+000$ & 1 & 2.30 E-001. & 1 & 10 \\
\hline ! & $2.90 E+001$ & 1 & 1. $\Xi 0 E-001$ & $i$ & 11 \\
\hline i & $3.70 E-001$ & $i$ & $3.67 E+000$ & i & 12 \\
\hline i & $1.601 E-002$ & 1 & $-1.00 E-002$ & $i$ & 13 \\
\hline ! & $1.00 \mathrm{E}-002$ & 1 & $-2.00 E-002$ & ! & 14 \\
\hline ! & $2.40 E-002$ & $i$ & $-2.00 E-002$ & i & 15 \\
\hline ! & $4.00 E-003$ & $i$ & $-2.00 E-002$ & i & 16 \\
\hline i & $4.00 E-003$ & $!$ & $-2.00 E-002$ & $!$ & 17 \\
\hline i & $2.50 E-001$ & 1 & $9.20 E-002$ & 1 & $1 \Xi$ \\
\hline 1 & $7.90 \mathrm{E}-002$ & $i$ & $5.10 E-002$ & $i$ & $1 \%$ \\
\hline i & $1.50 E+000$ & $\mathbf{i}$ & $8.10 E-002$ & 1 & 20 \\
\hline 1 & $3.80 E+000$ & $i$ & $6.90 E-002$ & 1 & 21 \\
\hline i & $1.20 E+002$ & $i$ & $2.40 E-001$ & $i$ & 22 \\
\hline & $2.20 E-002$ & $i$ & $-2.00 E-002$ & $i$ & 23 \\
\hline i & $4.30 E-002$ & 1 & $-2.00 E-002$ & 1 & 24 \\
\hline ; & $1.60 E-002$ & $i$ & $-2.00 E-002$ & 1 & 25 \\
\hline i & $4.30 E-002$ & 1 & $6.80 E-002$ & $!$ & 26 \\
\hline i & $5.00 E-001$ & $i$ & $3.10 E-001$ & $i$ & 27 \\
\hline I & $6.50 E-001$ & $i$ & 1. $6.0 E-001$ & $!$ & $2 E$ \\
\hline & $2.60 E-001$ & $i$ & $3.30 E-001$ & $:$ & 25 \\
\hline & $1.30 E+000$ & $i$ & $4.70 E-001$ & $i$ & 30 \\
\hline
\end{tabular}


TABLE B-3 Data for HCl extracts; RIVERTON, WYOMING

\begin{tabular}{|c|c|c|c|c|c|c|c|c|c|c|c|}
\hline $\begin{array}{l}\text { Site \& } \\
\text { Sample } \\
\text { Number. }\end{array}$ & 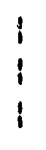 & $\begin{array}{l}\text { Sami- } \\
\text { Ple } \\
\text { Trpe }\end{array}$ & $\begin{array}{l}i \\
i \\
i\end{array}$ & $\begin{array}{l}\text { Sam } \\
\text { Tap } \\
\mathrm{cm}\end{array}$ & $\begin{array}{l}p_{1} \\
\vdots \\
i\end{array}$ & $\begin{array}{l}\text { le } \\
\text { Base } \\
\text { cmi }\end{array}$ & $\begin{array}{l}\mathbf{1} \\
\vdots \\
\mathbf{1}\end{array}$ & $\begin{array}{l}E H_{1} \\
m V\end{array}$ & & $i$ & $\mathrm{PH}$ \\
\hline 64.01 & 1 & 540 & 1 & 1 & i & 5 & & & 0 & 1 & 0.00 \\
\hline 84.02 & 1 & 540 & I & 5 & i & 10 & & & 0 & $i$ & 00 \\
\hline 3 & 1 & 540 & 1 & 10 & i & 15 & $i$ & & 0 & 1 & .00 \\
\hline 64.04 & $i$ & 540 & 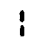 & 15 & $i$ & 23 & $i$ & & 0 & $i$ & .00 \\
\hline 05 & 1 & 540 & i & 23 & 1 & 26 & $!$ & & 0 & $i$ & .00 \\
\hline 06 & 1 & 140 & 1 & 26 & 1 & 30 & $i$ & & 0 & 1 & 0.00 \\
\hline 4.07 & 1 & 140 & 1 & 30 & 1 & 37 & 1 & & 0 & 1 & 0.00 \\
\hline 64.08 & 1 & 140 & $i$ & 37 & 1 & 43 & 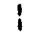 & & 0 & $i$ & .00 \\
\hline $0 \%$ & 1 & 140 & 1 & 43 & 1 & 53 & i & & 0 & $i$ & 00 \\
\hline 10 & $i$ & 140 & 1 & 74 & 1 & 79 & i & & 0 & $i$ & .00 \\
\hline 11 & $i$ & 140 & $i$ & 86 & 1 & 93 & i & & 0 & 1 & 0.00 \\
\hline 12 & 1 & 140 & $i$ & 96 & $i$ & 104 & $i$ & & 0 & $!$ & .00 \\
\hline 01 & 1 & 540 & $i$ & 1 & 1 & 5 & $i$ & & 0 & 1 & .00 \\
\hline 02 & $i$ & 540 & 1 & 5 & $\mathbf{i}$ & 10 & i & & 0 & 1 & .00 \\
\hline 03 & 1 & 540 & $i$ & 14 & i & 19 & i & & ( & 1 & 00 \\
\hline 04 & i & 540 & i & 19 & 1 & 213 & ? & & 0 & 1 & 0.00 \\
\hline 0.5 & $i$ & 540 & 1 & 28 & 1 & 35 & $r$ & & 0 & $i$ & 0.00 \\
\hline 06 & 1 & 540 & $i$ & 35 & $i$ & 37 & i & & 0 & $i$ & 0.00 \\
\hline 07 & $i$ & 140 & i & 38 & $i$ & 42 & $i$ & & 0 & 1 & 0.00 \\
\hline 08 & 1 & 140 & ! & 44 & $i$ & 51 & i & & 0 & 1 & .00 \\
\hline & $i$ & 140 & i & 52 & $!$ & 6.3 & ! & & 0 & 1 & 00 \\
\hline 10 & 1 & 140 & 1 & 82 & $i$ & 94 & $i$ & & 0 & 1 & 0.00 \\
\hline 01 & $i$ & 540 & ! & 1 & 1 & 5 & i & & 0 & 1 & 0.00 \\
\hline 02 & $i$ & 540 & i & 5 & $i$ & 10 & ! & & 0 & $i$ & 0.00 \\
\hline & $i$ & 540 & 1 & 13 & $i$ & 20 & i & & 0 & $i$ & 0.00 \\
\hline & 1 & 540 & 1 & 20 & 1 & 23 & & & 0 & 1 & 0.00 \\
\hline & 1 & 140 & i & 23 & 1 & 26 & & & 0 & : & 0.00 \\
\hline $0 \leqslant$ & 1 & 140 & ! & 27 & 1 & 33 & ! & & 0 & $i$ & 0.00 \\
\hline & 1 & 140 & i & 33 & 1 & 42 & i & & 0 & 1 & 0.00 \\
\hline & & 140 & $i$ & 61 & . & 66 & $i$ & & 0 & $i$ & 0.00 \\
\hline
\end{tabular}

NGTE: Zera value iridicates no determiriation was made. Negative sign indicates below analytical detection limit. 
TAELE B-3 (cantiruation)

\begin{tabular}{|c|c|c|c|c|c|c|c|c|c|c|}
\hline $\begin{array}{c}A 1 \\
U 9 / 9\end{array}$ & $\begin{array}{l}\mathbf{y} \\
\mathbf{1}\end{array}$ & $\begin{array}{c}\text { As } \\
\cup g / 9\end{array}$ & $\begin{array}{l}\mathbf{1} \\
\vdots \\
\mathbf{y}\end{array}$ & $\begin{array}{c}\mathrm{Ba} \\
\mathrm{ug} / \mathrm{g}\end{array}$ & : & $\begin{array}{c}\mathrm{Ca} \\
\mathrm{ug} / \mathrm{g}\end{array}$ & $\begin{array}{l}i \\
i \\
i\end{array}$ & $\begin{array}{c}c d \\
u g / g\end{array}$ & $\begin{array}{l}1 \\
i \\
i\end{array}$ & \\
\hline $2.55 E+002$ & 1 & $1.67 E+000$ & 1 & 1. $88 E+001$ & : & $1.41 E+004$ & 1 & $-1.02 E-001$ & 1 & 1 \\
\hline $2.04 E+002$ & 1 & 1. $07 E+000$ & 1 & 2. $31 E+001$ & i & 1. $50 E+004$ & 1 & $-1.02 E-001$ & $i$ & 2 \\
\hline $2.55 E+002$ & 1 & $1.10 E+000$ & 1 & $2.15 E+001$ & i & 1. $53 E+004$ & i & $-1.02 E-001$ & $i$ & 3 \\
\hline $3.08 E+002$ & $i$ & 1. $06 E+000$ & $i$ & 1. $03 E+001$ & $i$ & 1. $63 E+004$ & : & $-1.03 E-001$ & $i$ & 4 \\
\hline $8.61 E+002$ & ! & 1. $35 E+001$ & $i$ & $7.371-001$ & i & $4.9 \% E+003$ & $!$ & $-1.04 E-001$ & i & 5 \\
\hline $1.95 E+002$ & i & $9.77 E+000$ & i & $-1.03 E-001$ & $!$ & $2.28 E+003$ & $i$ & $-1.03 E-001$ & i & 6 \\
\hline E. $2 E E+001$ & i & $1.82 E+001$ & $i$ & $-1.04 E-001$ & i & 2. $55 E+003$ & i & $-1.04 E-001$ & i & 7 \\
\hline 1. $24 E+002$ & i & E. $30 E+000$ & : & $-1.04 E-001$ & 1 & $E+003$ & 1 & $-1.04 E-001$ & $i$ & $\theta$ \\
\hline 3.32E+001 & 1 & $7.17 E+000$ & 1 & $-1.04 E-001$ & $i$ & $2.39 E+003$ & i & $-1.04 E-001$ & i & 9 \\
\hline $1.36 E+002$ & ! & $4.50 E+000$ & $i$ & $-1.05 E-001$ & $i$ & $2.17 E+003$ & i & $-1.05 E-001$ & $i$ & 10 \\
\hline $2.11 E+002$ & i & $3.55 E+000$ & $i$ & $-1.11 E-001$ & i & $2.05 E+003$ & $i$ & $-1.11 E-001$ & $i$ & 11 \\
\hline $6.15 E+000$ & 1 & $1.84 \mathrm{E}+000$ & $i$ & $1.02 E-001$ & 1 & $4.61 E+002$ & 1 & $-1.02 E-001$ & : & 12 \\
\hline $3.24 E+002$ & 1 & $2.43 E+000$ & $i$ & 2. 42E+001 & 1 & $1.40 E+004$ & $i$ & $-1.01 E-001$ & i & 13 \\
\hline $4.57 E+002$ & i & $4.47 E+000$ & $i$ & $9.39 E+000$ & i & 1. $49 E+004$ & $i$ & $-1.02 E-001$ & 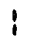 & 14 \\
\hline $3.32 E+002$ & 1 & 4. $03 E+000$ & 1 & $6.7 \Leftrightarrow E+000$ & i & $1.33 E+004$ & 1 & $-1.03 E-001$ & 1 & 15 \\
\hline $3.78 E+002$ & i & $2.45 E+000$ & $i$ & $8.945+000$ & i & 1. $5 O E+004$ & $i$ & $-1.02 \mathrm{E}-001$ & 1 & 16 \\
\hline $2.77 E+002$ & $i$ & 1. $5 E E+000$ & 1 & $8.72 E+000$ & i & 1. $29 E+004$ & $i$ & $-1.02 E-001$ & $i$ & 17 \\
\hline $6.39 E+002$ & i & $1.81 E+000$ & $i$ & 1. $03 E-001$ & 1 & $2.36 E+003$ & $i$ & $-1.03 E-001$ & 1 & 18 \\
\hline $7.14 E+001$ & $i$ & $9.6 \% E+000$ & $i$ & $-1.02 E-001$ & ! & $2.03 E+003$ & 1 & $-1.02 E-001$ & $i$ & $1 \%$ \\
\hline 1.54E+002 & $i$ & E. $32 E+000$ & 1 & $-1.03 E-001$ & 1 & 1. $75 E+00 \Omega$ & 1 & $-1.03 E-001$ & $i$ & 20 \\
\hline 1. $43 E+00=$ & $i$ & $5.33 E+000$ & 1 & $-1.02 E-001$ & $i$ & $1.67 E+003$ & 1 & $-1.02 E-001$ & : & 21 \\
\hline $4.93 E+002$ & 1 & $5.92 E+000$ & 1 & $-1.10 E-001$ & i & $1.49 E+003$ & 1 & $-1.10 \mathrm{E}-001$ & 1 & 22 \\
\hline $4.40 E+002$ & $i$ & $1.23 E+000$ & $i$ & $3.02 E+001$ & $i$ & 1. $97 E+004$ & $i$ & $-1.02 E-001$ & $i$ & 23 \\
\hline $4.21 E+002$ & $i$ & 1. $18 E+000$ & $i$ & $3.00 E+001$ & $i$ & $1.97 E+004$ & i & $-1.03 E-001$ & i & 24 \\
\hline $3.50 E+002$ & 1 & 9. BEE-001 & $i$ & $1.33 E+001$ & $i$ & $1.79 E+004$ & 1 & $-1.03 E-001$ & 1 & 25 \\
\hline $1.74 E+003$ & i & $8.37 E+000$ & 1 & $5.79 E-001$ & $:$ & $4.33 E+003$ & 1 & $-1.03 E-001$ & $i$ & 26 \\
\hline 1. $54 \mathrm{E}+002$ & 1 & $6.25 E+000$ & $i$ & $-1.02 E-001$ & 1 & $1.68 E+003$ & $i$ & $-1.02 E-001$ & $i$ & 27 \\
\hline $1.75 E+002$ & $i$ & $6.67 E+000$ & $i$ & $-1.03 E-001$ & $i$ & 1. $55 E+003$ & $i$ & $-1.03 E-001$ & i & 28 \\
\hline $8.75 E+001$ & $i$ & 8. $53 E+000$ & $i$ & $-1.0 \% E-001$ & $!$ & $2.29 \mathrm{E}+003$ & $i$ & $-1.0 \% E-001$ & $i$ & $2 \%$ \\
\hline $2.72 \mathrm{E}+002$ & $i$ & $7.43 E+000$ & $i$ & $-1.05 E-001$ & i & $1.55 E+003$ & i & $-1.05 E-001$ & $i$ & 30 \\
\hline
\end{tabular}


TABLE B-3(cantiruatiar)

\begin{tabular}{|c|c|c|c|c|c|c|c|c|c|}
\hline $\begin{array}{c}C_{U} / g \\
\end{array}$ & $\vdots$ & $\begin{array}{c}\mathrm{Co} \\
\mathrm{ug} / \mathrm{g}\end{array}$ & 1 & $\mathrm{Cr}_{\mathrm{ug} / \mathrm{g}}$ & $i$ & $\underset{u g / g}{F}$ & $\begin{array}{l}1 \\
1 \\
1\end{array}$ & $\begin{array}{c}\mathrm{Fe} \\
\mathrm{ug} / \mathrm{g}\end{array}$ & $\begin{array}{l}1 \\
\vdots \\
1\end{array}$ \\
\hline $0.00 E+000$ & 1 & $8.47 E-001$ & $i$ & $1.94 E-001$ & $i$ & 1. $33 \mathrm{E}+001$ & ! & $8.78 E+001$ & $i$ \\
\hline $0.00 E+000$ & i & $4.29 E-001$ & 1 & $1.33 E-001$ & 1 & $2.04 E+001$ & 1 & 1. $53 \mathrm{E}+001$ & 1 \\
\hline $0.00 E+000$ & $i$ & 4. $68 E-001$ & 1 & 1. $63 \mathrm{E}-001$ & 1 & 1. $63 \mathrm{E}+001$ & i & $4.79 E+001$ & $i$ \\
\hline $0.00 E+000$ & 1 & $4.11 E-001$ & $i$ & $1.64 E-001$ & $i$ & $1.75 E+001$ & $i$ & $1.64 E+001$ & 1 \\
\hline $0.00 E+000$ & 1 & 1. $05 E+000$ & 1 & $1.23 E+000$ & $i$ & $6.22 E+000$ & 1 & $1.23 E+002$ & 1 \\
\hline $0.00 E+000$ & $i$ & $3.70 E-001$ & 1 & 4. $12 E-001$ & $i$ & $2.06 E+000$ & i & $1.17 E+002$ & 1 \\
\hline $0.00 E+000$ & 1 & $-1.04 E-001$ & $i$ & 1. $45 E-001$ & $i$ & $1.04 E+000$ & 1 & $2.37 E+002$ & 1 \\
\hline $0.00 E+000$ & $!$ & $-1.04 E-001$ & 1 & $1.45 E-001$ & $i$ & 1. $04 E+000$ & 1 & $3.16 E+002$ & 1 \\
\hline $0.00 E+000$ & 1 & $-1.04 E-001$ & $i$ & 1. $04 E-001$ & $i$ & $1.04 E+000$ & 1 & $2.68 E+002$ & 1 \\
\hline $0.00 E+000$ & 1 & $1.05 \mathrm{E}-001$ & $i$ & $1.6 .7 E-001$ & $i$ & 1. OEE +000 & 1 & 4.8 & 1 \\
\hline $0.00 E+000$ & 1 & $2.22 \mathrm{E}-001$ & 1 & 2. SEE-001 & $i$ & $2.22 E+000$ & i & t. & i \\
\hline $0.00 E$ & $i$ & $-1.02 E-001$ & $i$ & $-1.02 E-001$ & i & $1.02 E+000$ & 1 & 01 & $!$ \\
\hline $0.00 E+000$ & $i$ & $7.59 E-001$ & $i$ & 1. $92 \mathrm{E}-001$ & $i$ & $1.01 E+001$ & i & 01 & $i$ \\
\hline $0.00 E+000$ & $i$ & $\% .04 E-001$ & ! & $3.56 E-001$ & $i$ & $1.12 E+001$ & $i$ & $6.10 E+001$ & i \\
\hline $0.00 E+000$ & 1 & 7.02E-001 & $i$ & $2.6 .9 E-001$ & i & $1.24 E+001$ & $!$ & $5.79 E+001$ & 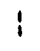 \\
\hline $0.00 E+000$ & $i$ & $5.92 E-001$ & $i$ & 2. $24 E-001$ & $i$ & $1.43 E+001$ & $i$ & 1. $84 E+001$ & $i$ \\
\hline $0.00 E+000$ & $i$ & $2.97 E-001$ & i & 1. $33 E-001$ & $i$ & 1. $64 E+001$ & $i$ & $9.20 E+000$ & i \\
\hline $0.00 E+000$ & $i$ & 8. $74 E-001$ & $i$ & $1.17 E+000$ & $i$ & $3.09 E+000$ & 1 & $2.57 E+001$ & i \\
\hline $0.00 E+000$ & $!$ & $-1.02 E-001$ & $i$ & $-1.02 \mathrm{E}-001$ & $i$ & 1. $02 E+000$ & i & $5.92 E+001$ & $!$ \\
\hline $0.00 E+000$ & $!$ & $1.54 E-001$ & $i$ & 1. $33 \mathrm{E}-001$ & i & 1. $0: 3 E+000$ & $i$ & 1. $37 E+002$ & i \\
\hline $0.00 E+000$ & 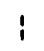 & 1. $6.4 \mathrm{E}-001$ & 1 & $1.43 E-001$ & i & $1.02 E+000$ & ! & 1. $62 E+002$ & i \\
\hline $0.00 E+000$ & $i$ & 1. $0<E+000$ & i & 1. $15 E+000$ & i & $3.29 E+000$ & 1 & $4.89 E+002$ & 1 \\
\hline $0.00 E+000$ & $i$ & $9.71 E-001$ & i & $3.07 E-001$ & $i$ & $3.18 E+000$ & $i$ & $4.91 E+001$ & $i$ \\
\hline $0.00 E+000$ & 1 & E.32E-001 & i & $2.77 E-001$ & $i$ & $1.13 \mathrm{E}+001$ & 1 & 6. $16 E+001$ & 1 \\
\hline $0.00 E+000$ & $i$ & $5.76 E-001$ & $i$ & $1.75 E-001$ & $i$ & $1.44 E+001$ & $i$ & $1.75 E+001$ & $i$ \\
\hline $0.00 E+000$ & 1 & $9.0 \% E-001$ & i & 1. $26 E+000$ & ! & $7.23 E+000$ & 1 & $4.65 E+001$ & i \\
\hline $0.00 E+000$ & 1 & 1. $33 \mathrm{E}-001$ & $i$ & 1. $84 \mathrm{E}-001$ & $i$ & 1. $02 E+000$ & $i$ & $6.76 E+001$ & ! \\
\hline $0.00 E+000$ & $i$ & $2.57 E-001$ & $i$ & $2.36 E-001$ & $i$ & $2.05 E+000$ & $i$ & $7.80 E+001$ & i \\
\hline $0.00 E+000$ & 1 & $-1.0 \% E-001$ & i & $1.0 \% E-001$ & 1 & $1.07 E+000$ & 1 & $7.33 E+001$ & i \\
\hline $0.00 E+000$ & $!$ & $5.75 E-001$ & $i$ & $4.81 E-001$ & $i$ & $2.0 \% E+000$ & $i$ & 2. $81 E+002$ & i \\
\hline
\end{tabular}


TABLEB-3(caritinuatian)

\begin{tabular}{|c|c|c|c|c|c|c|c|c|}
\hline $\begin{array}{c}K \\
u g / g\end{array}$ & 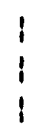 & $\begin{array}{c}\mathrm{Mg} \\
u g / g\end{array}$ & $\begin{array}{l}1 \\
1 \\
1\end{array}$ & $\underset{u g / 9}{M n}$ & $\begin{array}{l}\vdots \\
\vdots \\
\vdots\end{array}$ & $\begin{array}{c}\text { Mo } \\
u g / g\end{array}$ & $\begin{array}{l}1 \\
1 \\
1\end{array}$ & $\begin{array}{c}\mathrm{Na} \\
\mathrm{ug} / \mathrm{g}\end{array}$ \\
\hline
\end{tabular}

\begin{tabular}{|c|c|c|c|c|c|c|c|c|}
\hline . $27 E+002$ & 1 & 1. $43 E+003$ & i & $E+001$ & I & $2 E-C$ & & 1 \\
\hline & & 1 & & 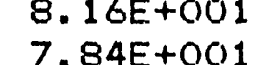 & 1 & $.02 E$ & & $\begin{array}{l}8.16 E+001 \\
9.16 E+001\end{array}$ \\
\hline & & $68 E+003$ & 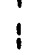 & $8.42 E+001$ & & $-1.03 E-001$ & & $9.24 E+001$ \\
\hline & I & 2 & i & 1 & 1 & 1 & & 01 \\
\hline 1 & i & 1 & 1 & 7. & i & 11 & & 01 \\
\hline 0 & 1 & 1 & 1 & -1 & $i$ & $3 E-$ & & 01 \\
\hline-000 & 1 & 1 & $i$ & 1 & $i$ & $O E$ & & 01 \\
\hline .000 & ! & 1 & $i$ & -1 & i & $B E$ & & 01 \\
\hline .000 & i & 2 & i & 0 & 1 & 00 & & 01 \\
\hline .000 & $i$ & +001 & i & 00 & 1 & 2.17Et & & 1001 \\
\hline 000 & 1 & 0 & $i$ & -1 & 1 & $3.28 \mathrm{E}$ & & -1 \\
\hline 02 & $!$ & +003 & $\mathbf{i}$ & 9. & 1 & $-1.01 E$ & & 01 \\
\hline 01 & i & 1 & $i$ & 12 & 1 & 1 & & \\
\hline 01 & i & 3 & ! & & 1 & 1 & & \\
\hline & i & & i & & $i$ & & & \\
\hline 10. & : & & i & & 1 & & & \\
\hline 101 & $i$ & 1 & 1 & & 1 & - & & \\
\hline 00 & 1 & & i & & 1 & - & & \\
\hline 101 & 1 & 4 & 1 & & $i$ & & & \\
\hline 100 & 1 & 2 & 1 & & 1 & & $i$ & -1 \\
\hline 01 & 1 & 1 & i & & $i$ & 1 & & -1 \\
\hline & 1 & 2 & 1 & & $i$ & -1 & & \\
\hline+002 & 1 & $E+C$ & $i$ & 1. & $i$ & -1 & & \\
\hline 1 & $i$ & 2. & $i$ & & $i$ & -1.8 & & \\
\hline$=+001$ & 1 & $3.41 E+002$ & i & $3.20 E+$ & 1 & 1. $76 \mathrm{E}-$ & & $E+001$ \\
\hline & 1 & $5.64 E+001$ & 1 & 1. $.02 \mathrm{E}+$ & 1 & 2. & & 01 \\
\hline & 1 & $5.13 E+001$ & 1 & $2.05 E+000$ & i & $1.95 \mathrm{E}-$ & & $1.03 E+001$ \\
\hline & ! & $E+O$ & 1 & -1 & $i$ & $3.50 \mathrm{E}$ & & $9 E+001$ \\
\hline & 1 & $5 E+0$ & $i$ & $23 E+000$ & 1 & $5.23 E-001$ & & $2.09 E+001$ \\
\hline
\end{tabular}


TABLEB-3(contiruation)

\begin{tabular}{|c|c|c|c|c|c|c|c|c|c|c|}
\hline $\begin{array}{c}\mathrm{Ni} \\
\mathrm{ug} / \mathrm{g}\end{array}$ & 1 & $\begin{array}{c}P b \\
u g / g\end{array}$ & $\begin{array}{l}1 \\
i \\
i\end{array}$ & $\begin{array}{r}\mathrm{PO4} \\
\mathrm{ug} / \mathrm{g}\end{array}$ & $\begin{array}{l}1 \\
i \\
i\end{array}$ & $\begin{array}{c}S e \\
u g / g\end{array}$ & $\begin{array}{l}1 \\
1 \\
1\end{array}$ & $\begin{array}{c}\mathrm{Si} \\
\mathrm{ug} / \mathrm{g}\end{array}$ & $\begin{array}{l}1 \\
\vdots \\
1\end{array}$ & \\
\hline 1.6 & 1 & $-1.02 E-001$ & 1 & $4.89 E+002$ & 1 & $-1.02 E-001$ & 1 & $1.36 \mathrm{E}+002$ & i & \\
\hline & $i$ & $-1 \cdot 0$ & $i$ & $E E+002$ & 1 & $-1.02 E-001$ & & $13 E+002$ & $r$ & \\
\hline 8.041 & $!$ & $-1.02 E-001$ & $i$ & $4.56 E+002$ & $i$ & $-1.02 E-001$ & $i$ & $1.42 E+002$ & 1 & \\
\hline 1.06 & $i$ & $-1.03 E-001$ & $i$ & $4.78 E+002$ & $i$ & $-1.03 E-001$ & $i$ & $8 E+002$ & $i$ & \\
\hline 1.5 & $i$ & $4 E-001$ & 1 & $2.03 E+002$ & $i$ & $9.75 E-001$ & 1 & $O E+0 O 2$ & 1 & \\
\hline 4.01 & 1 & $-1.03 E-001$ & $i$ & 2. $8 B E+001$ & ! & 0 & $!$ & $E+001$ & $i$ & \\
\hline$-1 . c$ & 1 & $H E-001$ & $!$ & $E+001$ & $i$ & 5. & i & 01 & $:$ & \\
\hline $2.28 E$ & 1 & $-1.04 E-001$ & ! & $7.30 E+000$ & 1 & 1. & $i$ & 1 & 1 & \\
\hline-1.0 & 1 & $-1 \cdot 0$ & 1 & $7.30 E+000$ & 1 & -1.0 & i & 2. & 1 & 9 \\
\hline 3. & $i$ & -1. & 1 & 4.2 & $!$ & -1 & i & 01 & $i$ & 0 \\
\hline 7.7 & 1 & $E-001$ & 1 & $5.50 E+$ & 1 & -1 & i & 1 & $i$ & \\
\hline 1.0 & 1 & -1.0 & ! & -3.1 & 1 & 4.5 & 1 & 0 & 1 & 2 \\
\hline 1.2 & 1 & -1. & 1 & 5.0 & 1 & 1. & $i$ & 02 & 1 & I. \\
\hline $3.85 E$ & 1 & $=-001$ & $i$ & $5.92 E+002$ & $i$ & 1.22E-001 & 1 & 02 & 1 & 16 \\
\hline $2.61 E$ & $i$ & $3 E-001$ & $i$ & $4.81 E+002$ & $i$ & 1. $24 E-001$ & i & $E+002$ & 1 & 15 \\
\hline 1. $55 E+$ & 1 & $-1.02 E-001$ & i & $4.94 E+002$ & 1 & $-1.02 E-001$ & i & $2.30 E+002$ & $i$ & 16 \\
\hline $1.37 E+000$ & $i$ & $-1.02 E-001$ & $i$ & $4.98 E+002$ & 1 & $-1.02 E-001$ & 1 & $2.06 E+002$ & $i$ & 1 \\
\hline 1. OGE & 1 & $-1.03 E-001$ & i & $2.16 E+001$ & 1 & $4.73 E-001$ & 1 & $2.17 E+002$ & 1 & 1 \\
\hline 1 & 1 & $-1.02 E-001$ & i & $1.02 E+001$ & 1 & $7.04 E-001$ & i & $2.35 E+001$ & 1 & \\
\hline 3. BOE- & 1 & $-1.03 E-001$ & i & 1. $.03 E+001$ & $i$ & 1. $04 E+000$ & i & $3.18 E+001$ & 1 & \\
\hline $3.38 E-001$ & $!$ & $E-001$ & ! & $6.10 E+000$ & 1 & $7.48 E-001$ & i & $3.07 E+001$ & 1 & \\
\hline 2. $50 E+O r$ & $i$ & $-1.10 E-001$ & $i$ & $1.31 E+001$ & 1 & $1.07 E+000$ & $i$ & $3.73 E+001$ & $i$ & \\
\hline $1.78 \mathrm{E}$ & $i$ & $-1.02 E-001$ & $i$ & $7.83 E+002$ & 1 & $-1.02 E-001$ & $i$ & $2.33 E+002$ & $i$ & 2 \\
\hline $2.06 E$ & 1 & $-1.03 E-001$ & 1 & $7.36 E+002$ & $i$ & $1.13 E-001$ & $i$ & $2.30 E+002$ & $i$ & 2 \\
\hline $2.25 E$ & $i$ & $-1.03 \mathrm{E}-001$ & 1 & $5.30 E+002$ & $i$ & $-1.03 E-001$ & $!$ & $2.00 E+002$ & $i$ & \\
\hline $3.38 E+000$ & i & $-1.03 E-001$ & $i$ & $2.15 E+002$ & 1 & $1.51 E+000$ & 1 & 8. $25 E+002$ & 1 & \\
\hline 3. 38E-001 & $i$ & $-1.02 E-001$ & i & 1. $02 E+001$ & 1 & 7. $48 E-001$ & i & $2.77 E+001$ & $!$ & 2 \\
\hline $24 E-001$ & 1 & $-1.03 E-001$ & 1 & $1.03 E+001$ & 1 & $7.60 E-001$ & 1 & $2.67 E+001$ & $i$ & $?$ \\
\hline$-1.0 \% E-001$ & i & $-1.09 \mathrm{E}-001$ & $i$ & $1.31 E+001$ & $i$ & $1.59 E+000$ & 1 & $1.86 E+001$ & 1 & 2 \\
\hline $1.57 E+000$ & $i$ & $-1.05 E-001$ & 1 & $1.78 E+001$ & 1 & $2.21 E+000$ & 1 & $3.45 E+001$ & i & \\
\hline
\end{tabular}


TABLE B-3 (continuation)

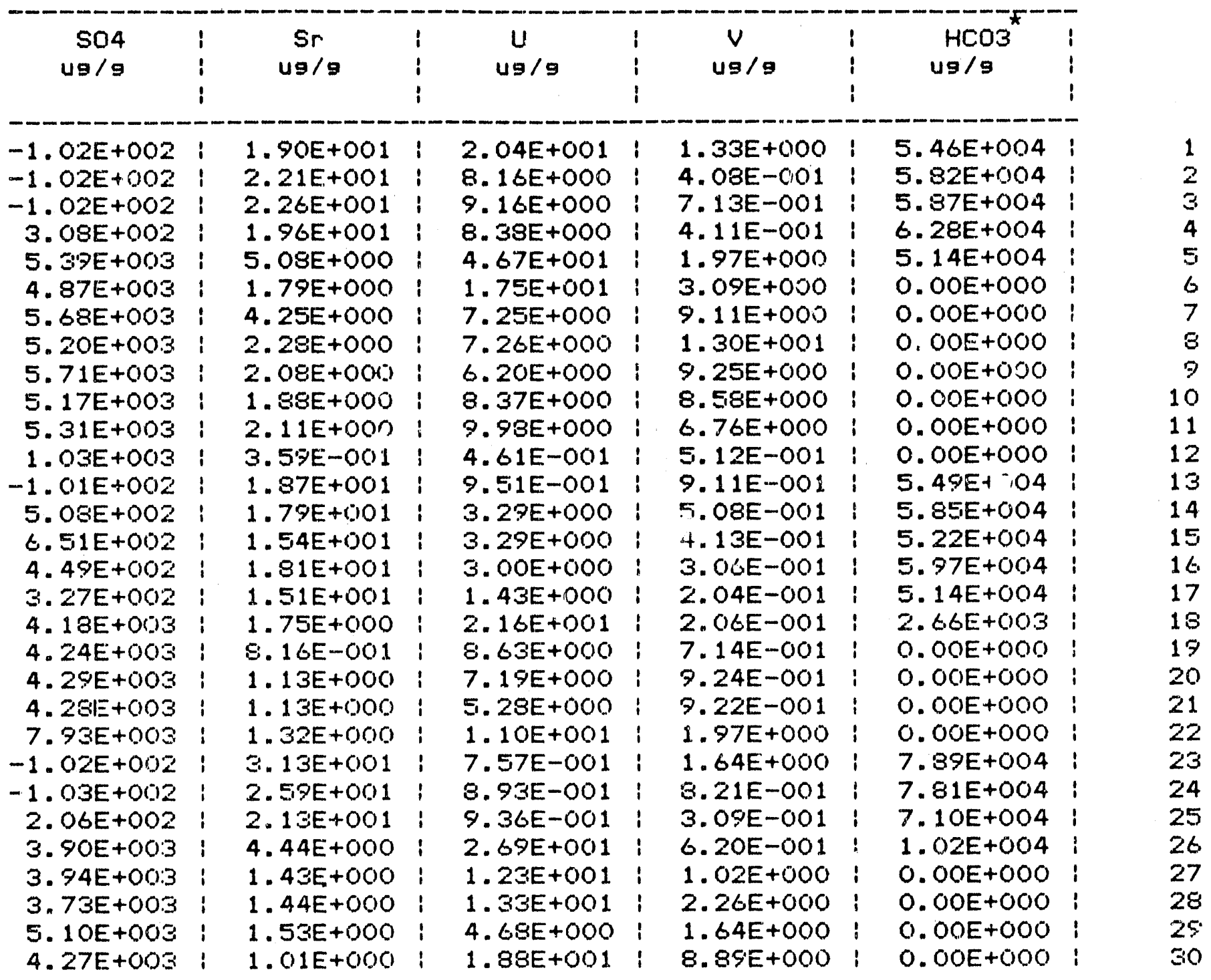

$\star$

Calculated as the missing anion in the charge balance. 
TABLE B-3(continuation)

\begin{tabular}{|c|c|c|c|c|c|}
\hline i & $\begin{array}{l}\text { Th-230 } \\
\mathrm{pCi} / \mathrm{g}\end{array}$ & $\begin{array}{l}\mathbf{1} \\
\vdots \\
\mathbf{1}\end{array}$ & $\begin{array}{l}\text { Fa } a-22 b \\
u g / g\end{array}$ & i & \\
\hline i & $1.40 E+000$ & i & $2.90 E+000$ & $\mathbf{i}$ & 1 \\
\hline$i$ & 3. $80 E-001$ & $i$ & 1. $7 \mathrm{CE}+000$ & $i$ & 2 \\
\hline 1 & $3.60 E-001$ & 1 & 1. $07 E+000$ & 1 & 3 \\
\hline 1 & $4.00 E-001$ & 1 & $3.59 E-001$ & $i$ & 4 \\
\hline$!$ & 2. $00 E+001$ & 1 & $6.02 \mathrm{E}-002$ & 1 & 5 \\
\hline$i$ & $2.20 E+001$ & 1 & $1.04 E-001$ & 1 & 6 \\
\hline i & $1.60 E+001$ & $\mathbf{i}$ & $3.11 E-002$ & $i$ & 7 \\
\hline$!$ & 1. $80 E+001$ & $i$ & $3.84 E-002$ & $i$ & 8 \\
\hline$!$ & 1. $10 E+001$ & 1 & $1.13 E-001$ & ! & 9 \\
\hline$i$ & $9.10 E+000$ & ! & $9.94 \mathrm{E} \cdot 002$ & $i$ & 10 \\
\hline 1 & $1.90 E+001$ & $i$ & 5.21E-002 & $i$ & 11 \\
\hline ! & $3.70 E+000$ & 1 & 1. $82 E+000$ & ! & 12 \\
\hline : & $1.30 E-001$ & 1 & $1.2 / E+000$ & $i$ & 13 \\
\hline i & 1. $80 E-001$ & $\mathbf{i}$ & $7.32 E-001$ & ! & 14 \\
\hline T & $2.80 E-001$ & $i$ & $5.17 E-001$ & i & 15 \\
\hline 1 & $3.40 E-001$ & $i$ & $5.20 E-001$ & $i$ & 16 \\
\hline i & $2.50 E-001$ & $i$ & $2.97 E-001$ & 1 & 17 \\
\hline i & $1.10 E+002$ & $i$ & $5.76 E-002$ & i & 18 \\
\hline$i$ & 1. $70 E+001$ & $i$ & $5.92 E-002$ & 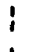 & 19 \\
\hline i & 3. $80 E+001$ & i & $4.41 E-002$ & $i$ & 20 \\
\hline i & $5.60 E+001$ & 1 & 3.89E-002 & $i$ & 21 \\
\hline i & $4.60 E+001$ & $!$ & $4.82 E-002$ & ; & 22 \\
\hline ! & 1. $80 E-001$ & i & $4.19 E-001$ & ! & 23 \\
\hline i & $2.80 E-001$ & 1 & $3.80 E-001$ & 1 & 24 \\
\hline i & $8.00 E-002$ & 1 & $2.16 E-001$ & i & 25 \\
\hline ! & $1.20 E+001$ & 1 & $3.41 E-001$ & 1 & 26 \\
\hline i & $1.70 E+001$ & $i$ & $2.66 E-001$ & i & 27 \\
\hline$i$ & $3.60 E+001$ & 1 & 1.23E-001 & $!$ & 28 \\
\hline i & $1.30 E+001$ & i & $2.15 \mathrm{E}-001$ & $i$ & 29 \\
\hline 1 & $7.60 E+001$ & $!$ & $2.41 E-001$ & 1 & 30 \\
\hline
\end{tabular}




\author{
APPENDIX C \\ X-RAY DIFFRACTION RESULTS FOR MINERALOGY OF \\ BULK SAMPLES, <5 MICRON FRACTIONS, AND \\ REPRECIPITATED WATER-SOLUBLE SALTS
}




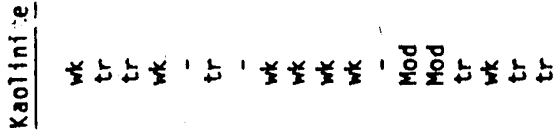

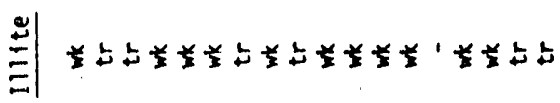

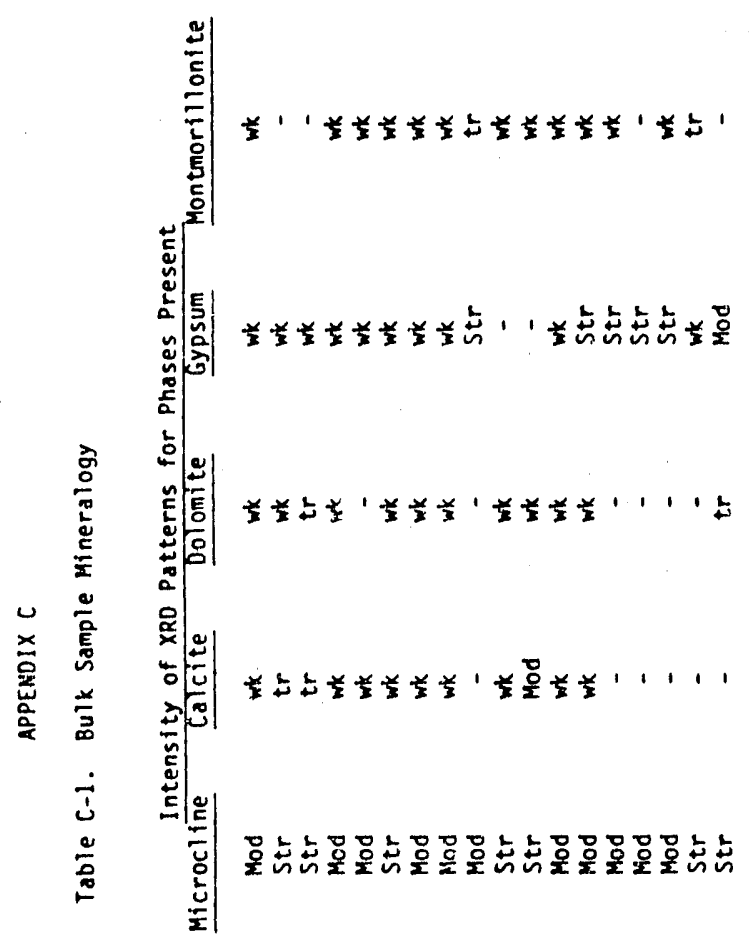

竞

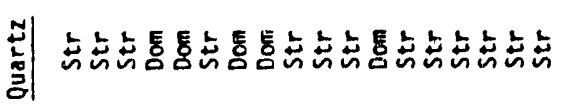

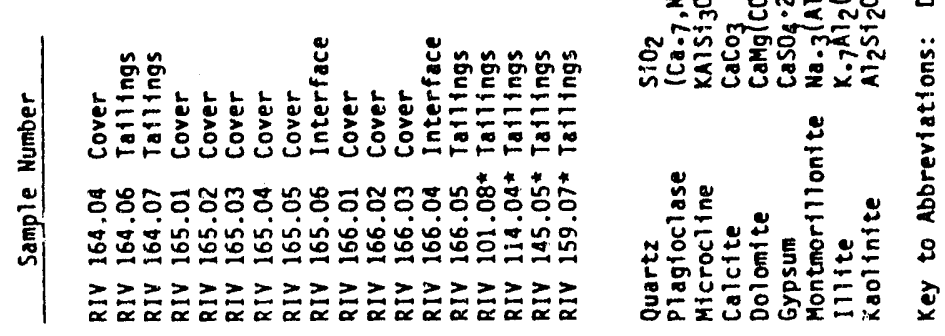

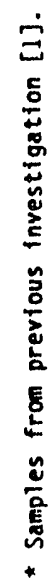



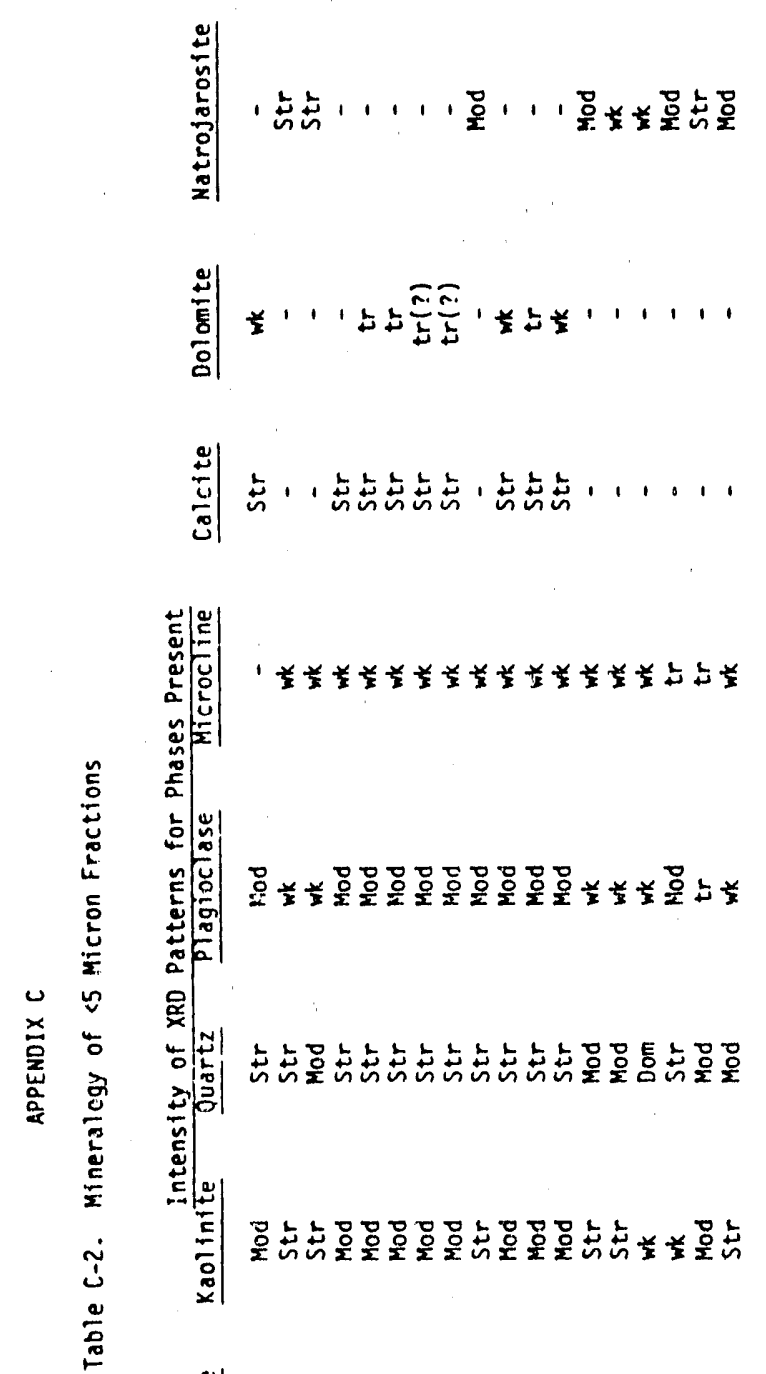

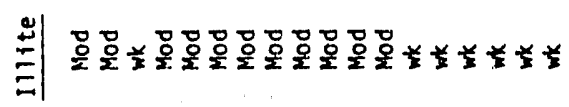

党

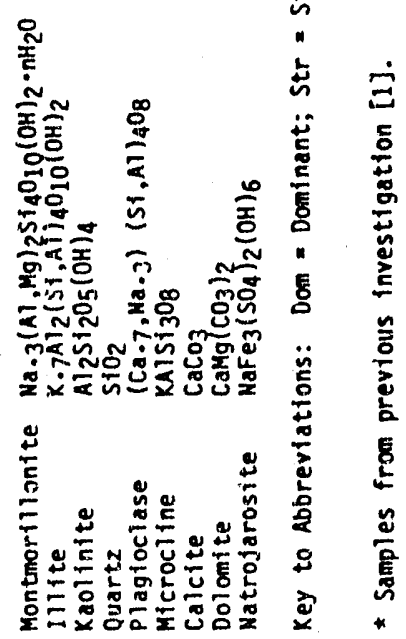




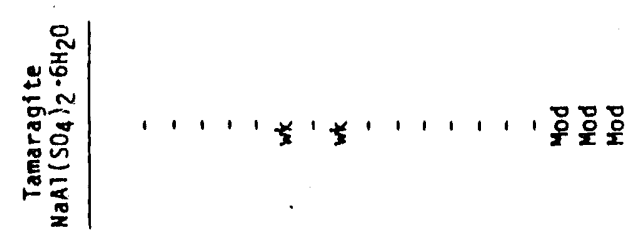

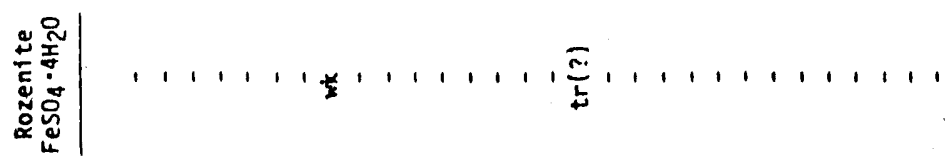

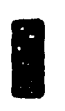

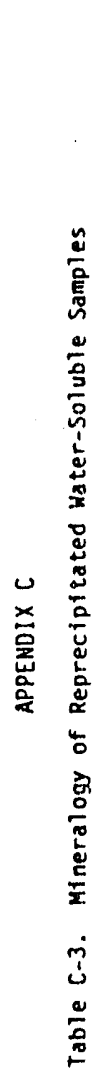

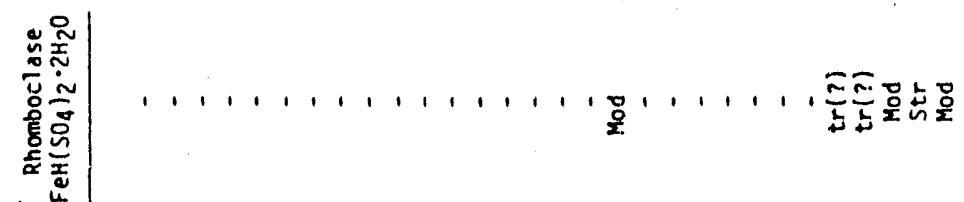

$\ldots, \ldots, \ldots, \ldots, \ldots$

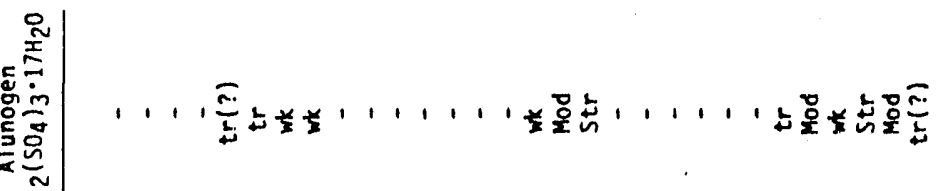

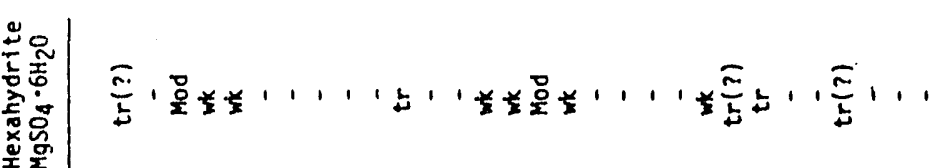

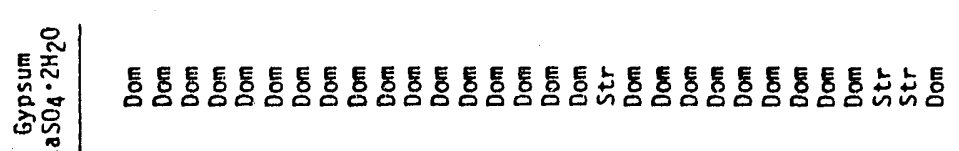

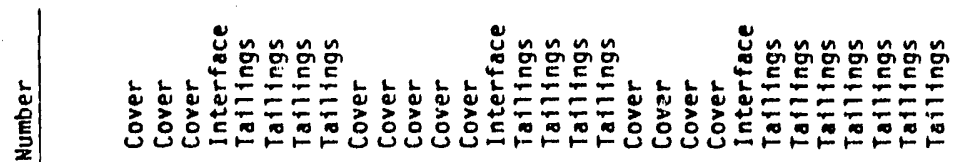

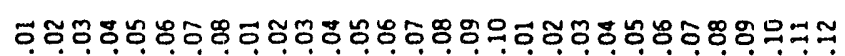

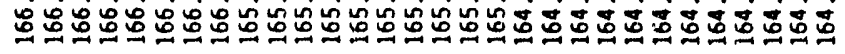

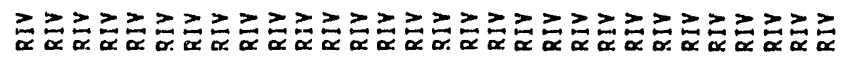



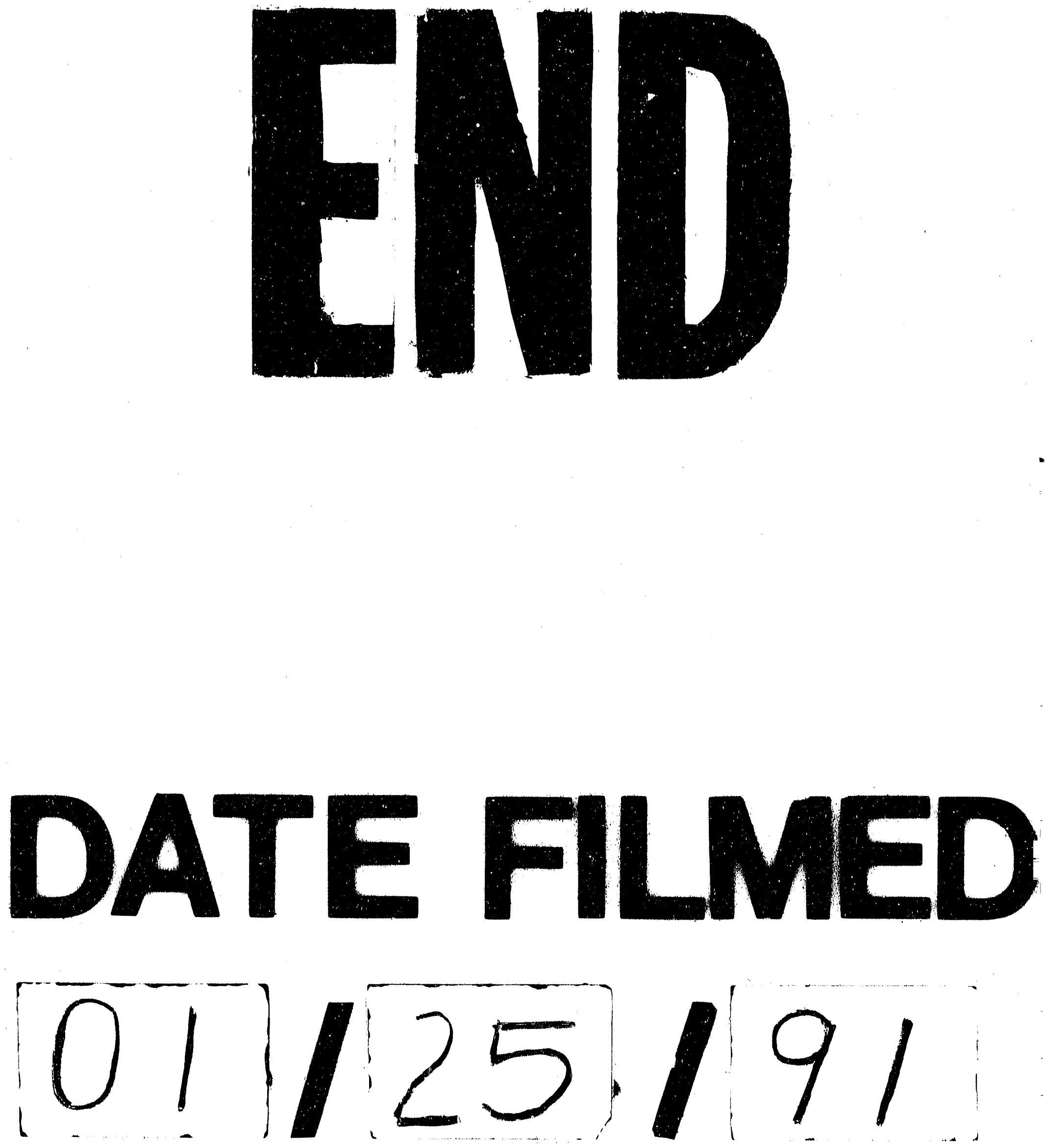
